\title{
Aspects of Osteoporosis and Fracture Risk
}

\section{Assessment in Primary Dental Care}

Attitudes, Willingness to Pay and Evaluation of an Automated Software
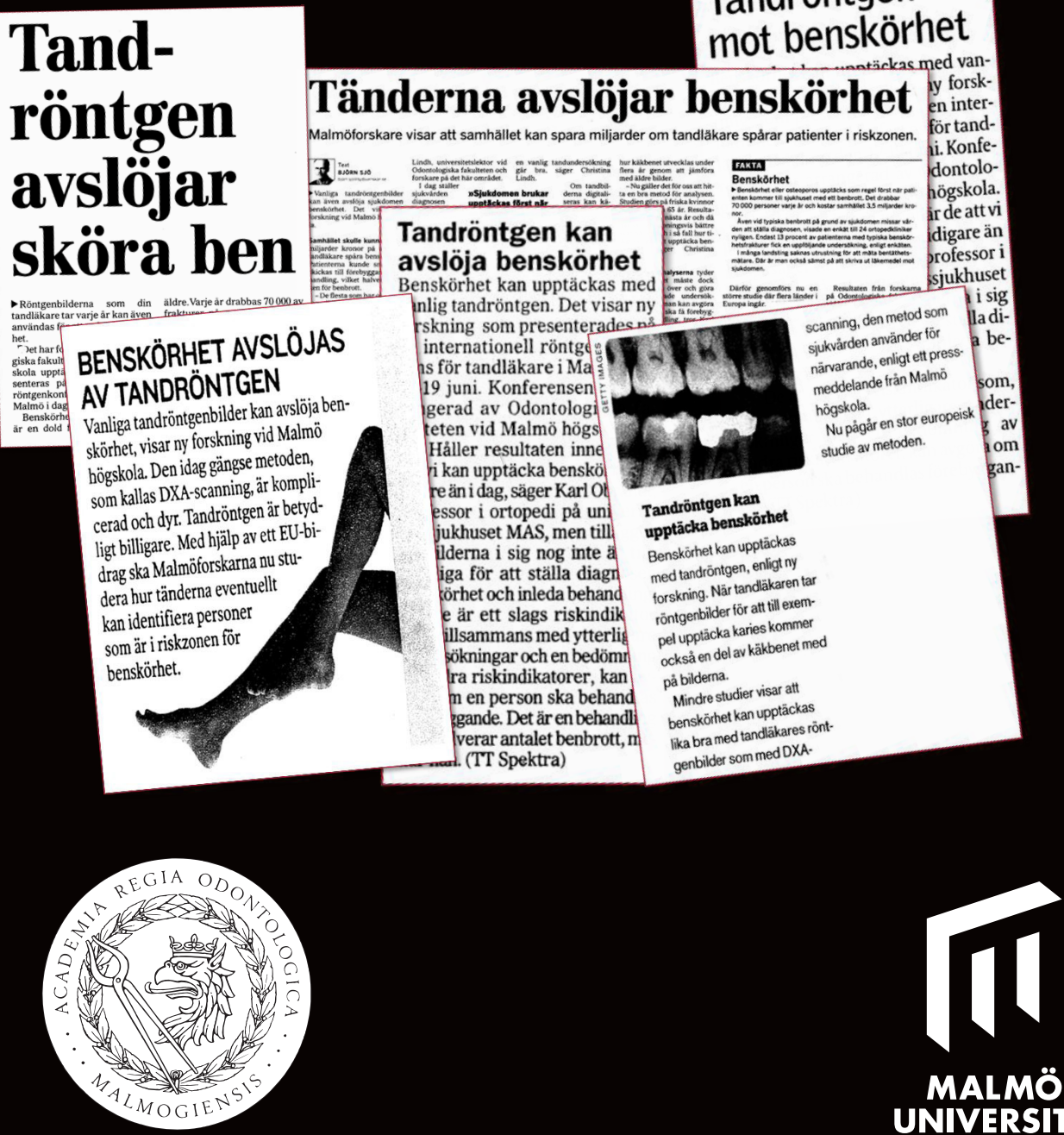

ASPECTS OF OSTEOPOROSIS AND FRACTURE RISK ASSESSMENT IN PRIMARY DENTAL CARE 


\section{Malmö University, Faculty of Odontology}

Doctoral Dissertation 2021

Cover illustration: Joanna Gullberg; images are courtesy of professor Christina Lindh Front cover illustrates headlines from Swedish newspapers about the subject ISBN 978-91-7877-200-1 (print)

ISBN 978-91-7877-201-8 (pdf)

DOI 10.24834/isbn.9789178772018

Print: Holmbergs, Malmö 2021 


\section{JOANNA GULLBERG}

Aspects of Osteoporosis and Fracture Risk Assessment in Primary Dental Care

Attitudes, Willingness to Pay and Evaluation of an Automated Software

Malmö University, 2021

Faculty of Odontology Malmö, Sweden 
This publication is also available in electronic format at: mau.diva-portal.org 
For their support

For their oceans of patience

To my family

"Learning is the only thing the mind never exhausts, never fears, and never regrets."

— Leonardo da Vinci 



\section{CONTENTS}

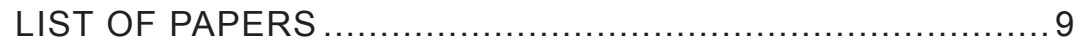

ABBREVIATIONS .................................................... 10

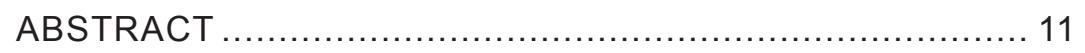

POPULÄRVETENSKAPLIG SAMMANFATTNING

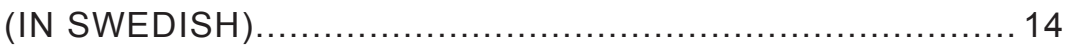

INTRODUCTION ...................................................... 16

Health promotion in a dental setting ........................................ 16

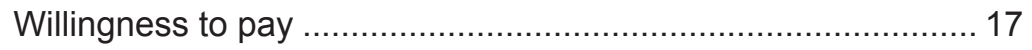

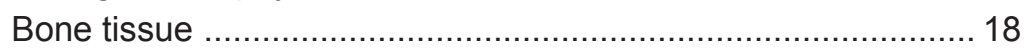

Composition and bone remodeling................................... 18

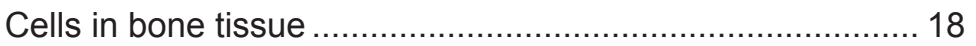

Osteoporosis and fragility fracture.......................................... 20

Measurements of bone mass and prediction of fracture ....... 22

Jawbone tissue and its role in the assessment of

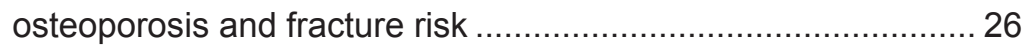

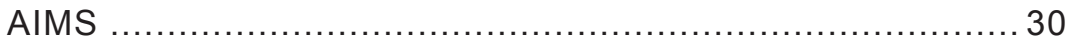

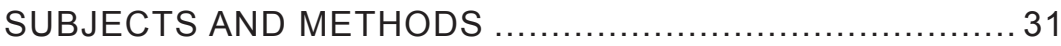

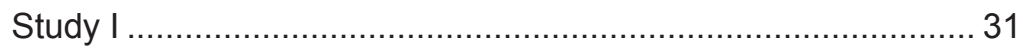

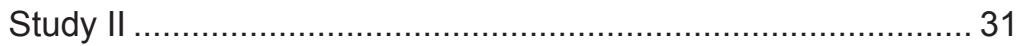

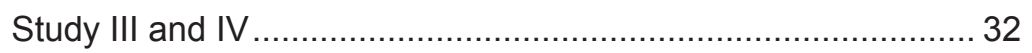

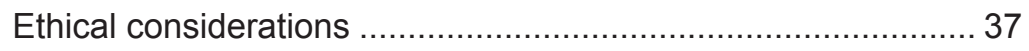




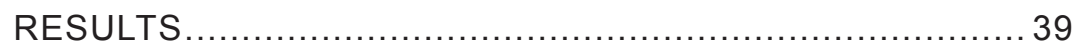

Study I

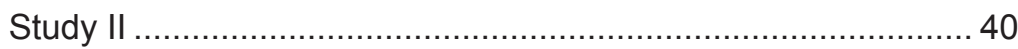

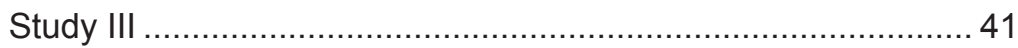

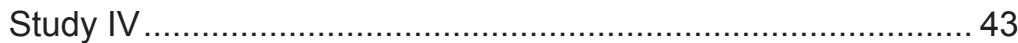

DISCUSSION .................................................... 44

Implementation of a new health-promoting method

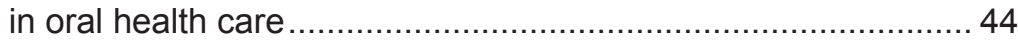

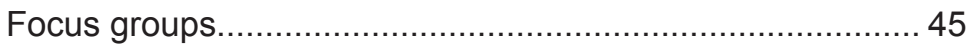

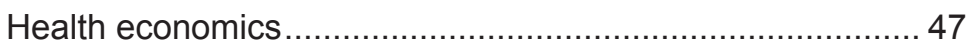

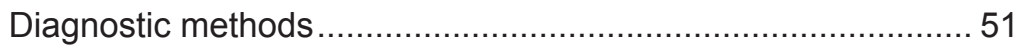

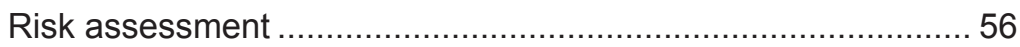

Artificial Intelligence ............................................................. 58

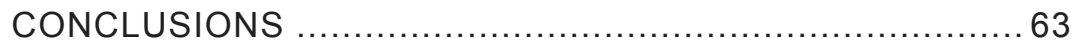

FUTURE PERSPECTIVES ...................................... 64

ACKNOWLEDGEMENTS ........................................ 66

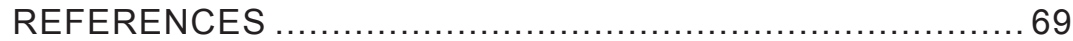

PAPERS I-IV .......................................................... 81 


\section{LIST OF PAPERS}

This thesis is based on the following studies, referred to in the text by their Roman numerals

I. Gullberg J, Lindh C, Axtelius B, Horner K, Devlin H, Povlsen L. Osteoporosis risk assessment in primary dental care - The attitudes of Swedish dentists, patients and medical specialists. Gerodontology 2020; 37: 208- 216.

https://doi.org/10.1111/ger.12462

II. Christell H, Gullberg J, Nilsson K, Heidari Olofsson S, Lindh C, Davidson T. Willingness to pay for osteoporosis risk assessment in primary dental care. Health Econ Rev 2019; 9: 14.

https://doi.org/10.1186/s13561-019-0232-z

III. Gullberg J, Al-Okshi A, Homar Asan D, Zainea A, Sundh D, Lorentzon $\mathrm{M}$, and Lindh $\mathrm{C}$. The challenge of applying digital image processing software on intraoral radiographs for osteoporosis risk assessment. Dentomaxillofac Radiol 2021; 50: 20210175.

https://doi.org/10.1259/dmfr.20210175

IV. Gullberg J, Sundh D, Johansson L, Isberg PE, Lorentzon M, Lindh C. The outcome of an automated assessment of trabecular pattern in intraoral radiographs as a fracture risk predictor.

Submitted to Osteoporosis International 16th September 2021. 


\section{ABBREVIATIONS}

\begin{tabular}{|c|c|}
\hline $\begin{array}{l}\text { AI } \\
\text { aBMD }\end{array}$ & $\begin{array}{l}\text { Artificial Intelligence } \\
\text { areal Bone Mineral Density }\end{array}$ \\
\hline ALARA & As Low As Reasonably Achievable \\
\hline ANN & Artificial Neural Network \\
\hline BMD & Bone Mineral Density \\
\hline BMU & Basic Multicellular Unit \\
\hline CBA & Cost-benefit Analysis \\
\hline CI & Confidence Interval \\
\hline $\mathrm{CNN}$ & Convolutional Neural Network \\
\hline DCNN & Deep Convolutional Neural Network \\
\hline DICOM & Digital Image and Communications in Medicine \\
\hline DXA & Dual X-ray Absorptiometry \\
\hline EU & European Union \\
\hline FGD & Focus Group Discussion \\
\hline FN & Femoral Neck \\
\hline FRAX & Fracture Risk Assessment Tool \\
\hline GDP & General Dental Practitioner \\
\hline LDCT & Low Dose Computed Tomography \\
\hline LS & Lumbar Spine \\
\hline MD & Medical Doctor \\
\hline NSB & Net Social Benefit \\
\hline ROI & Region of Interest \\
\hline SD & Standard Deviation \\
\hline $\mathrm{TH}$ & Total Hip \\
\hline WHO & World Health Organization \\
\hline WTP & Willingness to pay \\
\hline
\end{tabular}




\section{ABSTRACT}

The overall aim of this thesis was to study aspects of implementing osteoporosis and fracture risk assessment into primary dental care.

The specific aims were to:

- Explore and identify the attitudes of dentists, patients and medical specialists regarding benefits and barriers to the assessment and the implementation of osteoporosis detection into Swedish primary dental care (Study I)

- Investigate postmenopausal women's willingness to pay (WTP) for an osteoporosis risk assessment in primary dental care using a selfadministered questionnaire (Study II)

- Investigate rater agreement and the diagnostic accuracy of a semiautomated software and its fully-automated tool in osteoporosis risk assessment based on the analysis of trabecular pattern in intraoral radiographs obtained in a primary dental setting (Study III)

- Investigate if semi-automated and fully-automated digital analyses of the trabecular pattern in intraoral radiographs independently contribute to fracture risk assessment when other clinical risk factors incorporated in Fracture Risk Assessment Tool (FRAX) are taken into account. A secondary aim of this study was to explore the correlation between the automated trabecular pattern assessment in intraoral radiographs and Trabecular Bone Score (TBS) (Study IV). 
Study I used a qualitative research approach with focus group discussions (FGDs) and manifest content analysis. Five FGDs with dentists and representatives from patient support groups and one one-on-one interview with a medical specialist were included in the sample. From the manifest content analysis, three categories emerged: (a) barriers to change in practice, (b) benefits to change in practice, and (c) needs and requirements prior to change in practice. Most participants felt that the knowledge of osteoporosis was insufficient and that the current workload was heavy. Concern was expressed about medical practitioners' willingness to take on responsibility for patients referred by dentists. Representatives from patient support groups highlighted a lack of knowledge about osteoporosis among both the general public and medical professionals. Clear guidelines and improved communication channels between stakeholders would have to be established to ensure a smooth treatment path for patients.

Study II was based on a self-administered questionnaire that we constructed using the WTP tool where 144 postmenopausal women expressed their preferences for an osteoporosis risk assessment in primary dental care. Most respondents (129 of $144(90 \%)$ ) were willing to pay for an osteoporosis risk assessment in primary dental care. The overall mean WTP, including respondents that denoted none or zero, was 44.60 $€($ CI $95 \% 38.46-50.74 €$ ) (median $34.75 €$ ). A majority (80.6\%) of the respondents that denoted WTP also motivated their answer. The two most common reasons for being willing to pay for osteoporosis risk assessment were the importance of early diagnosis and preventive care to avoid fractures $(41.0 \%)$ and the importance of knowledge of a risk of osteoporosis (26.4\%). From a societal perspective, early diagnosis of osteoporosis by risk assessment in primary dental care could prevent fractures related to osteoporosis, benefit women's health and quality of life, and significantly impact the healthcare budget in terms of cost-savings.

Study III and IV were part of a large population-based, prospective study performed in the greater Gothenburg area between 2013 and 2016, comprising over 3000 older women (75-80 years old), with very high fracture risk. A total of 567 intraoral radiographs were selected retrospectively from image material sent in from private and public general dental practices as well as from regional archive from Västra Götaland Region. 
In study III, five raters assessed and, after four weeks, reassessed participants' risk of osteoporosis in the intraoral radiographs using semiautomated software. Radiographs were also assessed by the software's fully-automated tool for analysis. Overall interrater agreement for the five raters was 0.37 (95\% CI $0.32-0.41)$, and for the five raters with the fully-automated tool included as 'sixth rater' the overall Kappa was 0.34 (0.30-0.38). Intrarater agreement varied from moderate to substantial according to the Landis\&Koch [1977] interpretation scale. Diagnostic accuracy was calculated in relation to reference standard for osteoporosis diagnosis, which is T-score values for the spine, total hip and femoral neck and presented in the form of sensitivities, specificities, predictive values, likelihood ratios, and odds ratios. All raters' mean sensitivity, including the fully automated tool, was $40.4 \%$ (range $14.3 \%-57.6 \%$ ). Corresponding values for specificity was $69.5 \%$ (range $59.7 \%-90.4 \%$ ). The diagnostic odds ratios ranged between 1 and 2.7. The conclusion drawn from study III was that the low diagnostic odds ratio and agreement between raters in osteoporosis risk assessment using the software for analysis of the trabecular pattern in intraoral radiographs shows that more work needs to be done to optimize the automation of trabecular pattern analysis in intraoral radiographs.

Since osteoporosis is only one of the risk factors for fragility fractures, in study IV, we investigated the predictive value of the semi-automated and fully-automated analysis of the trabecular pattern in intraoral radiographs for risk of fracture when other clinical risk factors such as age, body mass index, previous fracture, heredity, smoking, glucocorticoid use, rheumatoid arthritis, secondary osteoporosis, and alcohol intake were taken into account. The results from automated trabecular pattern analysis were also compared to study participants' TBS values in the search for correlation. Neither the semi-automated nor the fully-automated assessment of trabecular pattern in intraoral radiographs showed the predictive value for fragility fracture. The correlation with TBS was rather weak and was only present for the semi-automated software. 


\section{POPULÄRVETENSKAPLIG SAMMANFATTNING (IN SWEDISH)}

Benskörhet (osteoporos) och dess följd - benbrott - är en av de främsta anledningarna till för tidig död och nedsatt rörelseförmåga i Europa idag. Sjukdomen benskörhet drabbar främst kvinnor efter klimakteriet och risken för benskörhetsrelaterade benbrott ökar drastiskt med åldern. Kostnaden för omhändertagande av patienter som drabbats av denna typ av frakturer är mycket hög och innebär dessutom ett stort lidande för den enskilde individen. Ändå är det inte samhällsekonomiskt försvarbart att utföra screeningundersökningar för att fastställa om kvinnor är drabbade av benskörhet efter en viss ålder. Istället ställs diagnosen benskörhet oftast först efter ett benbrott inträffat. Att fånga upp individer med risk för benskörhetsrelaterade benbrott förväntas inte bara minska lidande för individen utan även leda till samhällsekonomiska besparingar.

Majoriteten av svenska befolkningen besöker tandläkaren regelbundet för undersökning av tänder och munhåla, och i samband med detta tas tandröntgenbilder där även käkbenets benvävnad avbildas. Studier har visat att det finns ett samband mellan hur käkbenet förändras över tid hos personer med benskörhet jämfört med friska individer. Stora internationella studier har också visat att tandröntgenbilder kan vara ett verktyg för att identifiera individer som lider av benskörhet. Att integrera allmäntandläkare i tidig identifiering av patienter med benskörhet och som därmed löper risk för frakturer kan vara en framtida strategi att förebygga och hålla sjukdomsutveckling under kontroll. Det saknas dock vetenskapliga belägg gällande olika intressenters inställning till denna strategi och olika aspekter av vad implementering av benskörhets-och frakturriskbedömning inom tandvården kan innebära. 
Genom fokusgruppintervjuer i studie I undersöktes attityder bland tandläkare, patienter och medicinska specialister till att man inom tandvården skulle kunna identifiera individer med benskörhet och därmed kunna remittera dem för omhändertagande inom sjukvården. Det fanns generellt en positiv inställning till strategin, men flera svårigheter diskuterades och det uttrycktes ett behov av att upprätta tydliga riktlinjer och kommunikationsvägar till sjukvården för att säkerställa en smidig behandlingsväg för patienter. Utöver attityder undersöktes i studie II betalningsviljan för identifiering av individer med benskörhet hos tandläkaren bland kvinnor som passerat klimakteriet. Majoriteten av studiedeltagarna uttryckte sig positiva till att vilja betala för en sådan tjänst och snittvärdet de kunde tänka sig betala var 385 SEK (44.60 €). I studie III och IV utvärderades en kommersiell mjukvara som marknadsförs i Sverige för automatisk analys av benvävnaden i tandröntgenbilder med hänsyn till benskörhet. Eftersom mjukvaran finns i en halvautomatiserad version, utvärderades i studie III överensstämmelsen mellan olika användare samt hur väl resultaten stämmer överens med referensstandard, dvs det diagnostiska testet som idag används för att ställa diagnosen benskörhet. Överensstämmelse mellan olika användare samt mjukvarans diagnostiska träffsäkerhet blev som bäst måttlig och slutsatsen från studien var att mjukvaran behöver utvecklas vidare för att förbättra dess prestanda. I studie IV utvärderades mjukvarans förmåga att identifiera patienter med risk för benbrott. Intressant nog hittades det inget samband mellan bedömning av benvävnaden i tandröntgenbilder och frakturrisken.

Sammanfattningsvis kan det sägas att det finns en positiv attityd bland olika intressenter i samhället för bedömning av benskörhet inom tandvården liksom en betalningsvilja hos kvinnor i riskgrupp för benskörhet. Då det gäller mjukvaran som finns tillgänglig på marknaden för att genomföra bedömningen av benvävnaden $i$ tandröntgenbilder, behöver denna utvecklas vidare för att förbättra prestation gällande förmågan att identifiera individer med benskörhet och risk för benskörhetsrelaterade benbrott. 


\section{INTRODUCTION}

The overall aim of this thesis was to explore different aspects of implementing osteoporosis and fracture risk assessment into primary dental care. The thesis also aimed to investigate diagnostic accuracy efficacy of a method that could be used for this purpose.

\section{Health promotion in a dental setting}

Osteoporosis and the fragility fractures that come with it represent one of the leading causes of mortality and disability in Europe [Hernlund et al. 2013]. Health promotion and primary and secondary prevention have shown the potential to provide better general health outcomes than treatments alone. Health promotion has been defined as enabling people to increase control over and improve their health [WHO 1984]. Primary and secondary prevention aim to lower the disease's incidence rate or lower the occurrence of later and more severe stages of the disease, respectively. Tertiary prevention (i.e., treatment) aims at reducing the consequences of the disease. Integrating general dental practitioners (GDPs) into the early identification of individuals at risk of developing a chronic disease may be a future public health strategy to prevent and control the growing epidemic of chronic diseases. The success of such prevention strategies is dependent on several factors: (1) professional cooperation across disciplines (2) individuals at risk need to be identified, informed, and provided access to prevention programs [Greenberg\&Glick 2012] (3) communication of the strategies to the public (4) engagement of all levels of the society (from the government to individual) in the process [Macfarlane 2005]. Dental professionals are already involved in preventive health measures. Previous studies have shown that both GDPs and patients are interested in screening for conditions such as diabetes or cardiovascular diseases in dental settings 
[Greenberg et al. 2010, Greenberg et al. 2012, Creanor et al. 2014]. With the previously described established correlation between the trabecular bone patterns of the jaws and risk of osteoporosis [White\&Rudolph 1999] and with the regularity of dental check-ups in Sweden and the amount of intraoral radiographs taken for odontological reasons, dentists find themselves in an enviable position concerning their ability to prevent, arrest and reverse some of the burdens associated with osteoporosis.

Even though osteoporosis risk assessment has been partly introduced into the dental setting, there is no research regarding attitudes of patients, and dental and medical professionals towards assessing osteoporosis risk in the dental setting.

\section{Willingness to pay}

When a new diagnostic tool or a new treatment method is investigated, it is not enough to evaluate its clinical effects compared to the currently used method or assess society's attitudes towards the new treatment. Resources are scarce, therefore a systematic health economic evaluation is crucial as it allows for assessing the impact on the resources being spent compared to the benefits of the new strategy. Economic evaluation always implies comparing one method with another and from different perspectives (patient, institution, target group, society). Depending on the perspective, different costs and effects can be relevant to include. Therefore, the perspective is essential as one treatment method can seem attractive from one perspective but less so from another perspective [Drummond et al. 2015].

There are several types of economic evaluations, one of which is cost-benefit analysis (CBA). CBA aims to measure the costs and effects of an intervention in monetary terms using prices that are revealed in markets. When there are no functioning markets in place, WTP is often the method of choice for CBA evaluation. The general idea behind WTP is to ask individuals to express their hypothetical willingness to pay for a particular service, treatment, or outcome. The intervention for which the WTP exceeds the costs should be chosen because the result is perceived as the net gain to society.

Even though osteoporosis risk assessment has been partly introduced into the dental setting, there is no research regarding patients 'willingness to pay for such an assessment. 


\section{Bone tissue}

\section{Composition and bone remodeling}

The skeleton is the human body's internal framework and serves several crucial functions like mechanical support, locomotion, and loadbearing. It offers protection for internal organs such as the brain, heart, and lungs. It is a reservoir for minerals such as calcium and phosphorous, and it is the site for hematopoiesis in the body [Currey 2006, Standring et al. 2008].

The skeleton includes over 200 bones divided into long (femur or tibia), short (carpals in hand), flat (calvaria or scapula), and irregular (sphenoid bone) bones [Standring et al. 2008]. From the histological point of view there are two types of bone tissue building up the skeleton: cortical or compact bone and cancellous/trabecular or spongy bone. Cortical bone has a dense and ordered structure and builds almost $80 \%$ of all bone in the body [Zebaze et al. 2010]. However, the proportion of compact to cancellous bone varies dependent on the location; for example, midradius is almost all cortical bone (95\%), while vertebra is built mainly of trabecular bone (over 65\%) [Riggs et al. 1982]. The skeleton is a metabolically active organ that undergoes continuous remodeling throughout life. Bone remodeling involves removing mineralized bone followed by the formation of a bone matrix that subsequently becomes mineralized. The proportion of compact to cancellous bone is directly related to how much bone is accessible to the process of remodeling. A volume of bone with a large exposed surface will be remodeled more rapidly. Trabecular bone has a larger surface than an equal volume of cortical bone and is thus exposed to more remodeling, meaning that it is lost more rapidly than cortical bone. Therefore, aging and bone loss affect different bones to different extents and predispose different skeletal locations to fracture.

\section{Cells in bone tissue}

The skeleton consists of three different types of bone cells, all of which are involved in bone tissue remodeling. Osteoblasts synthesize and secrete an unmineralized bone matrix (osteoid) and are responsible for its deposition and mineralization. They comprise approximately $4-6 \%$ of the cells in the human skeleton and have a lifespan of three months [Capulli et al. 2014]. At the end of their lifetime, osteoblasts can either go through a programmed cell death (apoptosis), turn into osteocytes after being embedded into the matrix, or turn into bone-lining cells. Osteocytes represent the most dominant type of cells (90-95\%) in mature bone tissue and are widely 
spread within the matrix [Franz-Odendaal et al. 2006]. They are considered to be the conductors of bone remodeling. They communicate with each other through numerous dendritic processes interconnecting the cells and forming a complex network. Osteocytes maintain these connections with each other and with bone-lining cells and osteoblasts throughout their lifetime. In a well-vascularized bone, osteocytes are long-lived cells. They play a significant role in maintaining bone. Their death leads to the resorption of the matrix by osteoclasts. Osteoclasts are the least abundant within an adult skeleton (1-2\%) with the shortest life span (2-3 weeks). They are responsible for the local removal of bone during the growth and subsequent remodeling of osteons and surface bone. Demineralization occurs through proton release, creates a lytic acidic environment locally and organic matrix destruction. Factors stimulating osteoclasts to resorb bone include osteoblast-derived signals and cytokines from macrophages or lymphocytes.

Both osteoblasts and osteoclasts are incorporated in a basic multicellular unit (BMU), where the remodeling process of one bone structural unit (osteon) takes place in a sequence of phases: (1) resting, (2) activation of osteoclasts, and retraction of bone-lining cells, (3) resorption by osteoclasts through acidification and proteolytic digestion in Howship's lacunae in cancellous bone, or 'cutting cones' in cortical bone, (4) reversal, i.e., 1- to 2-week interval between completion of resorption and initiation of bone matrix formation; (5) formation and mineralization of bone matrix by osteoblasts, with (6) complete mineralization taking approximately 3 to 6 months and return to resting (Figure 1). 


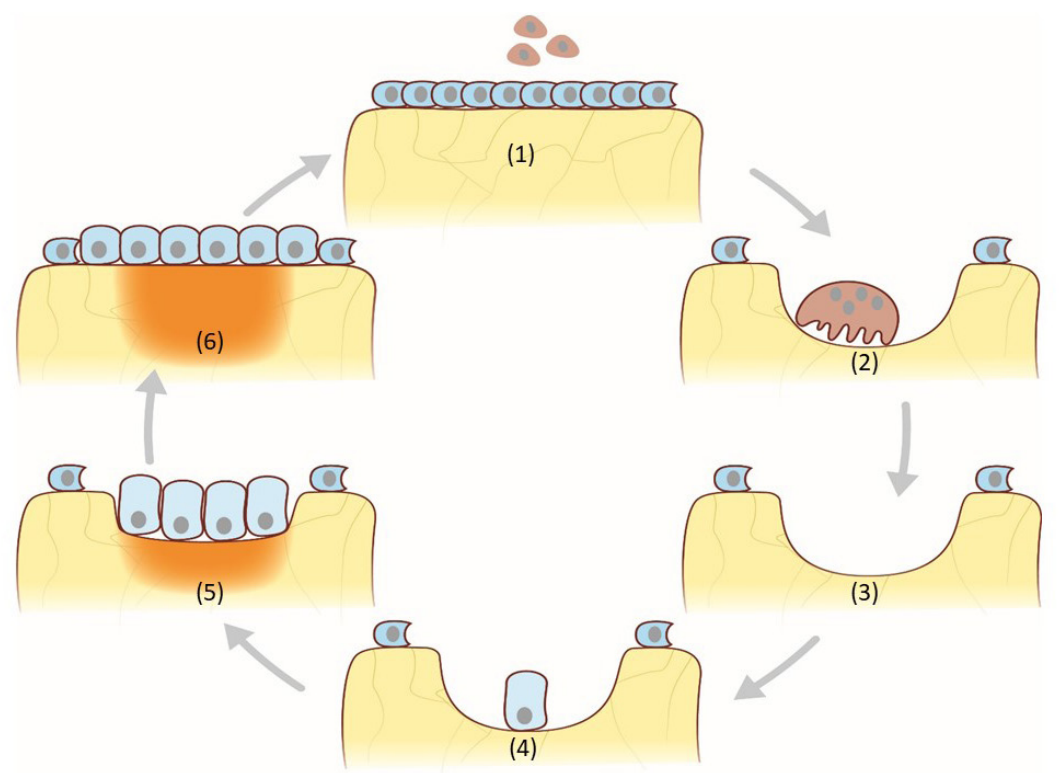

Figure 1 Schematical presentation of remodeling process of bone divided in phases: (1) resting, (2) activation of osteoclasts (3) resorption by osteoclasts (4) reversal, i.e., 1- to 2-week interval between completion of resorption and initiation of bone matrix formation; (5) formation and mineralization of bone matrix by osteoblasts, with (6) complete mineralization taking approximately 3 to 6 months; and return to resting. (Courtesy of prof. Christina Lindh).

In the adult skeleton, the remodeling process continues throughout an individual's lifetime. It is estimated that approximately $10 \%$ of our entire skeleton is substituted annually. The turnover of cortical bone progresses slower (2-4\% annually) than the turnover of trabecular bone $(25-28 \%$ annually) [Manolagas\&Jilka 1995, Clarke 2008].

\section{Osteoporosis and fragility fracture}

The etymology of the word osteoporosis can be traced back to the 1820 s and has Greek origins from osteon, meaning bone, and poros meaning small hole, pore. The term was coined by French pathologist Jean Lobstein [Glob 2014]. For decades the skeleton was treated as an amorphous lump, whose only important property was mass. This was especially the case in discussions on osteoporosis. But bone is a complex structure composed of unique material. Fracture, the only clinically significant consequence of age-related bone loss, represents the failure under load of this complex structure. The first to report and establish a relationship between vertebral 
fractures in women after menopause was Fuller Albright in 1941 [Albright et al. 1941].

Osteoporosis is characterized by low bone density and microarchitectural deterioration of bone tissue, leading to increased susceptibility for fragility fractures, i.e., fractures due to low energy trauma [NIH Consensus Development Panel on Osteoporosis Prevention 2001]. Unbalanced remodeling of the skeleton in post-menopausal osteoporosis due to excessive osteoclastic bone resorption and reduced capacity of osteoblasts

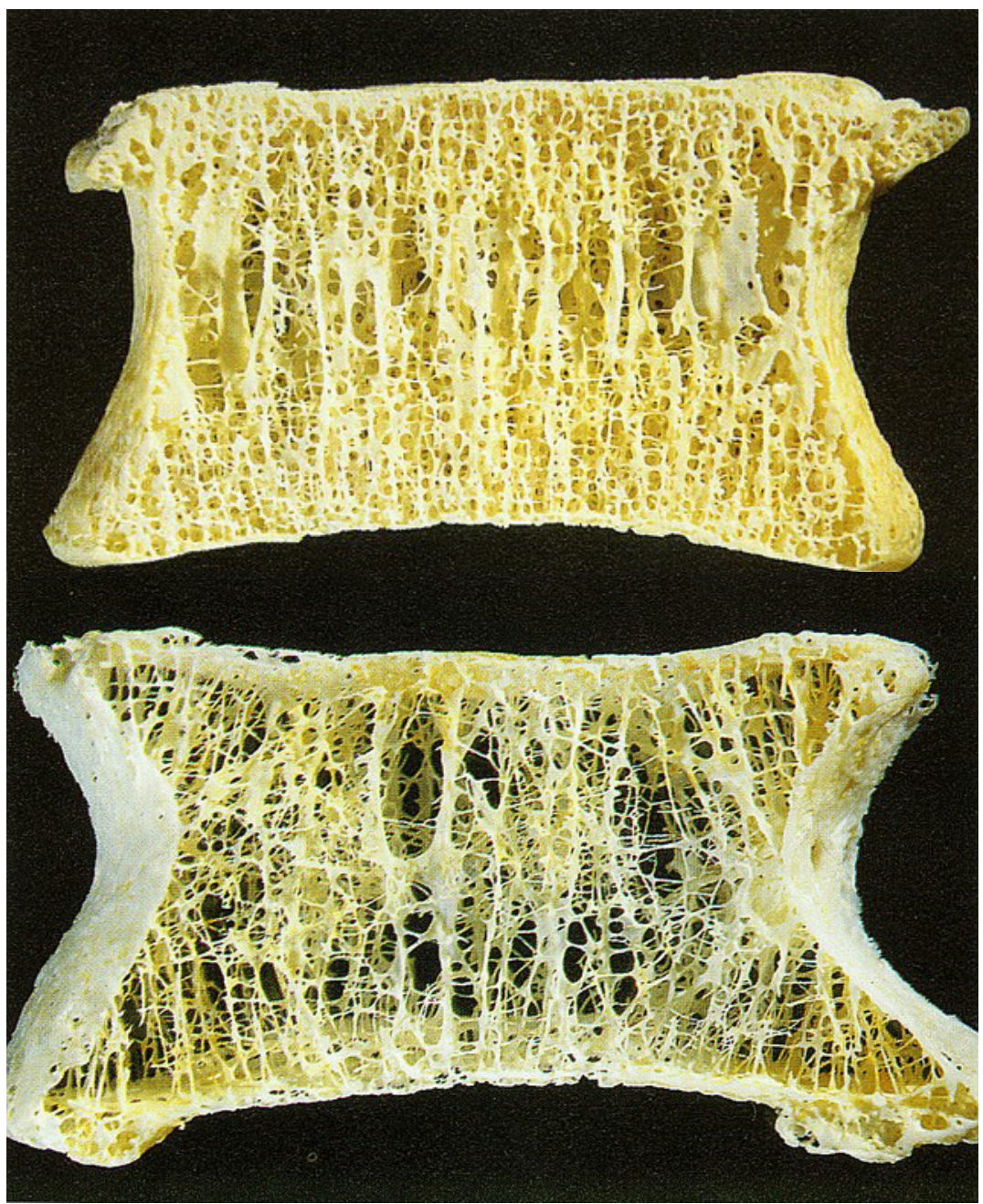

Figure 2 Visual representation of a healthy vertebra (top image) and an osteoporotic vertebra (bottom image) with thin trabeculae and large intertrabecular spaces [Mosekilde 1989]. 
to refill the resorption lacunae results in a decreased amount of bone tissue, loss of trabecular bone architecture, and, eventually, increased risk for fracture (Figure 2).

Osteoporosis can either be a product of the aging process and subsequent hormonal changes (primary osteoporosis) or a consequence of long-term medication such as glucocorticoids or diseases such as hyperparathyroidism that cause structural deterioration of bone tissue [NIH Consensus Development Panel on Osteoporosis Prevention 2001]. Osteoporosis is often referred to as a 'silent disease' because it does not cause any pain [International Osteoporosis Foundation 2021]. However, the clinical consequence of osteoporosis is a fracture. The lifetime risk of any osteoporotic fracture is very high and lies within the range of $40-50 \%$ in women and $13-22 \%$ in men [Johnell\&Kanis 2005, Sambrook\&Cooper 2006]. The most common fragility fractures are the vertebral compression fractures in the spine, proximal femur fractures in the hip, and distal forearm (wrist) fractures. Over three and a half million osteoporotic fractures occurred in 2010 in Europe, with a corresponding monetary cost estimated at 37 billion euros [Hernlund et al. 2013]. By 2025 these numbers are expected to rise to four and a half million osteoporotic fractures and a cost of 46.8 billion euros. While hip fractures make up $20 \%$ of fragility fractures, they account for more than half of the total costs (almost 60\%) [Borgström et al. 2020]. Apart from the economic burden, osteoporotic fractures carry with them the consequences of patients' painful suffering and loss of quality of life due to lost mobility (especially in cases of hip fracture), disability, or loss of independence. It has been estimated that annually more than 26000 life years and more than one million quality-adjusted life years (QALYs) are lost due to osteoporotic fractures [Hernlund et al. 2013]. Therefore, osteoporosis and related fractures are significant public health issue.

\section{Measurements of bone mass and prediction of fracture Bone mineral density}

Individuals with osteoporosis are identified by measuring Bone Mineral Density (BMD) using Dual X-ray Absorptiometry (DXA) at the femoral neck, spine, and forearm (Figure 3). BMD is expressed in grams of mineral per area of volume. Its value depends on peak bone mass and the rate of bone loss. Peak bone mass is a measure of maximal acquired bone mass at the end of skeletal maturation, which is generally thought to be reached in the late second or early third decade of life [Bonjour et al. 1994, Lorentzon et al. 2005]. Skeletal mass and density remain fairly 
unchanged in adulthood until approximately the age of 50 [Robert et al. 2013]. Because of the Gaussian distribution, bone BMD values can be expressed in relation to a reference population in standard deviation (SD) units. This measurement is called the T score. The World Health Organization (WHO) has defined osteopenia, the pre-stage of osteoporosis, at a BMD value of between 1 and 2.5 SDs below the average healthy young adult female ( $\mathrm{T}$ score $<-1$ and $>-2.5$ ) and osteoporosis at $\mathrm{BMD}$ value $2.5 \mathrm{SD}$ or more below the average healthy young adult female (T score $\leq-2.5$ ) (Figure 4), [WHO 1994]. This operational definition has evolved into the clinical diagnostic definition of osteoporosis [Curtis et al. 2017]. It has been shown that the risk of fracture doubles for every SD reduction in BMD [Marshall et al. 1996]. Although low BMD has been recognized as a significant predictor of future fracture risk, diagnosing osteoporosis has not been enough. Many individuals in the population who sustain a fragility fracture have BMD values within the osteopenic or normal range [Kanis et al. 2007, Murray et al. 2015]. In other words, the risk of fracture is high when osteoporosis is present, but it is by no means insignificant when BMD is normal (Figure 4) [Kanis 2002].

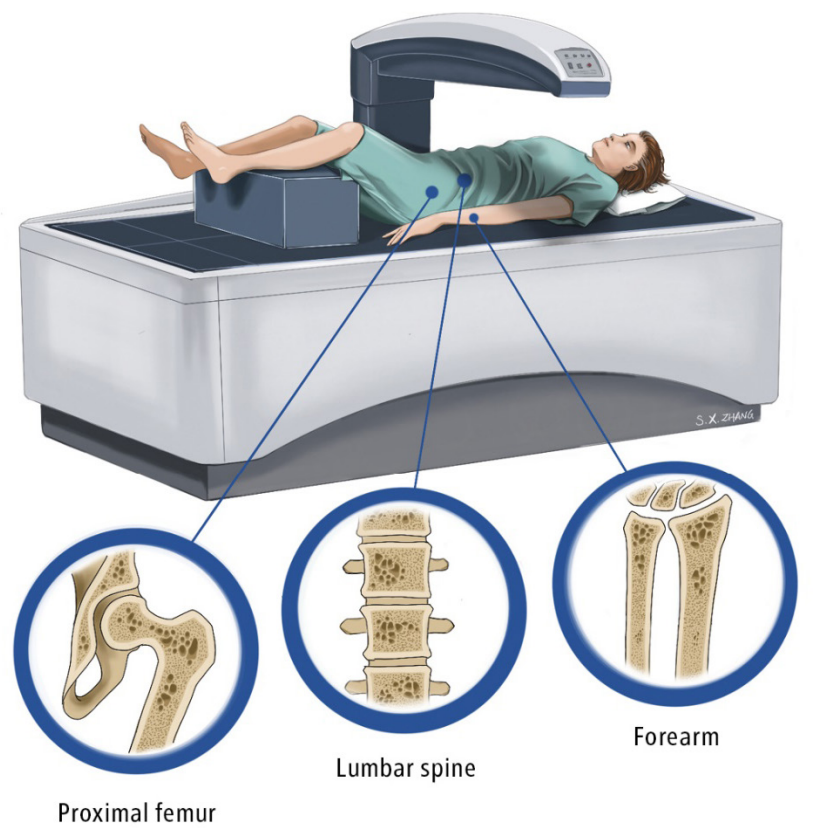

Figure 3 Dual x-ray absorptiometry (DXA) showing the proximal femur, lumbar spine, and bones of the forearm (Illustration courtesy of Dr Shannon Zhang), [McMaster 2021]. 


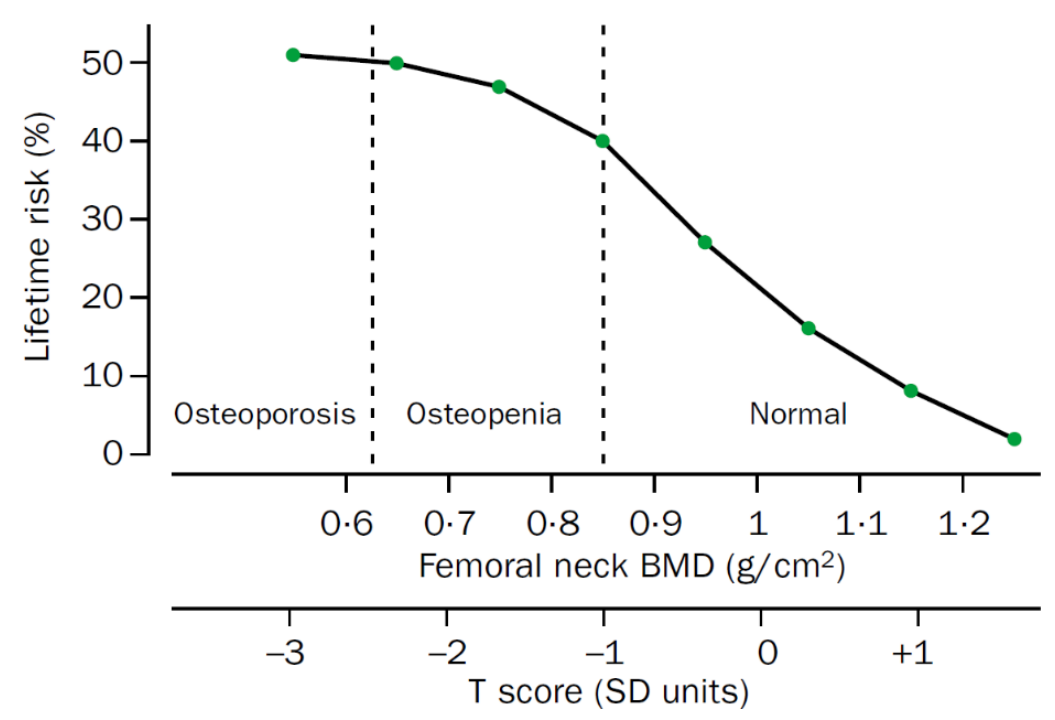

Figure 4 Remaining lifetime risk of hip fracture in women aged 50 years according to BMD or T score at the hip [Kanis 2002].

\section{Clinical risk factors}

It has become evident that several risk factors other than BMD are associated with increased fracture risk. Taken together with BMD, these risk factors have a greater predictive value than BMD alone [Kanis 2002]. Using information from primary data of nine population cohorts from around the globe and validated in a further 11 independent cohorts to identify relationships between clinical risk factors for fracture, a computer-based algorithm for fracture risk prediction (FRAX https://www.sheffield.ac.uk/FRAX/) has been developed that compute age-specific 10-year fracture probability [Kanis et al. 2009]. FRAX incorporates BMD value from the femoral neck as it is considered to be the most extensively validated site for BMD value and it has the highest predictive value of hip fracture, which is the most severe complication of osteoporosis [Marshall et al. 1996]. It is, however, not necessary to incorporate BMD value if it is not available because, apart from BMD, FRAX includes all the other relevant risk factors for predicting future fractures, such as age, gender, previous fracture, heredity, smoking and alcohol habits, medication with glucocorticoids, rheumatoid arthritis (RA), and secondary osteoporosis (Figure 5). It has become an internationally recognized instrument for estimating the 10-year probability of fracture and has been adjusted for local differences, including recommended thresholds for intervention [Kanis et al. 2008]. 


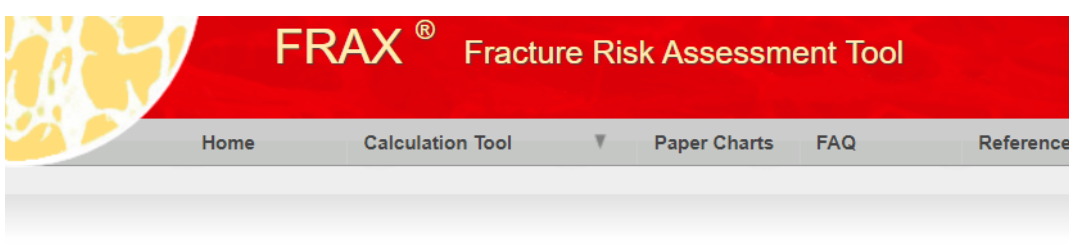

\section{Calculation Tool}

Please answer the questions below to calculate the ten year probability of fracture with BMD.

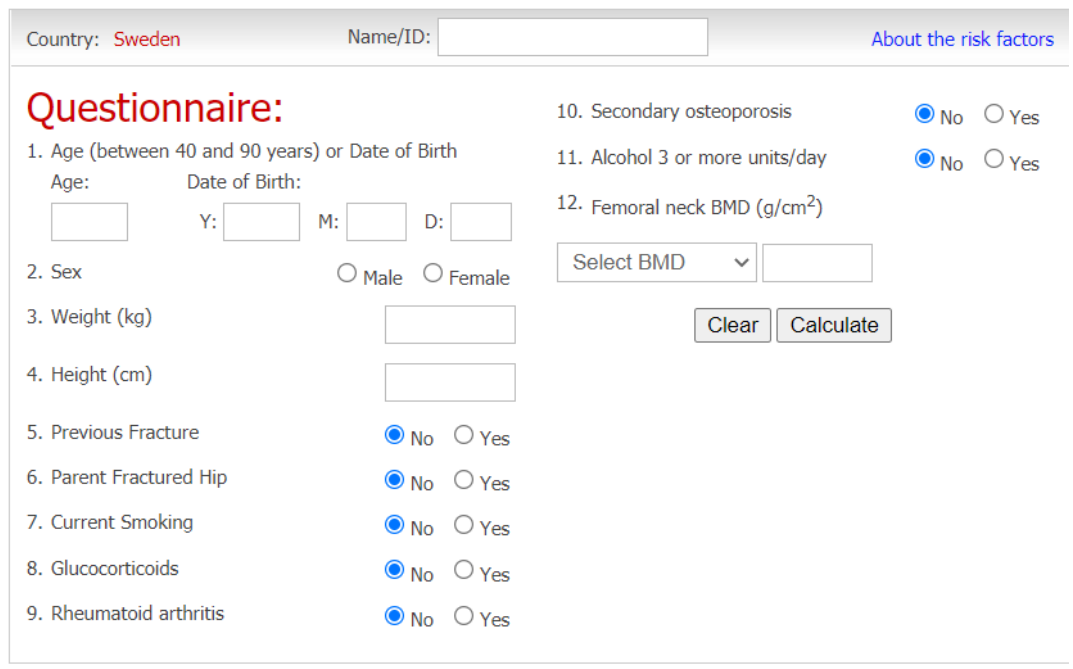

Figure 5 Graphic presentation of FRAX available at https://www.sheffield.ac.uk/ FRAX/.

\section{Trabecular bone structure}

Although DXA and FRAX have substantially increased the chances of identifying individuals at risk, their main limitation is that neither can capture all skeletal determinants of bone strength, such as trabecular bone microarchitecture. TBS is a novel tool created to reflect bone microarchitecture and is proposed to be used as a surrogate for bone strength [Pothuaud et al. 2008, Bousson et al. 2012]. TBS is applied directly on DXA machines and computed successively after areal BMD (aBMD) measurement in the same region of interest (ROI) of the lumbar spine [Pothuaud et al. 2008]. The method was first developed on micro-computed tomography $(\mu \mathrm{CT})$ slices and thereafter adapted for DXA images. A high TBS value reflects a dense trabecular microarchitecture and thus good mechanical strength of bone, while a low TBS value is associated with sparse microarchitecture [Bousson et al. 2015]. Several studies confirm 
TBS as a significant risk factor for fragility fractures [Rabier et al. 2010, Krueger et al. 2014]. TBS has shown incremental improvement in fracture prediction when combined with FRAX [Leslie et al. 2014], particularly for hip fracture outcomes.

\section{Jawbone tissue and its role in the assessment of osteoporosis and fracture risk}

The bone tissue of the jaws has been investigated regarding density and structure as well as the relationship of these parameters to other skeletal sites [Horner\&Devlin 1992, Horner et al. 1996, Lindh et al. 1996]. Being part of the skeleton, the jawbone may also be subject to changes depending on age, functional changes, and local or general bone diseases such as osteoporosis. Perhaps one of the earliest suggestions of an association between osteoporosis and oral bone loss was made in 1960 [Groen et al. 1960]. It was recognized early on that maxillary measurements are of limited value because of marked intra- and interindividual variation in the maxilla's shape and structure and because the maxilla's trabecular bone mass is independent of age [von Wowern\&Stoltze 1978]. On the other hand, mandibular bone has mental foramen, which is stable in the adult mandible, and only assessment of fibers from a minor muscle ( $\mathrm{m}$. quadratus labii inferior) is present. The molar region is occupied by the mandibular canal and strong trajectories, while the incisor region of the mandible is dominated by the insertion of muscles on both sides. Therefore, the area just anterior to the mental foramen has been considered the most suitable when a reliable and representative measure of bone mass and activity in the mandible is wanted to analyze intermandibular differences [von Wowern\&Stoltze 1978]. Mandibular bone and skeletal bone showed a significant correlation in an osteoporotic population, suggesting that mandibular bone tissue reflects the status of the entire skeleton [Kribbs et al. 1989]. The differences between the osteoporotic women and their healthy counterparts in mandibular bone mass and density are significant, which means osteoporosis affects mandibular bone [Kribbs 1990]. However, there is an overlap between the osteoporotic and healthy groups which cannot be neglected [Kribbs 1990]. Therefore, it has been concluded that osteoporosis cannot be diagnosed simply by measuring one of the mandibular parameters (mandibular mass and density, cortical thickness at the gonion, tooth loss) alone. 
Bone mineral density of the jaws correlates with other skeletal sites [Horner\&Devlin 1992, Horner et al. 1996, Taguchi et al. 1996, Lindh et al. 2004] and patients with osteoporosis show an altered trabecular pattern in the jaws compared with normal subjects [White\&Rudolph 1999]. A number of architectural features in the trabecular pattern of the bone have been thoroughly described in conventional radiographs, including the area of the bony plates, the circumference of the trabeculae, the number of marrow spaces, trabecular thickness, trabecular spacing, and osseous fractal dimension [Geraets et al. 1990, Geraets et al. 1993]. These authors found that morphologic features of the trabecular pattern correlated with the bone mineral density of the lumbar spine [Geraets et al. 1993] and with the risk of hip fracture in the elderly [Geraets et al. 1998].

Dental radiographs, in particular intraoral dental radiographs that present both teeth and parts of alveolar bone, are the most common of all radiological examinations [Hart et al. 2010]. As the majority of the Swedish adult population regularly goes for dental check-ups where radiographs are routinely taken [Hugoson et al. 2005, Norderyd et al. 2015] for diagnostic purposes, an opportunity presents itself for developing methods for identifying individuals at risk of osteoporosis and fragility fractures.

In 2003, the European Commission's Fifth Framework Program sponsored a clinical study in five European cities: Amsterdam, Athens, Leuven, Malmö, and Manchester. This project, called OSTEODENT, investigated the diagnostic validity of a full range of dental radiographic methods, or combinations of radiographic and clinical methods, to diagnose osteoporosis. One of the main findings of the OSTEODENT project was that a visual index categorizing the trabecular pattern in intraoral radiographs into dense homogeneous, heterogeneous, or sparse homogeneous showed a potential to identify women at risk of osteoporosis (Figure 6), [Lindh et al. 2008].

The visual index was then investigated regarding its ability to predict fracture risk. It was shown that sparse trabecular pattern in the alveolar bone assessed on intraoral radiographs of mandibular premolar area was associated with a high fracture rate and dense trabecular pattern with low fracture frequency [Jonasson et al. 2009].

Since there is a certain level of subjectivity in the visual interpretation of radiographs, and since it can be difficult to register small changes for a human eye, several attempts have been made to develop a digital image processing system for quantitative assessment of trabecular pattern that 


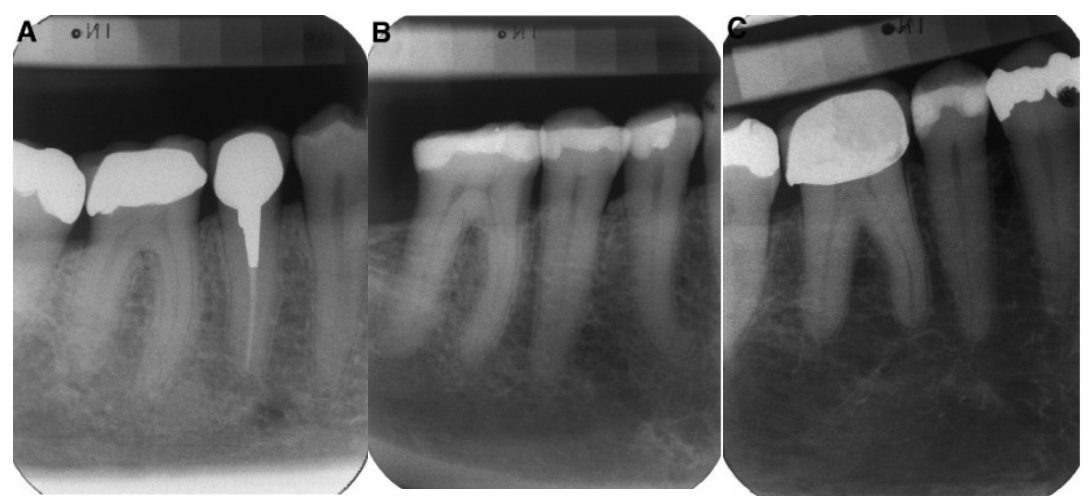

Figure 6 Reference images representing visual index in the assessment of the trabecular pattern in the lower jaw A, Dense homogeneous (left) B, Heterogeneous (middle) C, Sparse homogeneous (right) [Lindh et al. 2008].

could be applied on intraoral radiographs. Geraets et al. [1990] reported a digitalized method for structural analysis of the trabecular pattern depicted in radiographs of the wrist, which later was also applied on dental radiographs, first on a smaller sample [White\&Rudolph 1999, White et al. 2000] and later on the OSTEODENT project participants [Geraets et al. 2007, Geraets et al. 2008]. With relatively high sensitivity and specificity results ( 0.7 and 0.69 respectively), digitalized analysis of trabecular pattern in intraoral radiographs proved to be as good as using age to predict osteoporosis. Moreover, combined with age, the assessment of trabecular pattern increases the specificity level significantly, ultimately implying that trabecular pattern analysis on dental radiographs helps prevent the unnecessary referral of healthy women for DXA examination.

Based on the radiographs from the OSTEODENT study, commercial software was developed in another attempt to analyze trabecular pattern for osteoporosis risk assessment. This software was first known as Jaw-X (Crebone AB, Sundbyberg, Sweden) but later became Boneprox (Boneprox, Gothenburg, Sweden). Its algorithm uses a binary filtered image to analyze trabecular patterns in the radiograph automatically. First, gray levels in the image are reduced to 8 bit-data, and the application of histogram stretch allows for the gray levels to be linearly stretched to cover all intensities (dark areas become black, and the bright areas become white). Then, the software analyzes the final value representing the sum of the sizes and intensities of the spaces between the trabeculae. With this in mind, the Boneprox software algorithm falls under the definition of artificial intelligence (AI) and can be considered a form of AI. 
Academic and hospital-based research is a world away from an everyday dental practice, and a challenge is translating research success into clinical service. Boneprox software has been an attempt to do so. The software is now marketed in Sweden, and it is possible to submit a radiograph online for osteoporosis risk assessment. However, the software's semi-automated version relies on its user to place the ROI marker in the image before the analysis. Therefore, the question is if the user influence has an impact on the result and how accurate the result is compared to the reference standard in diagnosing osteoporosis which is DXA. Moreover, since osteoporosis is only one of the risk factors for fragility fracture, it is also of interest to investigate whether or not trabecular pattern assessment using Boneprox software can predict which individuals are at risk of fragility fracture. 


\section{AIMS}

The overall aim of this thesis was to study aspects of implementing osteoporosis and fracture risk assessment into primary dental care.

\section{The specific aims for each included study were to:}

1) Explore and identify the attitudes of dentists, patients and medical specialists regarding benefits and barriers to the assessment and the implementation of osteoporosis detection into Swedish primary dental care

2) Investigate postmenopausal women's preferences for an osteoporosis risk assessment in primary dental care using a selfadministered questionnaire to assess WTP

3) Investigate rater agreement and the diagnostic accuracy of a semiautomated software and its fully-automated tool in osteoporosis risk assessment based on the analysis of trabecular pattern in intraoral radiographs obtained in a primary dental setting

4) Investigate if semi-automated and fully-automated digital analyses of the trabecular pattern in intraoral radiographs independently contribute to fracture risk assessment when other clinical risk factors incorporated in FRAX are taken into account. A secondary aim of this study was to explore the correlation between the automated trabecular pattern assessment in intraoral radiographs and TBS. 


\section{SUBJECTS AND METHODS}

\section{Study I}

Representatives of Swedish private and public GDPs, local osteoporosis patient support groups and medical specialists were recruited for the study. The study consisted of a total of 17 participants (14 women and three men). We chose participants who knew or worked with each other to facilitate conversation and make the participants feel comfortable. Data was collected through five FGDs and one one-on-one interview, with the aim of attaining an exchange of opinions with minimal interaction with the research team. A moderator and an observer conducted the FGDs and the one-on-one interview. To ensure that participants felt free to express their thoughts openly, no other persons were present during the discussions. We used a semi-structured interview guide consisting of open-ended questions constructed under the supervision of public health experts and with the help of relevant literature. The guide was pre-tested on the first FGD, which only led to minor changes in the probing questions. The interviews were transcribed verbatim. Quality control of the transcripts was performed by listening to the recording while reading the text of the transcripts. The transcripts were analyzed through manifest content analysis [Graneheim\&Lundman 2004, Hsieh\&Shannon 2005]. After the five FGDs and the single interview, no new insights were provided [Glaser\&Strauss 1967], and no further FGD were therefore considered necessary.

\section{Study II}

Female patients over the age of 50 attending primary dental care clinics that could read and comprehend the Swedish language were consecutively invited to take part in the study. All who agreed to participate received a booklet with information on osteoporosis and a description of a hypothetical 
scenario of identifying women at risk of osteoporosis in two steps (1) risk assessment based on dental radiographs at the dental office and (2) referral for DXA examination for confirmation of the result and diagnosis. All the study participants were to answer a questionnaire developed specifically for the purpose of this study under the supervision of a health economist. The first section of the questionnaire aimed to measure the respondents' WTP for an osteoporosis risk assessment at the general dental practice using a payment scale. The WTP question was followed by an openended question where the study participants were supposed to motivate their answer to the first question. The respondents were also asked if they considered it valuable to be offered an osteoporosis risk assessment in connection with a dental check-up.

\section{Statistics}

All statistical calculations were performed using IBM SPSS statistics 24 software for Windows (SPSS Corporation, Chicago, Illinois, USA). The analysis of choice was descriptive statistics with $95 \%$ confidence intervals (CI) and one-way ANOVA for the analysis of the correlation between mean WTP and any of the variables $(p<0.05)$. WTP was the dependent variable and the independent variables were diagnosis osteoporosis, osteoporotic fracture, family history of osteoporosis or osteoporotic fracture, age, educational level, occupation, and annual income.

\section{Study III and IV}

Participants recruited between 2013-2016 for a prospective population study in the greater Gothenburg area called SUPERB cohort (Sahlgrenska University hospital Prospective Evaluation of Risk of Bone fractures) formed the basis for studies III and IV. A total of 3028 women aged 75-80 years who were ambulant and able to understand instructions in Swedish agreed to participate [Nilsson et al. 2017, Larsson et al. 2018].

All study participants had to answer a questionnaire on clinical risk factors for fracture such as medical history, history of fracture, parental history of hip fracture, current smoking habits, oral glucocorticoids use for three months, or more with prednisolone $5 \mathrm{mg}$ or equivalent, diabetes, rheumatoid arthritis, and alcohol consumption. In addition, all study participants underwent body weight and height measurements and DXA examination.

The BMD of the total hip (TH), femoral neck (FN), lumbar spine L1 to L4 (LS), and TBS of L1 to L4 were assessed using DXA device, Hologic 
Discovery A (S/N 86491) (Waltham, MA, USA) on most participants of the SUPERB cohort $(n=2995)$. However, a small proportion of women $(\mathrm{n}=33)$ was measured with another Hologic Discovery A DXA device (Waltham, MA, USA) due to machine failure. Therefore, a cross-calibration study was performed to check for potential discrepancies between the two machines [Lorentzon et al. 2019]. The BMD of the lumbar spine and TBS were calculated as the mean of L1 to L4, and any fractured vertebra or vertebra with osteosynthesis material was excluded.

Incident fractures were recorded using radiographs and radiology reports retrieved from the regional archive of the Västra Götaland region. An experienced orthopedic surgeon examined radiographs without available radiology reports or reports with uncertain fracture diagnoses. Major osteoporotic fractures (MOF) included clinical spine, hip, forearm, and proximal humerus fractures. All fractures included all incident fractures except for fractures of the skull and face.

Based on the questionnaire FRAX was calculated for all study participants. Self-reported fractures sustained at any location, except the skull and face, after the age of 50 were included in the FRAX-score calculations. Current smoking was defined by a validated questionnaire [Vartiainen et al. 2002]. A limit of 21 standard drinks per week was used to describe high alcohol consumption [Bergman\&Källmén 2002].

\section{Collection of dental radiographs}

Dental radiographs were collected retrospectively. Figure 7 presents a flow chart of how the radiographs were obtained for the study.

Data collection was performed in two stages. First, in mid-2015, while the recruitment of participants for the SUPERB study was still ongoing, the Swedish National Insurance Agency provided details on dental examinations from 2010-2015 on a subpopulation of 1898 women out of 2060 recruited to the study by that time. Thus, letters requesting intraoral radiographs were sent to the involved clinics. Second, in 2017 data on all 3028 women recruited for the SUPERB cohort was requested from the regional archive of the Västra Götaland region. The archive provided a total of 21175 dental radiographs from 1214 participants. Radiographs from both rounds of data collection were combined, and images were selected according to the following criteria: (a) vertical bitewing and/or periapical image including the ROI between roots of premolars in the lower jaw (b) acceptable image quality (image geometry, resolution, sharpness and contrast) (c) images obtained within three years before or after DXA 


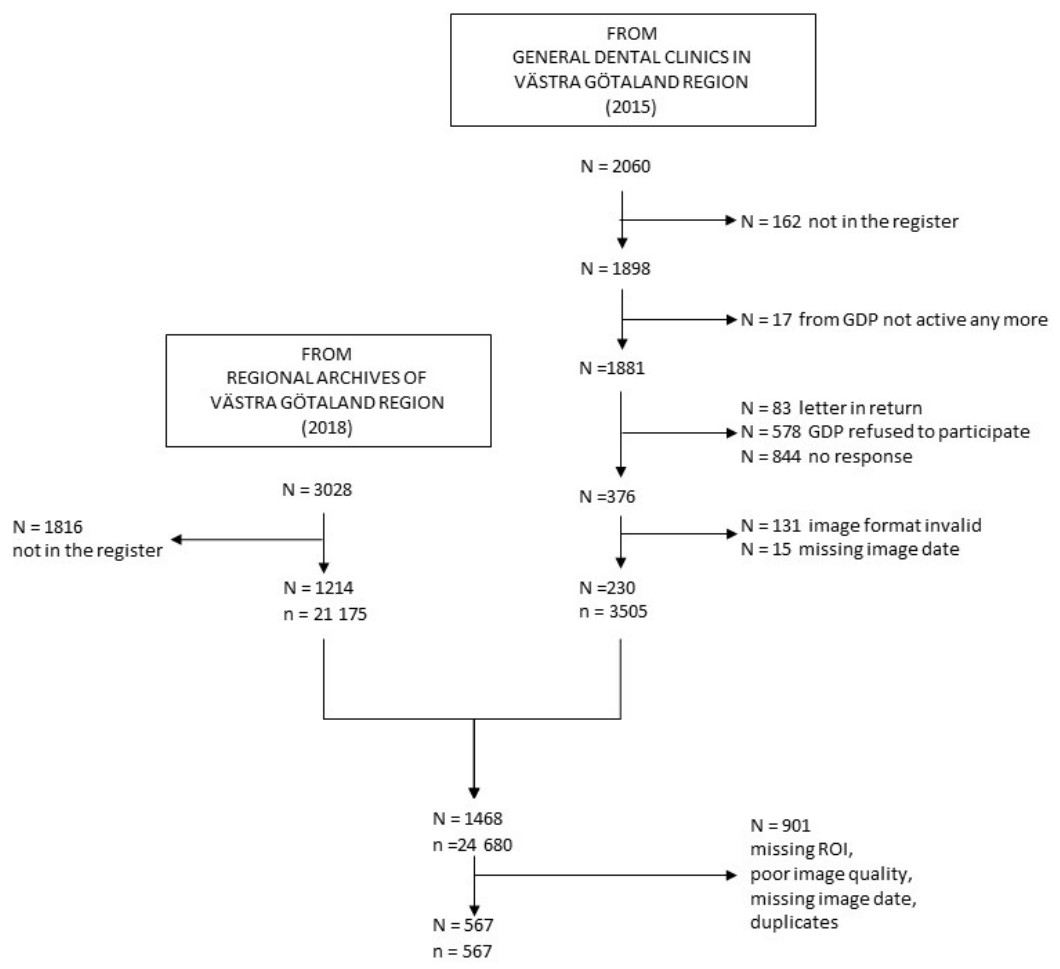

Figure 7 Flow chart of participant recruitment and data collection. $N=$ number of study participants, $n=$ number of dental radiographs, $R O I=$ region of interest, GDP = General Dental Practitioner.

examination. A total of 567 radiographs was chosen from the same number of patients. All DICOM images were converted to JPG format using Image J software (Rasband, W.S., ImageJ, U. S. National Institutes of Health, Bethesda, Maryland, USA, 1997-2018). Analog images were scanned with 1000 dpi using UMAX Mirage IIse (Umax Technologies, Inc., Hsinchu, Taiwan) flatbed scanner.

\section{Boneprox@ Software}

The Boneprox software (Boneprox, Gothenburg, Sweden) is the next generation of the software previously known as Jaw-X (Crebone AB, Sundbyberg, Sweden) [Jonasson et al. 2013]. The software algorithm creates a binary filtered image for automated analysis of the trabecular pattern within the ROI limited by a trapezoid marker (Figure 8). The trapezoid marker has a fixed size but can be manually rotated or moved around in the image. 


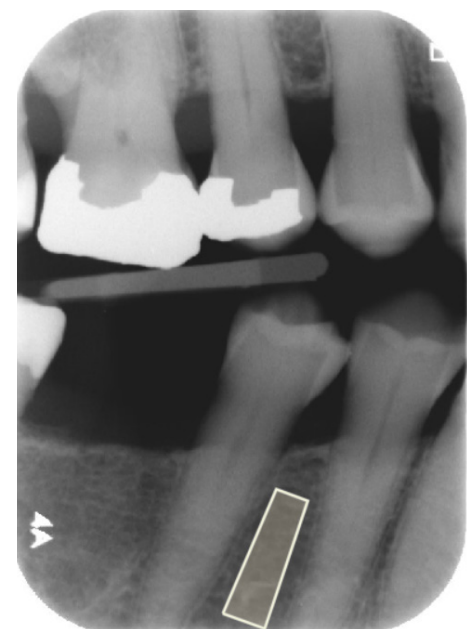

Figure 8 An example of an intraoral radiograph uploaded to the software with the trapezoid marker symbolizing ROI between the roots/apices of the premolar area in the lower jaw.

The area within the marker is resampled in size to make the resulting image match a fixed reference size. For the automated analysis, the images' gray levels are first reduced to 8 bit-data as the application of histogram stretch allows for the grey levels to be linearly stretched to cover all intensities. Then the algorithm identifies the largest intertrabecular space, followed by the next largest until the 20 largest spaces have been located.

The software comes in two versions - a semi-automated one, where the placement of the trapezoid marker is performed manually by the user, and a fully-automated one. The fully-automated version of the software uses new technology where the whole process from locating the trapezoid marker to analyzing the trabecular pattern within has been automated. The final resulting value represents the sum of the sizes and intensities of the spaces between the trabeculae.

\section{Analyses}

For study III, five raters performed the image analyses of the intraoral radiographs using semi-automated software. The raters differed substantially with regards to their level of professional experience, which ranged from over 30 years of experience within the field of dental and maxillofacial radiology to less than one year of experience. The images were also analyzed using the fully-automated tool.

All the raters and a representative from the software company participated in an information and calibration session before the analyses. In addition, the assessment instructions were specified both verbally and 
in writing. All raters performed the analyses independently of each other at their own location using computer screens with resolution 1920x1080 pixels. The observation rooms were dimly lit, and the recommended distance to the screen was approximately $0.5 \mathrm{~m}$. There was no restriction regarding observation time. All raters were blinded to clinical features such as the patients' age, medical history, and individual DXA results.

After uploading the images to the software, every rater manually placed the trapezoid marker (symbolizing ROI) between the roots/apices of the premolar area in the lower jaw. The software developers performed the analysis with the fully-automated tool. During the analysis with the fullyautomated tool, the trapezoid marker was placed by the software itself.

After four weeks, all the raters performed the second round of observations for study III on $121(20 \%)$ randomly selected images.

Only the first rater's results, including all radiographs selected for this study, and the fully-automated tool were considered for study IV.

\section{Statistics}

Most of the statistical analysis for studies III and IV was performed using SPSS software version 24.0 for Windows (IBM Corp., Armonk, NY, USA). For study III Kappa ( $\kappa)$ was calculated for pairwaise inter- and intrarater agreement. The overall rater agreement was calculated using Fleiss' kappa using STATA software version 16 for Windows (StataCorp LLC, College Station, Texas, USA). Rater agreement was evaluated following the Landis\&Koch [1977] interpretation scale (Table 1). Online statistical calculator MedCalc ${ }^{\circledR}$ (MedCalc Software, Ostend, Belgium) was used for calculating sensitivity, specificity, predictive values, and likelihood ratios for study III [MedCalc 2021]. Differences between groups for dichotomized variables were evaluated through $\chi 2$ test using Chi-Square Calculator [Stangroom 2018]. 
Table 1 Landis\&Koch [1977] interpretation scale of rater agreement.

\begin{tabular}{cc}
\hline Kappa statistics & Strength of agreement \\
\hline$<0$ & poor \\
$0.01-0.20$ & slight \\
$0.21-0.40$ & fair \\
$0.41-0.60$ & moderate \\
$0.61-0.80$ & substantial \\
$0.81-1.00$ & almost perfect \\
\hline
\end{tabular}

For study IV, study sample characteristics were presented using descriptive statistics. Independent sample t-tests and $\chi 2$ test were used to examine differences between groups of continuous and dichotomized variables, respectively. Cox proportional hazard model was used to analyze associations between trabecular pattern analysis in intraoral radiographs and incident fractures, where Boneprox scores were expressed in thousands of units in these models to make the interpretation clearer. The model was performed both unadjusted and adjusted for FRAX risk factors (previous fracture, family history of hip fracture, smoking, corticosteroids, rheumatoid arthritis, without and with femoral neck BMD) except for secondary osteoporosis and alcohol consumption due to there being none or very few cases in the study sample. In addition, Pearson's correlation analysis was performed to study the correlation between scores of semiand fully-automated analysis of trabecular pattern in intraoral radiographs and TBS.

\section{Ethical considerations}

Both studies I and II followed the ethical considerations of the Declaration of Helsinki, according to which no ethical approval was necessary as participation in the study was voluntary, anonymous (no identifying features were reported), and no data can be traced back to the study participants. Information about the study, worded according to the general outlines provided by the Regional Ethical Review Board, Lund, Sweden, was provided before the study.

The ethical considerations for both studies III and IV concerned mainly radiation exposure. The radiation exposure due to bone densitometry and radiographs taken for fracture confirmation was low and approved by the local radiation protection committee. Dental radiographs used for the 
purpose of both studies were collected retrospectively and were taken for odontological indications, meaning that there was no additional radiation exposure.

Epidemiologic studies are associated with issues regarding the personal integrity of the participants. A written agreement was signed by the Prefect of the Institute of Medicine at Gothenburg University and by the Dean of the Faculty of Odontology at Malmö University specifying security requirements for handling of sensitive data. To ensure there was no violation of data security, all data was coded, stored on secured encrypted hard drives, and only handled by authorized personnel. Furthermore, the analyses and presentation of results were only performed on the group level with no possibility to identify unique individuals. The study participants could withdraw their consent at any time and thereby be excluded from the study. The ethical review board in Gothenburg approved both studies (Dnr T297-15/Ad 929-12), and all study participants signed informed consent. 


\section{RESULTS}

\section{Study I}

In this study, we investigated stakeholders' preconceptions of issues connected to implementing osteoporosis risk assessment into primary dental care. Five FGDs and one single interview, including 17 participants, were performed for this purpose.

Main results in the form of categories and subcategories extracted from the transcripts of the interviews are presented in Figure 9:

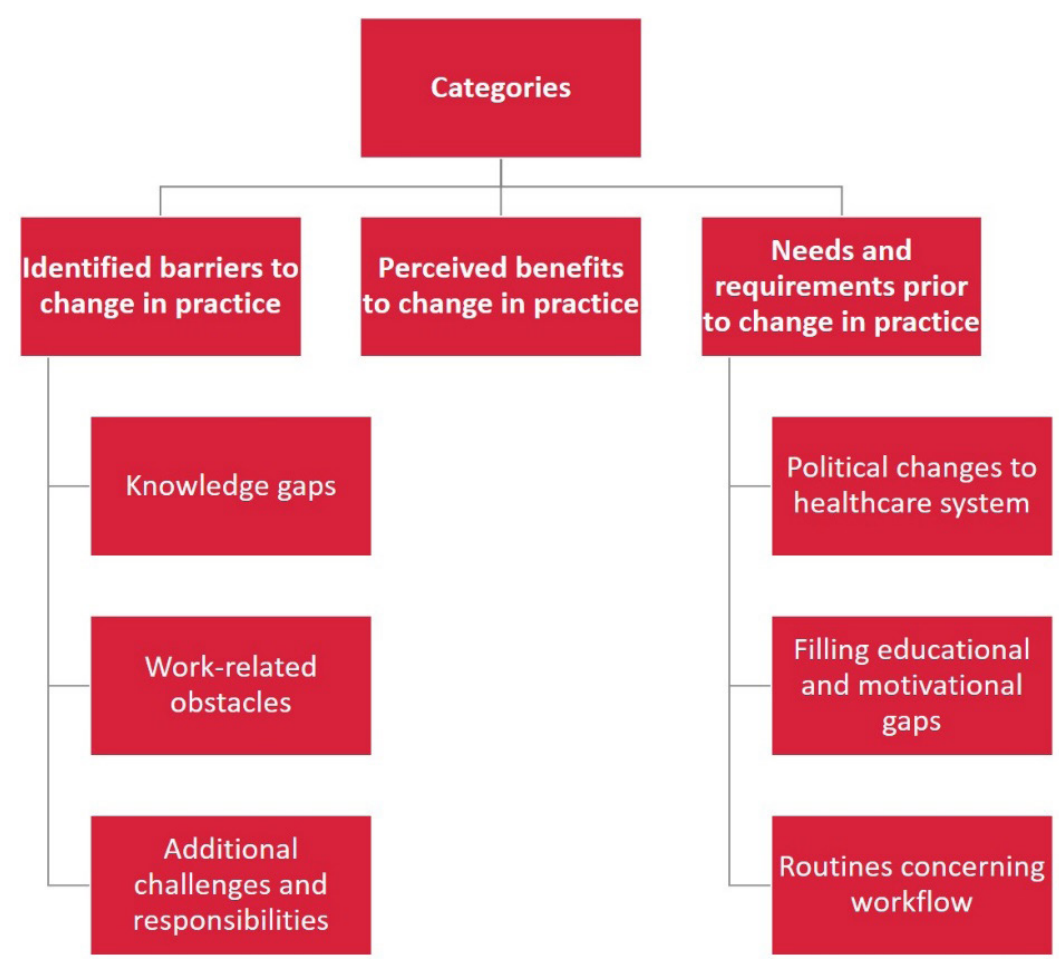

Figure 9 Categories and subcategories extracted from the analysis of transcripts in Study I. 


\section{Study II}

In this study, we performed a health economic evaluation of osteoporosis risk assessment in general dental care using WTP instrument. A total of 144 study participants responded to the applied questionnaire.

Main results:

- Most respondents (90\%) were willing to pay for an osteoporosis risk assessment in primary dental care with a mean value of 44.60 $€(\mathrm{CI} 95 \%$ 38.46-50.74 $€$ ). The two most common reasons were the importance of early diagnosis and preventive care to avoid fractures $(41.0 \%)$ and the importance of knowledge of a risk of osteoporosis (26.4\%). Most respondents (67.8\%) considered it valuable if dental clinics could offer osteoporosis risk assessment.

- No statistically significant association was shown between WTP and age, education level, income, occupation, osteoporosis diagnosis, osteoporotic fracture, having a relative with osteoporosis diagnosis, or osteoporotic fracture.

- Net social benefit (NSB) for osteoporosis risk assessment in primary dental shows a positive value calculated as:

$\mathrm{NSB}=\mathrm{WTP}-$ cost for dentist's working time

Where:

$\mathrm{WTP}=44.60 €$

Cost of dentist's working time/minute $\approx 3.67 €$

Time needed for osteoporosis risk assessment $\approx 10 \mathrm{~min}$

$\mathrm{NSB}=44.60 €-3.67 € \times 10 \mathrm{~min}=7.92 €$ 


\section{Study III}

This study investigated rater agreement and diagnostic accuracy of semiautomated and fully-automated analysis of trabecular pattern in intraoral radiographs to assess the risk of osteoporosis in older female subjects.

Main results:

- Pairwise agreement between the five raters varied from fair (the lowest being $\kappa=0.21$ with $95 \%$ CI $0.14-0.28$ ) to moderate (the highest being $\kappa=0.52$ with $95 \%$ CI $0.44-0.61$ ). The agreement between the five raters and the softwares' fully-automated tool was mostly fair (mean value $=0.29$ with lowest $\kappa$ value 0.16 and highest $\kappa$ value 0.39 ) [Landis\&Koch 1977].

- Overall interrater agreement for the five raters was 0.37 (95\% CI $0.32-0.41)$, and for the five raters with the fully-automated tool included as a "sixth rater" $0.34(95 \%$ CI $0.30-0.38)$.

- Intrarater agreement varied from moderate to substantial (lowest $\kappa$ value 0.49 and highest $\kappa$ value 0.73 ).

- The mean sensitivity was $40.4 \%$ (range $14.3 \%$ to $57.6 \%$ ), while mean specificity was $69.5 \%$ (range $59.7 \%$ to $90.4 \%$ ) with large differences between the raters. Positive predictive values varied between $8-19 \%$ while negative predictive values ranged from 88 $95 \%$. The diagnostic odds ratios varied between 1 and 2.7. Detailed presentation of results of diagnostic accuracy parameters is in Table 2.

- Sensitivity analysis for study participants who had been treated with osteoporosis medication before the study or at the start of the study compared to the group of study participants who never underwent osteoporosis treatment showed no statistically significant difference. 


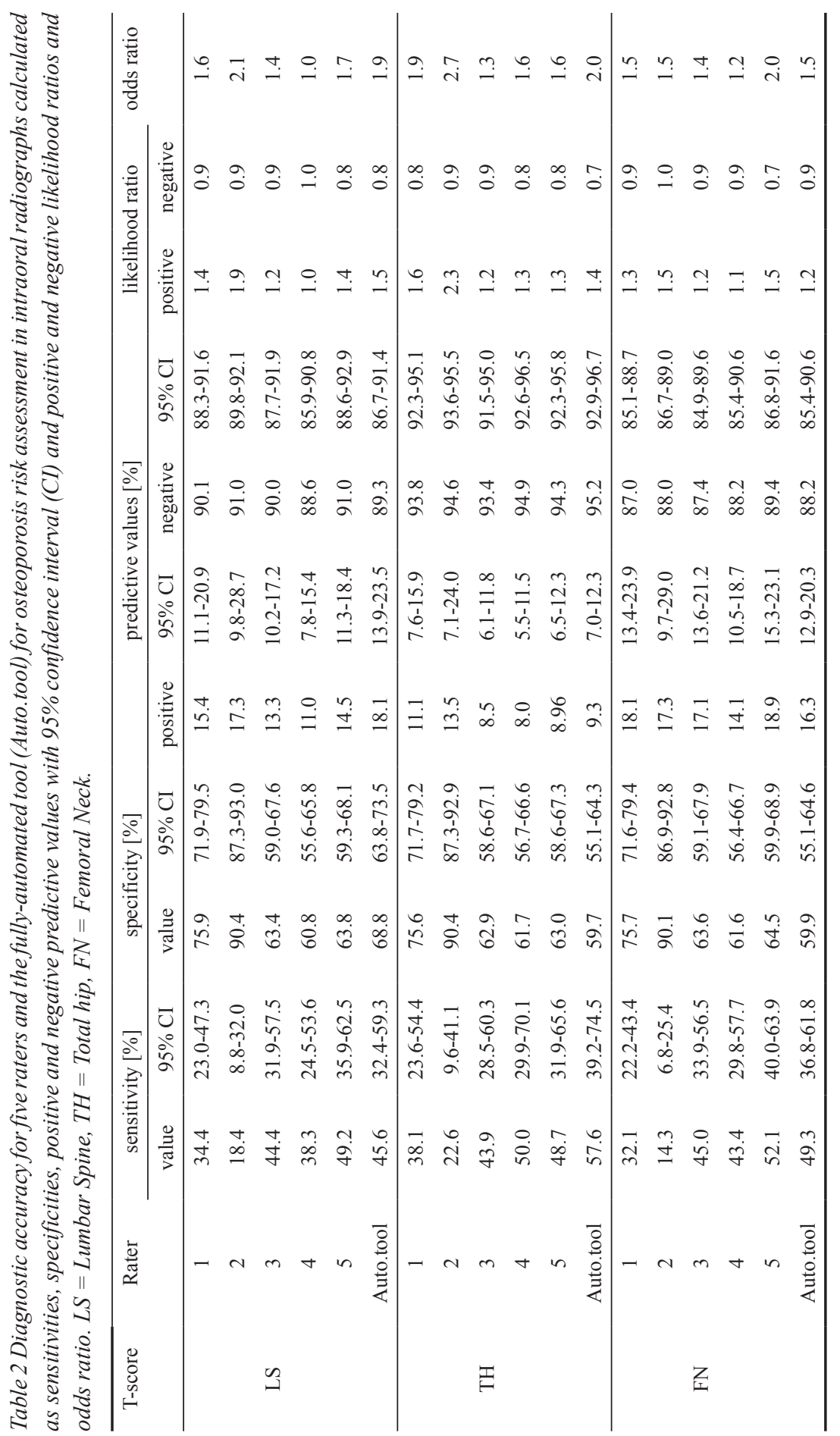




\section{Study IV}

In this study, we investigated if semi-automated and fully-automated digital analyses of the trabecular pattern in intraoral radiographs independently contributed to fracture risk assessment when other clinical risk factors incorporated in FRAX were taken into account. Furthermore, the correlation between the automated trabecular pattern assessment in intraoral radiographs and TBS was investigated.

Main results:

- No predictive association could be found between MOF or any fracture and semi-automated analysis of trabecular pattern

- No predictive association could be found between MOF or any fracture and fully-automated analysis of trabecular pattern

- Only a weak correlation was found between trabecular pattern analysis in intraoral radiographs using semi-automated analysis and TBS. No correlation was found between the fully-automated analysis of the trabecular pattern and TBS. 


\section{DISCUSSION}

This thesis aimed to investigate aspects of implementing osteoporosis and fracture risk assessment into primary dental care. The research questions were approached by both qualitative (study I) and quantitative (studies II-IV) methods.

\section{Implementation of a new health-promoting method in oral health care}

For the past 20 years, several research groups have investigated the possibility of assessing osteoporosis risk from dental radiographs and it has been proved that it might be possible [White\&Rudolph 1999, White et al. 2000, Jonasson et al. 2001, White 2002, Lindh et al. 2004, White et al. 2005, Devlin et al. 2007, Geraets et al. 2007, Jonasson et al. 2007, Karayianni et al. 2007, Devlin et al. 2008, Lindh et al. 2008, Jonasson 2009, Jonasson et al. 2009, Verheij et al. 2009, Horner et al. 2010, Pham et al. 2010, Jonasson et al. 2011, Geraets et al. 2012, Hassani-Nejad et al. 2013, Jonasson\&Billhult 2013, Jonasson et al. 2013, Jonasson\&Rythén 2016, Sundh et al. 2017, Geraets et al. 2018]. Therefore, we decided it is time to investigate the subject from the implementation research point of view. We asked ourselves what implementation aspects need to be addressed for the osteoporosis and fracture risk assessment to be put into practice in primary dental care? Is the method desired, useful, applicable, and financially justifiable?

We chose to focus on intraoral radiographs as a method of execution for two reasons: (1) they are the most common choice of radiological examination in the dental setting, and (2) the software evaluated in this project was only applicable to intraoral radiographs. The advantage of intraoral radiographs is that they are a high-resolution two-dimensional 
representation of a relatively limited area, typically showing two to three teeth and the adjacent jawbone. They are, however, very sensitive to several factors during image acquisition, including patient and receptor positioning, proper angulation of the radiation source, and correct selection of the exposure settings [Hubar 2017], which requires much skill from the clinician.

Implementation research has as a goal to evaluate methods for introducing new research results, such as osteoporosis and fracture risk assessment using intraoral radiographs, into everyday practice. It focuses on exploring and describing the possible problems that the implementation of a new method might encounter as well as possible facilitating factors [Nilsen 2010]. Together, the factors that could obstruct or ease the implementation process (i.e. determinants) have been described in several different frameworks in previous studies [Flottorp et al. 2013]. The implementation frameworks discuss how planning complex changes in practice need to address potential barriers at various levels, taking into account aspects such as the nature of the innovation, characteristics of the professionals and patients involved, and the social, organizational, economic, and political context [Grol\&Wensing 2004].

\section{Focus groups}

To familiarize ourselves with possible determinants that could influence the implementation of osteoporosis and fracture risk assessment in a dental setting, we performed a qualitative study using FGDs (study I) and a WTP study (study II). For the FGDs, we constructed a semi-structured interview guide that covered all these aspects for the participants to discuss. Of the frameworks mentioned above, only three address the target group, i.e. the individuals that will be most affected by implementing the method [Cochrane et al. 2007, Damschroder et al. 2009, Grol et al. 2013]. We considered the target group, which in this project was postmenopausal women being assessed for osteoporosis, as an equally relevant determinant as the innovation itself or the healthcare professionals who are going to use it. We considered their opinions and thoughts to be highly important since they are the 'receiver' of the service. Therefore, we chose to include them in both studies I and II.

FGD is a form of an interview carried out during the data collection stage of a research project where the study participants chosen from a target research population are engaged in a conversation on a particular subject. 
The distinct feature of FGD is the active interaction between participants in order to explore their views and opinions. The questions asked in FGD are similar to those asked in a one-on-one interview. The difference is that the group dynamic in FGD aims to assist people in expressing themselves and clarifying their views, something that is much less likely to occur in a one-on-one interview. We specifically chose homogeneous groups because this was supported by previous research as a way to provide comfort to the participants and it yields the additional benefit that friends and colleagues can relate to each other's comments and encourage each other to elaborate their thoughts [Khan\&Manderson 1992, Kitzinger 1994].

FGDs have become an increasingly popular method of data collection in healthcare research. It is well established that FGDs are the most appropriate method to generate meaningful conversation evaluating opinions on a specific subject with minimal supervision of the research team. In healthcare studies, FGDs have been applied to evaluate subjective attitudes such as attitudes within elderly care concerning oral health [Grönbeck Lindén et al. 2017] or dentists' willingness to change behavior based on newly acquired knowledge [Wårdh et al. 2009] that would be hard to measure in a quantitative study design. Our study provided us with insights into the attitudes of all involved parties (dentists, medical specialists and patients) towards osteoporosis risk assessment in a dental setting. We deliberately chose to do the interviews as FGDs with specific representatives from all the stakeholder groups instead a survey or a selfadministered questionnaire sent out to the general population for several reasons. Firstly, the advantage of FGD instead of a survey is that we could interact with the discussion participants if anything needed clarification. A survey is a more passive way of obtaining answers. Secondly, in FGDs it is desirable to ask open questions in order to leave room for the participants to answer freely, while a questionnaire tends to provide a limited amount of possibilities to quantify the answer. However, self-administered questionnaires are less time-consuming than FGDs, thus enabling a larger study sample and minimizing biased answers due to influence from an interviewer [Tausch\&Menold 2016]. Thirdly, we chose participants who had knowledge of the subject of osteoporosis - representatives from osteoporosis patient support groups, dentists who had a special interest in health-promoting activities within dental settings, and medical specialists within the field of osteoporosis. Because osteoporosis is a disease that mainly affects the older population, we were not interested in answers 
from random representatives of the general population who probably had neither knowledge nor interest in the subject.

Similarly, we only wanted to interview the stakeholder groups who would later be involved in the implementation and the potential subsequent clinical trials. In general, the FGD participants agreed on the benefits of incorporating osteoporosis risk assessment in primary dental care, which is in line with previous studies on other health-promoting activities performed by dentists [Albert et al. 2005, Barasch et al. 2012]. Dental professionals expressed interest in conducting osteoporosis risk assessment alongside their daily activities, which also is in agreement with previous results on other health-promoting interventions in a dental setting [Dyer\&Robinson 2006]. The barriers pointed out in the discussion, such as time and financial factors, current workload, and lack of deeper knowledge on the subject, were the same as the concerns noted in other research on general health promotion in dental settings [Dyer\&Robinson 2006]. We found that seventeen study participants who built five FGDs and one one-on-one interview provided enough of an overview of the issues and concerns that need to be considered in the implementation of osteoporosis risk assessment in dental settings. No new insights were provided after that. Therefore, no more FGDs were considered necessary as they would not contribute further to the analysis.

Another common practice often included in mixed-methods studies is to perform FGD to gain more information on how to construct questionnaires or interpret results. For that reason, we also performed a FGD in study II before applying our WTP questionnaire. A FGD with four post-menopausal women helped us revise the information booklet and the survey questions according to their understanding and interpretation.

\section{Health economics}

In 2012 the Swedish National Board of Health and Welfare introduced a set of guidelines for the care process of individuals that suffered an osteoporosis-related fracture [Socialstyrelsen 2012]. The National Board of Health and Welfare performed a health economic assessment in 2012, which showed that if the new guidelines for the care process for patients with osteoporosis-related fractures were implemented nationally, it would lead to short-term increased costs (approximately SEK 70 million nationally) for pharmaceuticals as the number of patients receiving drug treatment with bisphosphonates was estimated to increase by 15 000-20 000 individuals. 
However, long-term, the costs were decreased by a grand total of SEK 267 million per year because the number of fractures in inpatient care that could be avoided was estimated at around SEK 3200 per year in Sweden, of which about SEK 1900 were costs related hip fractures. With an estimated cost of SEK 125000 per hip fracture and SEK 22 000-130 000 per other fracture, and the mean costs of long-term care around SEK 60 000-80 000 per hip fracture, the cost of these could be reduced by SEK 267 million per year [Socialstyrelsen 2012]. Västra Götaland Region, where the SUPERB cohort study was performed (and with it our studies III and IV), estimated in 2013 in agreement with data published by the National Board of Health and Welfare that the new recommendations could reduce the number of osteoporosis-related fractures by 600 every year within the region, yielding SEK 45 million of saved resources annually.

Furthermore, it was estimated that the care process would gradually increase the proportion of elderly with fractures treated with medication from $13.6 \%$ to $22 \%$ in $2014,32 \%$ in 2015 , and $40 \%$ in 2016 . However, according to the updated report on Osteoporosis care in Västra Götaland Region published 15th June 2021, the proportion of treated individuals remained unchanged at around 15\% [Västra Götalands Regionen 2021] to $22 \%$ [Lorentzon et al. 2019]. The main reason for the lack of improvement was, among other factors, misinformation or unwanted additional costs for the primary healthcare clinics and an opinion among medical doctors (MDs) that this is outside the scope of the practice of primary healthcare clinics.

On the other hand, GDPs have a genuine interest in introducing osteoporosis and fracture risk assessment into primary dental care (Study I). Furthermore, the median WTP of SEK 298 (34.75€) showed in the WTP study (Study II) proves that women above the age of 50 are interested in paying an additional cost corresponding to the patient fee for a specialist visit in southern Sweden SEK 300 ( $35 €$ in 2013), which agrees with the compilation of WTP of diagnostic methods reviewed in 2013 where most studies reported a median WTP below $\$ 100$ [Lin et al. 2013].

For the past ten years women over the age of 55 constituted $16.5 \%$ of the population in Sweden. In 2020 this corresponded to 1715302 individuals. In Sweden, approximately $85 \%$ of the population regularly visits the dentist. During such visits, intraoral radiography is commonly performed in combination with the clinical examination. The images used in studies III and IV had already been taken for odontological indications, 
thus no additional costs were incurred for the dentist or the clinic except for time spent on the analysis. Hypothetically, if we assume that $1 \%$ of all the women over 55 years of age (i.e. $n=17$ 153) agree to perform the risk assessment, the accumulated WTP would be SEK 6603913 (based on the resulting average WTP in study II which was SEK 385 or $44.60 €$ ), (see Table 3). Corrected for the cost of the time spent performing the assessment by dentists (approximately 10min/patient), SEK 5711956 for all the women leaves us with SEK 891957 in excess. If we assume that of all the assessed women, only $1 \%$ will show a high risk of osteoporosis $(\mathrm{n}=172)$, the cumulative cost of DXA examination for them would be SEK 257295 , which is roughly one-fourth of the excess amount of money from the accumulated WTP fee. The total reduction of costs for five confirmed cases of severe osteoporosis would be almost SEK 1 million annually. Hence, it would be enough if only five of the 172 examined women (3\%) were confirmed as severely osteoporotic to level the DXA examination cost with saved costs from avoided fractures. This suggests that risk assessment of osteoporosis in general dental practice might be a cost-effective method to save society money. However, this calculation is only a simplified model that does not consider the software's performance and possible additional costs for over-diagnosing and excess DXA examinations, not to mention the excess radiation that the patient would be exposed to. 
Table 3 The modeled cumulative cost consequences of implementing osteoporosis and fracture risk assessment by dentists based on data from the National Board of Health and Welfare report from 2012 [Socialstyrelsen 2012] with the average WTP value from study II. Refers to the average per patient with fracture and calendar year (SEK, nondiscounted values).

\begin{tabular}{|c|c|}
\hline \# of osteoporosis-related fractures in Sweden per year & 70000 \\
\hline \# of hip fractures in Sweden per year* & 16000 \\
\hline cost per hip fracture* & $125000.00 \mathrm{SEK}$ \\
\hline cost for other osteoporosis-related fractures* & $30000.00 \mathrm{SEK}$ \\
\hline alendronate acid cost per patient* & 400.00 SEK \\
\hline zolendrone acid cost per patient* & $4000.00 \mathrm{SEK}$ \\
\hline DXA cost per examination* & $1500.00 \mathrm{SEK}$ \\
\hline $\begin{array}{l}\text { proportion of Swedish population visiting a dentist } \\
\text { every year [Hugoson et al. 2005, Norderyd et al. 2015] }\end{array}$ & $85 \%$ \\
\hline$\%$ of women +55 years in Sweden in 2020 & $16.50 \%$ \\
\hline$\#$ of women +55 years in Sweden in 2020 & 1715302 \\
\hline $\begin{array}{l}1 \% \text { of women }+55 \text { years that agreed to osteoporosis } \\
\text { risk assessment by dentists }\end{array}$ & 17153 \\
\hline mean WTP from study II & 385.00 SEK \\
\hline total reimbursement from WTP & $6603912.70 \mathrm{SEK}$ \\
\hline $\begin{array}{l}\text { cost for the time needed by the dentist to perform the } \\
\text { assessments }(10 \mathrm{~min} / \text { patient })\end{array}$ & $5711955.66 \mathrm{SEK}$ \\
\hline $\begin{array}{l}\text { total reimbursement from WTP minus costs for the time } \\
\text { needed by the dentist to perform the assessment }\end{array}$ & 891957.04 SEK \\
\hline $\begin{array}{l}1 \% \text { of the women assessed by dentist show risk of } \\
\text { osteoporosis }\end{array}$ & 172 \\
\hline $\begin{array}{l}\text { DXA costs for the } 1 \% \text { of women assessed at risk of } \\
\text { osteoporosis by dentists }\end{array}$ & 257 295.30 SEK \\
\hline $3 \%$ confirmed osteoporotic & 5 \\
\hline $\begin{array}{l}\text { saved costs from avoided fractures (23\% hip fractures, } \\
\text { the rest other fractures) }\end{array}$ & $272733.02 \mathrm{SEK}$ \\
\hline Total amount saved & 907 394.76 SEK \\
\hline
\end{tabular}

*[Socialstyrelsen 2012] 


\section{Diagnostic methods}

Aside from relieving pain and curing disease, modern medicine has developed an interest in disease prediction, prevention, and prophylaxis. As a result, screening for various conditions such as high blood pressure or high blood sugar has become increasingly popular in order to prevent serious consequences otherwise likely to occur. Although the relationship between the benefits and harm of diagnostic methods continues to be the subject of controversial scientific debate, the social value of effective disease prevention is undisputed. One form of screening is opportunistic screening, where everyone attending a regular doctor's appointment for a particular reason and fulfills the criteria is offered an additional diagnostic test, for example, blood pressure measurement.

Osteoporosis has been an object of interest for screening because its consequence, fracture, has a devastating effect on the individual and those close to them, the healthcare system, and society as a whole. However, screening for osteoporosis using DXA has not been recommended because there is no scientific basis for using DXA examination as a screening method for healthy, middle-aged people. On the other hand, the measurement of BMD has a clear role in the investigation of individuals with multiple risk factors to predict their fracture risk [Marshall et al. 1996, SBU 2003]. The SCOOP randomized control trial (Screening for prevention of fractures in older women) compared a screening program for older women (70-85 years) using FRAX in addition to BMD with standard management showing a reduction in the incidence of hip fractures in the screening group [Shepstone et al. 2018, Shepstone\&McCloskey 2018] which was recently confirmed by a systematic review [Merlijn et al. 2020]. Moreover, the SCOOP study showed that the systematic communitybased screening program for fracture risk in older women was a highly cost-effective intervention [Turner et al. 2018]. To make decisions about whether or not to implement any screening program it should be considered if the program is likely to constitute good use of healthcare resources if it is cost-effective etc.

Over time new alternative methods have come to light that could help identify individuals at risk of osteoporosis and fragility fracture. As previously mentioned, it has been established that there is a correlation between the trabecular pattern of the jaws and the risk of osteoporosis, which led to the development of a new tool for the analysis of trabecular pattern in the intraoral radiographs for the purpose of osteoporosis risk 
assessment. This tool is called Boneprox software. It is a commercial software advertised on the Swedish market to be applied on intraoral radiographs from the lower jaw's premolar region to perform the analysis in an automated manner. However, even though the software is already partly implemented in practice, evaluation of its performance is still scarce, which is why we chose to investigate this in studies III and IV.

Any diagnostic method or test used in healthcare is expected to benefit the patient undergoing the analysis. However, using a diagnostic test just for testing may lead to contradictory and confusing results, overdiagnosing, and unnecessary costs [Leeflang\&Allerberger 2019]. Therefore, before diagnostic tests can be used in the clinical management of patients, they must be thoroughly evaluated. Fryback\&Thornbury [1991] described a framework presenting six levels of diagnostic test efficacy: (1) technical efficacy, (2) diagnostic accuracy efficacy, (3) diagnostic thinking efficacy, (4) therapeutic efficacy, (5) patient outcome efficacy, and (6) societal efficacy (Figure 10). To enable efficacy on the higher levels, the efficacy on the lower levels must be effective. However there are no guarantee as efficacy on lower levels does not necessarily ensure efficacy on higher levels. It is therefore essential to assess imaging methods for osteoporosis and fracture risk assessment before introducing them in practice in a dental setting.

The first level, technical efficacy, concerns aspects such as resolution, contrast and noise. Since the early 1990s, intraoral radiographic systems have been gradually introduced, and most GDPs in Sweden gradually

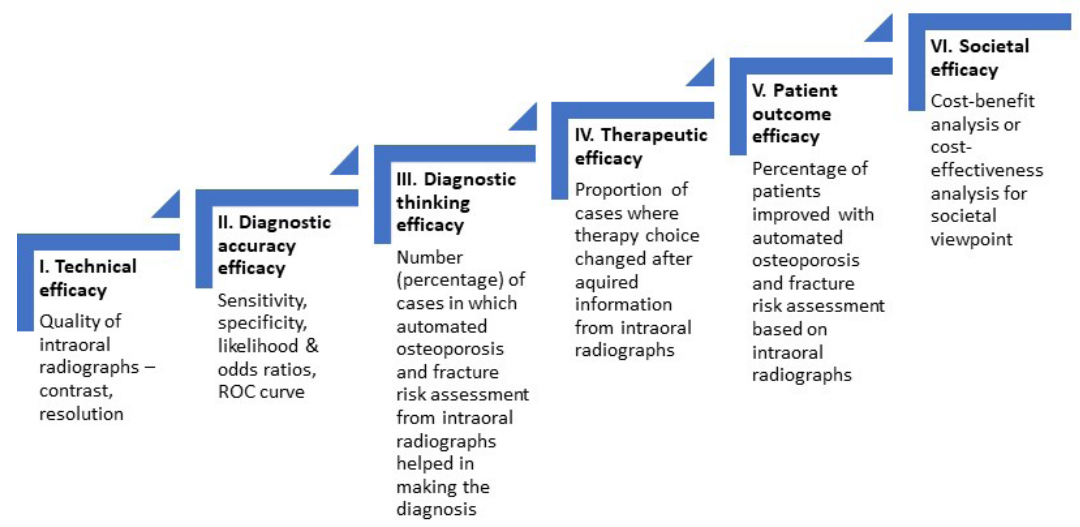

Figure 10 Modified hierarchical model of efficacy suggested by Fryback\&Thornbury [1991] with examples of outcome measures related to automated osteoporosis and fracture risk assessment by dentists. 
shifted from analog to digital radiography in their practice [Svenson et al. 2018]. The image quality of these systems has to be evaluated along with the corresponding radiation dose because the principle of 'as low as reasonably achievable' (ALARA) [ICRP 1973] should always apply to new techniques. However, it proved to be problematic because, despite standardized recommendations on image quality, studies show great variability in image quality, often leading to additional exposure and inadequate or inferior diagnostic value [Svenson et al. 1995, Hellén-Halme et al. 2004, Hellén-Halme et al. 2007], something that GDPs experienced [Hellén-Halme et al. 2005] and that we also experienced while selecting images for studies III and IV.

In agreement with the second level concerning diagnostic accuracy efficacy, in study III, we chose to evaluate the semi-automated and fullyautomated software performance concerning rater agreement and accuracy in relation to osteoporosis risk assessment. The study was conducted, analyzed, and reported following the Guidelines for Reporting Reliability and Agreement Studies (GRRAS) [Kottner et al. 2011]. To our knowledge, this is the first study to perform such an analysis of rater agreement on the application of the automated software. None of the previous studies that used Boneprox software performed a rater agreement evaluation. The software's accuracy was either compared to other methods (visual assessment, Bone Texture) or used side-by-side with other methods to evaluate the predictive value of trabecular pattern analysis for fracture risk [Hassani-Nejad et al. 2013, Jonasson\&Billhult 2013]. Our study showed that the degree of agreement between the raters assessed following Landis\&Koch [1977] interpretation scale was only fair to moderate, which agrees with previous studies using visual assessment method to assess trabecular pattern for osteoporosis risk assessment [Lindh et al. 2008]. However, compared to this study, we chose raters with very different experience levels and expertise, whereas in the study using a visual assessment approach, four out of five raters were experienced radiologists with several years of highly specialized training. Additionally, the image acquisition in that study was more standardized and images were obtained in the controlled environment, while image material in our study consisted of retrospectively gathered radiographs from sources we had no knowledge of. With that in mind, our study showed that the evaluated software achieved similar levels of inter- and intrarater agreement when used on radiographs attained retrospectively from unknown conditions and analyzed by raters with different levels of clinical experience. However, the 
fully-automated tool built into the software in order to eliminate the user's influence showed only slight to fair agreement with the five raters, which indicates it needs further improvement before it can be recommended for commercial use.

Other guidelines are at hand for transparent and complete reporting, enabling validation and critical appraisal in studies on accuracy. For study III STARD-statement items [Bossuyt et al. 2015] were implemented. STARD stands for 'Standards for Reporting Diagnostic accuracy studies' and is a checklist of essential elements to be included in diagnostic accuracy studies to improve the completeness and transparency of reports. STARD was first published in 2003 [Bossuyt et al. 2003] and updated in 2015 [Bossuyt et al. 2015]. A comprehensive explanation of the updating process and the justification for the changes are available on the EQUATOR (Enhancing the QUAlity and Transparency Of health Research) website at www.equator-network.org/reporting-guidelines/stard.

We investigated software accuracy through sensitivity, specificity, likelihood ratios, and odds ratios. Generally, sensitivity was lower than specificity, which agrees with previous studies investigating the same software sensitivity and specificity [Hassani-Nejad et al. 2013]. Although most studies describe how well tests identify patients with the disease (sensitivity) or without the disease (specificity), further evidence is needed to determine a test's true clinical value because, in the end, the test should ultimately lead to an improvement of the health status of the tested person [Ferrante di Ruffano et al. 2012]. Confirmed in several studies, likelihood ratios are considered the most useful measure of accuracy since the clinicians base their decision on the likelihood of presence or absence of a clinical outcome once the test result is known [Chien\&Khan 2001]. In contrast to sensitivity or specificity, the main strength of likelihood ratios is that they use all four cells of the $2 \times 2$ table, which is more informative. Moreover, likelihood ratios are useful across various disease frequencies independent of prevalence, making them applicable to a specific patient [Grimes\&Schulz 2005]. Although Deeks [2001] admits that the diagnostic odds ratio is difficult to apply in clinical practice, it is convenient when combining studies in a systematic review because it is often reasonably constant regardless of the diagnostic threshold.

Another issue is that in order to assess the accuracy of a diagnostic test, a reference standard is needed to classify subjects into those who really have 
the condition and those who do not. In her review of systematic reviews and meta-analysis of diagnostic test accuracy, Leeflang [2014] defines reference standard as 'the test used to define the target condition, and the underlying assumption is that it reflects the truth'. Similarly, according to the STARD definition, a reference standard is 'the best available method for establishing the presence or absence of the target condition' while gold standard is defined as an error-free reference standard [Bossuyt et al. 2015]. Wenzel\&Hintze [1999] formulated criteria for the gold standard to '(1) be reproducible, (2) reflect the pathoanatomical appearance of the disease, and (3) be independent of the diagnostic method under evaluation". The current reference standard for osteoporosis diagnosis is BMD measurement at the femoral neck achieved through DXA examination. This site was proposed as a reference standard in 2008 as the most extensively validated compared to other techniques [Kanis et al. 2008]. DXA was adopted as a reference standard due to the lack of a true gold standard and was expected to provide a platform on which other methods' performance characteristics could be compared. But DXA examination has its flaws, and therefore comparing another diagnostic test to an imperfect reference standard can lead to bias [Walter et al. 2012].

Since the majority of individuals with fragility fractures show BMD values within normal or osteopenic range [Pasco et al. 2006] osteoporosis is nowadays considered to be one of many risk factors increasing the risk of fracture rather than a major diagnostic tool in the choice of treatment. Therefore efforts have instead been directed towards evaluating the predictive value of assessment of trabecular pattern in intraoral radiographs for fracture risk. Interestingly, we did not find any predictive value for fracture in the obtained results in study IV, which means further work is needed before the automated trabecular pattern analysis in intraoral radiographs for fracture risk assessment can be applied in practice.

To the best of our knowledge, the other levels of the Fryback\&Thornbury [1991] framework (diagnostic thinking efficacy, therapeutic efficacy, patient outcome efficacy, and societal efficacy) have not yet been assessed in the context of osteoporosis and fracture risk assessment. Rohlin et al. [2020] suggest thorough recommendations for research within dentomaxillofacial imaging inspired by the Fryback\&Thornbury [1991] framework. 


\section{Risk assessment}

Dentists and medical professionals perform risk assessments daily. Risk assessment is essential for the delivery of safe and appropriate dental care as well as for the overall health of the patient. But when talking about risk assessment, we should ask ourselves what exactly risk is because it is considered a rather ambiguous term originating from conflicting values and human judgment and knowledge [Aven 2010, 2012]. There is no unanimous definition. Instead, there are several definitions of risk, but most of them have in common that the concept of risk comprises events, consequences (i.e. outcomes), and probabilities, where the latter is a tool to express uncertainty [Aven 2010]. Quantifying risk using probabilities can be misleading because it may give the impression that it is possible to measure risk with high precision [Aven 2011]. However, probabilistic analysis requires strong simplifications and assumptions that can omit important yet not so obvious factors hidden in the background knowledge. What seems to be certain is that there is no such thing as an individual risk because no two individuals are exactly alike [Stern 2012], which means that any risk assessment for an individual is only an estimation of their probability of encountering the undesired event. No matter how many risk factors we include in the assessment, we can never be certain.

According to the US National Library of Medicine, risk is defined as: 'The probability that an event will occur. It encompasses various measures of the probability of a generally unfavorable outcome.' (2021). The same source defines risk assessment as: 'The qualitative or quantitative estimation of the likelihood of adverse effects that may result from exposure to specified health hazards or from the absence of beneficial influences' (2021). Quantitative analyses such as FRAX or Boneprox software are based on mathematical models representing reality dependent on several hypotheses and parameters. Reality can never be characterized exactly because the knowledge of the underlying phenomena is incomplete, causing uncertainty. The word 'qualitative' in the definition of risk assessment additionally opens the possibility of subjective judgment in the decision-making process. In an ideal world, the decision-maker would be well informed about the problem to reason with confidence [Aven\&Zio 2011]. However, in reality, heuristics have an unavoidable dimension of bias that can lead to systematic errors in the decision-making process [Tversky\&Kahneman 1974]. In other words, one way or another, uncertainty is an unavoidable component in risk analysis [Aven\&Zio 2011] and should be carefully considered. 
Suppose the dentist were to play a role in osteoporosis and fracture risk assessment. Using intraoral radiographs for osteoporosis and fracture risk assessment can be appropriate because the remodeling rate of trabecular bone is much higher than that of cortical bone [Manolagas\&Jilka 1995]. However, it is of the highest importance to keep the number of falsepositive assessments as low as possible to avoid unnecessary worry for the patients and redundant excessive workload in the medical clinics that handle possible referrals. Two recently performed systematic reviews by Pachêco-Pereira et al. [2019] and Johanen et al. [2021] presented a comprehensive compilation of research papers within the field of trabecular bone pattern analysis using dental radiographs for systemic disorder screening and fracture risk, respectively. Only three of the included studies (one in Pachêco-Pereira et al. [2019] and two in Johanen et al. [2021]) used intraoral radiographs and a software/algorithm for the purpose of trabecular pattern analysis. Interestingly, only Jonasson et al. [2013] used Jaw-X software, a previous generation of Boneprox software that we used in studies III and IV. In this study, Jaw-X predictive value for the 'total' fracture risk (i.e., previous and future) and the risk of incident fractures were compared to visual assessment and Bone Texture software. Similar to our results, the Jaw-X software showed no significant predictive value for future fracture risk. The same software has been used in three other studies [Hassani-Nejad et al. 2013, Jonasson et al. 2014, Elleby et al. 2021] to evaluate the association between the sparse trabecular pattern in intraoral radiographs and fracture risk assessment. Only one of them showed significant association [Hassani-Nejad et al. 2013]. As thoroughly described by Elleby et al. [2021], the full version of Boneprox software includes questions on gender, age, previous fractures, and family history of fractures, as well as cortisone use. In our studies III and IV, we chose, for several reasons, to limit our usage of Boneprox software to only the algorithm assessing the trabecular pattern. Firstly, our goal was to evaluate the performance of the algorithm concerning trabecular bone analysis, not its performance combined with the clinical questions, especially that, as pointed out by Hassani-Nejad et al. [2013], answering 'yes' on the question about previous fracture led straight to the recommendation of further examination, i.e., DXA examination and possibly FRAX evaluation according to current recommendations of the National Board of Health and Welfare [Socialstyrelsen 2012]. Secondly, these questions on patients' medical history, together with several other risk factors, are 
already included in FRAX, which is a well-established and well-evaluated, free-of-charge online tool to assess the ten-year probability of suffering a fragility fracture [FRAX 2019], while the Boneprox software is still largely unknown. Since we do not know the details of the Boneprox algorithm, to increase the comparability of our results with other studies, we chose an independent COX hazard model that included all the risk factors included in FRAX and the results from the analysis of trabecular pattern using Boneprox semi-automated and fully-automated version to evaluate the predictive value of the software for fragility fractures.

\section{Artificial Intelligence}

Radiologists use their experience and ability to recognize patterns, their memory, and their cognitive reasoning to interpret examinations under numerous extrinsic distractors, heavy workload, and fatigue [Hanna et al. 2018]. Unfortunately, human judgment and perception are individual, meaning they can never be fully objective. Therefore, we are always at risk of bias if human judgment is involved. Thus, some degree of error is unavoidable even with experienced professionals [Waite et al. 2017]. The commercial software used in studies III and IV was specifically developed to mitigate interpretative errors and improve patient safety. According to the software developers, it is built on artificial intelligence and algorithms. But what is AI, and can it eliminate the risk of human error?

The term AI was coined by John McCarthy in 1956 during the famous Dartmouth conference on this subject [Rajaraman 2014]. The origins of the discipline AI can be traced to this conference that sparked the crucial period from the 1950 s to the 1970 s, during which extensive research was done. Over the years, AI has become more popular thanks to increased data volumes, advanced algorithms, and computing power and storage improvements. Although there is no straightforward definition and there is plenty of room for interpretation of what can be regarded as AI, it is considered to be the capability of a machine to imitate intelligent human behavior [Webster]. AI has been categorized based on its ability as weak artificial intelligence (that only performs a narrow task) and strong artificial intelligence (complex and complicated systems that can perform humanlike tasks).

In medicine, especially in radiology, the most exciting areas of AI are image processing, computer vision, artificial neural network (ANN), and machine learning (Figure 11). Image processing is defined as a 


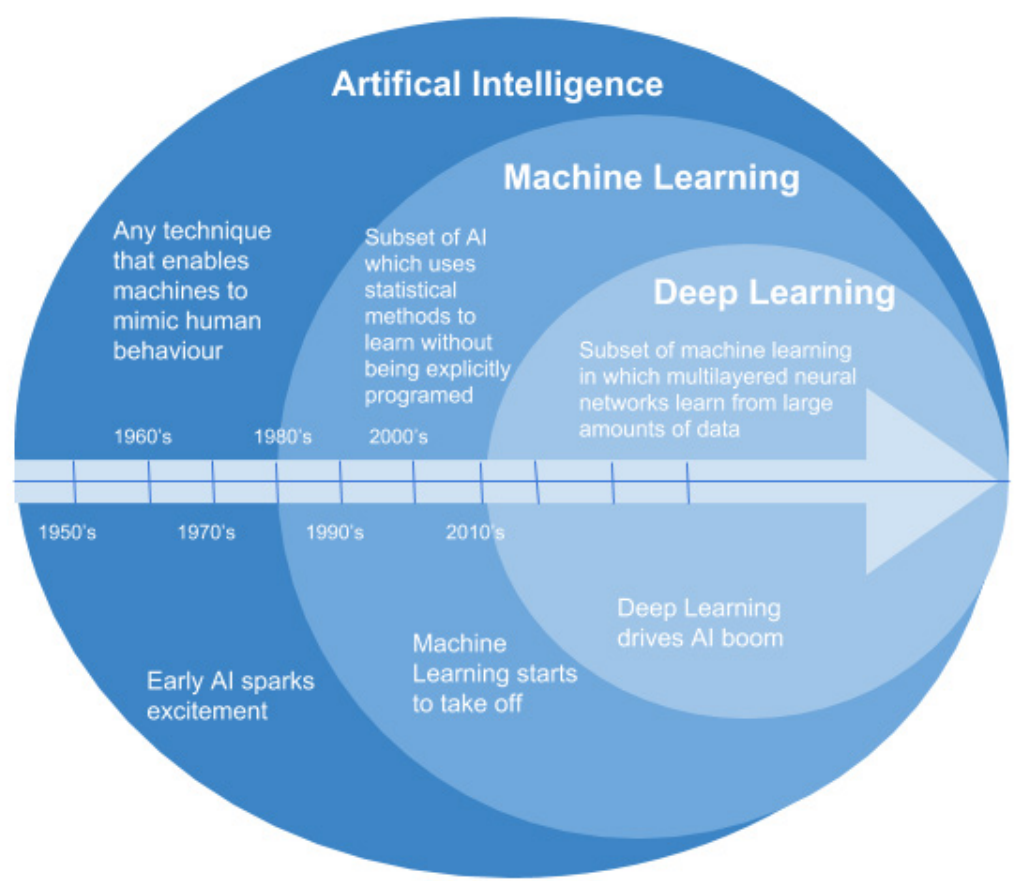

Figure 11 Illustration presenting how AI can be divided in sub-groups. AI is the larger circle that encapsulates Machine and Deep Learning. Illustration is the courtesy of Helena Williams [Williams 2019].

mathematical process enhancing an image to retrieve specific information, for instance, pattern measurements. Computer vision is defined as processing an image to identify the image input and provide an appropriate output. ANN and machine learning are forms of AI where ANN imitates the human brain by making decisions through processing data and using neural networks. Machine learning, and its subset called deep learning, is a computers' power to learn from experience, i.e., to modify its processing based on newly acquired information [Mintz\&Brodie 2019]. A subgroup of ANNs called Convolutional neural networks (CNNs) have demonstrated excellent performance in computer vision, including pattern recognition, tracking, and three-dimensional mapping and localization [Sklan et al. 2015]. CNNs have been adopted within the field of medical segmentation and diagnosis, showing promising results with high accuracy and efficiency in the detection and classification of diabetic retinopathy, skin cancer, and pulmonary tuberculosis. Radiological images, pathology slides, and 
patients' electronic medical records (EMR) are evaluated by machine learning algorithms, aiding in diagnosing and treating patients.

AI has made deep inroads into dentistry in the last few years. Khanagar et al. [2021], in their systematic review, describes the development of AI application within dentistry and evaluates the performance in terms of diagnosis, clinical decision making, and treatment prognosis prediction. Of the 43 studies included in the qualitative synthesis, 18 applied AI systems within oral and maxillofacial radiology. Most of those AI systems presented excellent results, with the precision exceeding $90 \%$.

In recent years several studies have proposed different AI algorithms for diagnosing osteoporosis based on medical images. One applied a deep learning model on low-dose computed tomography (LDCT) chest scans originally obtained for lung cancer screening, demonstrating the potential for opportunistic osteoporosis screening [Pan et al. 2020]. Another used a neural network classifier to diagnose osteoporosis from hand and wrist radiographs [Areeckal et al. 2018]. Panoramic radiographs have also been a subject of interest for applying deep CNNs (DCNNs) to successfully detect osteoporosis [Lee et al. 2019, Lee et al. 2020]. Gao et al. [2021] performed a comprehensive systematic review and meta-analysis, including all relevant studies on the diagnostic accuracy of AI-based systems detecting osteoporosis in medical images. The pooled sensitivity was 0.96 (95\% CI $0.93-1.00)$, and the pooled specificity was 0.95 (95\% CI $0.91-0.99$ ) in the seven included studies. Their main conclusion was that the AI-based systems had good accuracy in diagnosing osteoporosis, but they suggested that more prospective randomized multi-center control trials are needed to confirm that conclusion.

In contrast to the studies in the systematic review by Gao et al. [2021], the automated software used in studies III and IV applied AI techniques on intraoral radiographs to distinguish trabecular patterns. Interestingly, the software used in our studies did not perform as well as the AI-based systems presented in both the systematic reviews. With the mean sensitivity of 50.8\% (95\% CI 36.1-65.2) and mean specificity 62.8\% (95\% CI 58.067.4) for osteoporosis risk assessment with the fully-automated tool, the results obtained from study III suggest that the automation process of trabecular pattern analysis in intraoral radiographs for assessment of osteoporosis might be improved further.

In order to reach a good level of proficiency, AI needs to learn from a supervisor. With unlimited resources and comprehensive cooperation, it 
could learn from all the specialists in the world and ultimately from itself and eventually become better than the human specialists, like in the case of CheXnet that became better at diagnosing pneumonia than any human radiologist [Rajpurkar et al. 2017]. CheXNet is built of 121-layer CNNs trained on the largest publicly available chest X-ray dataset, containing over 100000 frontal view X-ray images with 14 diseases. In the case of the commercial software Boneprox, we know very little about how it works, and because of trade secrets and patent protection, it is not easy to establish in detail the similarities or differences between other algorithms for trabecular pattern analysis. However, we know that compared with CheXNet, Boneprox software does not have the luxury of working with a publicly available dataset, so it has been trained on a limited amount of radiographs. This limitation most probably influences the performance of the software, as measured in studies III and IV. Another aspect that could potentially influence the software performance is the fact that the quality of data can be affected by different technologies for image acquisition (analog radiographs scanned, digital radiographs) and different file formats (DICOM converted to JPEG, JPEG, TIFF, and BMP). DICOM (Digital Image and Communications in Medicine) is the standard protocol for managing and communicating medical image information and related data, and it is widely used within medicine and dentistry. A DICOM file consists of the site of origin, patient identification, the image itself, and image attributes (ex. pixel size), ensuring that patient and picture data cannot be separated. The downside of a DICOM image is that it is big in size, making sending these images over the network slow. Also, patient data embedded in the image limits the possibility of exporting it outside of the clinical network to online services such as the Boneprox website for osteoporosis risk assessment. It is possible to convert DICOM to other image formats, but only under controlled circumstances (such as conversion using ImageJ software as we did with DICOM files for study III and IV) will we know the degree of compression between the formats [Varma 2012, Ujgare\&Baviskar 2013]. Otherwise, as was the case in our study where we received images already converted to the other formats (JPG, TIFF, BMP), we cannot know how much information has been lost in the conversion process[Varma 2012]. Our suggestion would be to incorporate Boneprox in the image processing software at the clinic and use the original format of intraoral radiographs, i.e. the DICOM file, making it possible to introduce the software to a wide database of intraoral radiographs such as the regional 
archive. This would also introduce it to the wide variety of image quality that normally exists in the reality of dental offices.

Also affecting the performance is the limitation of the current state-ofthe-art AI algorithms. If an evaluated algorithm does not perform as well as expected, it might be due to a high bias or variance. In other words, it is either an underfitting or an overfitting problem. Overfitting happens when a machine learning model has become too attuned to the data on which it was trained. Such a model loses its applicability to any other dataset because it is so specific to the original data resulting in less-than-optimal decisions. On the other hand, underfitting happens when a machine learning model is not complex enough to accurately capture relationships between a dataset's features and a target variable. An underfitted model results in problematic or erroneous outcomes on new data and often performs poorly even on training data (Figure 12).

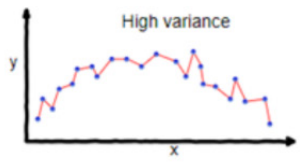

overfitting

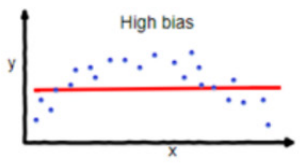

underfitting

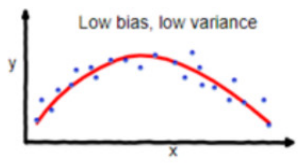

Good balance

Figure 12 Graphical representation of overfitting, underfitting and good balance. 


\section{CONCLUSIONS}

- The present study shows that barriers concerning workflow, education, and the current healthcare system in Sweden must be carefully approached in order to successfully implement osteoporosis risk assessment in primary dental care. In addition, clear guidelines and improved communication channels between stakeholders are needed to guarantee a smooth treatment path for patients. Overall, however, the general attitude of Swedish dental practitioners and patients is a positive one concerning implementing osteoporosis risk assessment in primary dental care using dental radiographs already taken for dental purposes.

- Most postmenopausal women appreciated the concept of osteoporosis risk assessment in a dental setting and are willing to pay for it. Osteoporosis risk assessment in primary dental care could potentially identify individuals at risk early enough to avoid a fracture, which would free resources that are currently designated for treatment and rehabilitation.

- The analysis of trabecular pattern in intraoral radiographs using semiautomated and fully-automated software shows low rater agreement, low diagnostic odds for osteoporosis risk assessment, no predictive value towards fracture risk, and weak correlation to TBS, leading to the conclusion that more work needs to be done to optimize the process. 


\section{FUTURE PERSPECTIVES}

There is still much work to be done within the field of osteoporosis and fracture risk assessment in a dental setting. The research presented in this thesis has shed some light on chosen aspects such as stakeholders' attitudes towards the concept, patients' WTP for the service, and the qualities of commercial software available on the market for that purpose.

To start with, this project was mainly focused on female participants. However, since osteoporosis and fragility fractures are a growing problem among older men, it would be interesting to perform FGD with older men from osteoporosis support groups to hear what they have to say about incorporating osteoporosis risk assessment in primary dental care. It would also be interesting to include them in the WTP study and investigate their WTP for the service.

It is still unknown how the Boneprox software fully-automated tool would perform if retested after a certain amount of time on the same images to investigate agreement. Also, it is not known how the software would perform tested in a large-scale prospective study with image acquisition optimal for the needs of the software. Also, a study with a long follow-up period considering incident fractures would be of great interest for stronger power to assess the predictive value of the software.

Our study evaluating the software investigated the correlation between the semi-automated and fully-automated analysis of trabecular pattern in intraoral radiographs and TBS obtained from DXA images. The correlation was rather weak, but since the power was low, it would be interesting to follow up on our cohort and investigate the correlation when a longer period of time has passed, which would likely mean a higher fracture incidence. Also, it would be interesting to look into the correlation between semi-automated and fully-automated analysis regarding other important 
structural parameters of trabecular bone, such as the number and thickness of trabecula or trabecular spacing and separation.

Even though the automation of the analysis of trabecular pattern in intraoral radiographs is still being developed and improved, the implementation process takes time. Another intriguing but still unknown aspect to look into is if implementing osteoporosis and fracture risk assessment into primary dental care would have a successful outcome considering the execution of the routine and benefit to the society. As suggested in our FGD interviews with all stakeholders, implementing a new method means barriers need to be overcome to succeed. Therefore a largescale clinical trial executing the method in practice, with an established referral system and cooperation routines, with clear guidelines and division of responsibilities, would be of great interest. Such a trial should include assessment of benefits in terms of health and cost of a multidisciplinary collaboration aiming to increase knowledge on health economic aspects of such an extended collaboration between dental and medical fields. 


\section{ACKNOWLEDGEMENTS}

A long journey has come to an end. It was a lifetime supply of experiences, a roller coaster of emotions, but most importantly, it has turned into a huge window of opportunities that I could not have had imagined in the best of my dreams. On this page of my thesis, I would like to honor everyone involved directly and indirectly in helping me pull this off.

To my mentor and main supervisor over the years, professor Christina Lindh - it has been a privilege to be your Ph.D student. Your energy and enthusiasm were so contagious that I could not resist joining this project, and now, after all these years, I am glad I did. Thank you for this opportunity, and thank you for introducing me to the world of research and your broad network of colleagues and fellow researchers. I could not have done it without your guidance and support.

Thank you to Jonas Becktor and Sofia Petrén for taking on the role of the head supervisor in the last stages of the doctoral education program and for providing security and administrative support.

Thank you to docent Lene Povlsen and professor Björn Axtelius for sharing your knowledge on qualitative methods and for the help with our first manuscript.

Thank you to professor Keith Horner and professor Hugh Devlin for taking on this project together. I am very grateful for your support and introduction to your network of colleagues and associates every time we met at international gatherings and congresses.

Thank you to Odont Dr. Helena Christell for introducing me to the subject of health economics and for giving me the opportunity to perform research together. I highly appreciate your feedback on this thesis. Thank you for all your comments and encouragement. It has been a pleasure to work with you, Helena, and I hope we can get more done together in the future. 
Special thank you to Odont Dr. Anna Senneby for your support from the very beginning of my journey at the Faculty of Odontology in Malmö. I do not know what I would do without your guidance both in my first steps as a tutor for the students and as a Ph.D. student. Thank you for always being there, for all your advice, and for the invaluable feedback on this thesis.

Thank you to Odont Dr Ayman Al-Okshi for your assistance in sorting out thousands of thousands of radiographs under extreme time pressure and for your creativity in presenting the data for the third manuscript. I really enjoyed working together so thank you for your time and all the positive energy.

Thank you to Dalia Homar and Anita Zainea, my colleagues and coauthors on the rater study. When we first met, you were still students, and I could see you grow both as dental professionals and as researchers. Your curiosity and thirst for knowledge was really encouraging and I am very grateful our paths have crossed. I am looking forward to seeing who you become and in which direction your own carrier will guide you.

Special thank you to professor Mattias Lorentzon, Clinical Osteoporosis Research School (CORS), and the whole research team from Gothenburg University for including our team in the SUPERB study and allowing us to look at the data from the 'dental' point of view. I feel very grateful for being part of your project, so thank you for this opportunity.

Thank you to all the colleagues and friends from the Faculty of Odontology at Malmö University. It was a pleasure to work with all of you.

I want to thank everyone involved in the National Clinical Research School of Odontology. Thank you to the mentors and coordinators professor Björn Klinge, Alfheidur Astvaldsdottir, Bengt Sjödin and Karin Sunnegårdh-Grönberg. It was thanks to the spot at the research school that it all started. I applied, and (to my surprise) I got in! Thank you to all the participants who became my dear friends and whom I can also proudly call my own personal network of researchers! It was an honor to serve with you guys!

Thank you to my dearest family, who cheered on me through the whole process, and who celebrated the good days, and supported me when it was tough. Special thank you to my beloved Michael. You have been my rock. Not only did you stand by my side, but you provided us with technical support throughout the project, especially in the third and fourth manuscript and this thesis. It would not be possible without you! Thank you to my parents, who have always believed in me and supported me in all the 
choices - from Poland, through Italy to Sweden, from medical to dental school, and through the Ph.D. program. I love you both with all my heart.

A special thank you to a dear family friend Mathias Haage, whose invaluable knowledge on the fascinating topic of AI kept me sane while writing this part of the thesis. Thank you for your guidance and feedback.

This thesis was supported by The Swedish Dental Association, The C-O Henriksson Foundation, Ingvar Kamprad Foundation and the Faculty of Odontology at Malmö University. 


\section{REFERENCES}

Albert D. A., Severson H., Gordon J., Ward A., Andrews J. and Sadowsky D. (2005). "Tobacco attitudes, practices, and behaviors: a survey of dentists participating in managed care." Nicotine Tob Res. 7: S9-18.

Albright F., Smith P. H. and Richardson A. M. (1941). "Postmenopausal Osteoporosis: its clinical features." J Am Med Assoc. 116: 2465-74.

Areeckal A. S., Jayasheelan N., Kamath J., Zawadynski S., Kocher M. and David S S. (2018). "Early diagnosis of osteoporosis using radiogrammetry and texture analysis from hand and wrist radiographs in Indian population." Osteoporos Int. 29: $665-73$.

Aven T. (2010). "On how to define, understand and describe risk." Reliab Eng Syst. 95: 623-31.

Aven T. (2011). "On the new ISO guide on risk management terminology." Reliab Eng Syst. 96: 719-26.

Aven T. and Zio E. (2011). "Some considerations on the treatment of uncertainties in risk assessment for practical decision making.” Reliab Eng Syst. 96: 64-74.

Aven T. (2012). "Foundational Issues in Risk Assessment and Risk Management." Risk Anal. 32: 1647-56.

Barasch A., Safford M. M., Qvist V., Palmore R., Gesko D. and Gilbert G. H. (2012). "Random blood glucose testing in dental practice: A community-based feasibility study from The Dental Practice-Based Research Network " J Am Dent Assoc. 143: 262-69.

Bergman H. and Källmén H. (2002). "Alcohol use among Swedes and psychometric evaluation of the alcohol use disorders identification test." Alcohol Alcohol. 37: 245-51.

Bonjour J. P., Theintz G., Law F., Slosman D. and Rizzoli R. (1994). "Peak bone mass." Osteoporos Int. 4: S7-S13.

Borgström F., Karlsson L., Ortsäter G., Norton N., Halbout P., Cooper C., et al. Kanis J. A. for the International Osteoporosis Foundation (2020). "Fragility fractures in Europe: burden, management and opportunities." Arch Osteoporos. 15: 59. 
Bossuyt P. M., Reitsma J. B., Bruns D. E., Gatsonis C. A., Glasziou P. P., Irwig L. M., et al. de Vet H. C. (2003). "Towards complete and accurate reporting of studies of diagnostic accuracy: the STARD initiative. The Standards for Reporting of Diagnostic Accuracy Group." Croat Med J. 44: 635-8.

Bossuyt P. M., Reitsma J. B., Bruns D. E., Gatsonis C. A., Glasziou P. P., Irwig L., et al. Cohen J. F. (2015). "STARD 2015: an updated list of essential items for reporting diagnostic accuracy studies." Br Med J. 351: h5527.

Bousson V., Bergot C., Sutter B., Levitz P., Cortet B. and the Scientific Committee of the GRIO (Groupe de Recherche et d'Information sur les Ostéoporoses) (2012). "Trabecular bone score (TBS): available knowledge, clinical relevance, and future prospects." Osteoporos Int. 23: 1489-501.

Bousson V., Bergot C., Sutter B., Thomas T., Bendavid S., Benhamou C. L., et al. Cortet B. (2015). “Trabecular Bone Score: Where are we now?” Joint Bone Spine. 82: $320-25$.

Capulli M., Paone R. and Rucci N. (2014). "Osteoblast and osteocyte: Games without frontiers." Arch Biochem Biophys. 561: 3-12.

Chien P. F. W. and Khan K. S. (2001). "Evaluation of a clinical test. II: Assessment of validity." BJOG. 108: 568-72.

Clarke B. (2008). "Normal Bone Anatomy and Physiology." Clin J Am Soc Nephrol. 3: S131-S39.

Cochrane L. J., Olson C. A., Murray S., Dupuis M., Tooman T. and Hayes S. (2007). "Gaps between knowing and doing: Understanding and assessing the barriers to optimal health care." J Contin Educ Health Prof. 27: 94-102.

Creanor S., Millward B. A., Demaine A., Price L., Smith W., Brown N. and Creanor S. L. (2014). "Patients' attitudes towards screening for diabetes and other medical conditions in the dental setting." Br Dent J. 216: E2.

Currey J. D. (2006). Bones: structure and mechanics. Princeton University Press.

Curtis E. M., Moon R. J., Harvey N. C. and Cooper C. (2017). "Reprint of: The impact of fragility fracture and approaches to osteoporosis risk assessment worldwide." Int J Orthop Trauma Nurs. 26: 7-17.

Damschroder L. J., Aron D. C., Keith R. E., Kirsh S. R., Alexander J. A. and Lowery J. C. (2009). "Fostering implementation of health services research findings into practice: a consolidated framework for advancing implementation science." Implement Sci. 4: 50.

Deeks J. J. (2001). "Systematic reviews in health care: Systematic reviews of evaluations of diagnostic and screening tests." $\mathrm{Br}$ Med J. 323: 157-62.

Devlin H., Allen P. D., Graham J., Jacobs R., Karayianni K., Lindh C., et al. Horner K. (2007). "Automated osteoporosis risk assessment by dentists: a new pathway to diagnosis." Bone. 40: 835-42. 
Devlin H., Allen P., Graham J., Jacobs R., Nicopoulou-Karayianni K., Lindh C., et al. Horner K. (2008). "The role of the dental surgeon in detecting osteoporosis: the OSTEODENT study.” Br Dent J. 204: E16-discussion 560-1.

Drummond M. F., Sculpher M. J., Claxton K., Stoddart G. L. and Torrance G. W. (2015). Methods for the economic evaluation of health care programmes. Oxford. Oxford University Press.

Dyer T. A. and Robinson P. G. (2006). "General health promotion in general dental practice--the involvement of the dental team Part 2: A qualitative and quantitative investigation of the views of practice principals in South Yorkshire." $\mathrm{Br}$ Dent $J$. 201: 45-51; discussion 31 .

Elleby C., Skott P., Jonasson G., Theobald H., Nyrén S. and Salminen H. (2021). "Two methods of evaluating mandibular trabecular pattern in intraoral radiographs and the association to fragility fractures during a 47-year follow up." Eur J Oral Sci. n/a: e12801.

Ferrante di Ruffano L., Hyde C. J., McCaffery K. J., Bossuyt P. M. M. and Deeks J. J. (2012). "Assessing the value of diagnostic tests: a framework for designing and evaluating trials." BMJ. 344: e686.

Flottorp S. A., Oxman A. D., Krause J., Musila N. R., Wensing M., Godycki-Cwirko M., et al. Eccles M. P. (2013). "A checklist for identifying determinants of practice: A systematic review and synthesis of frameworks and taxonomies of factors that prevent or enable improvements in healthcare professional practice." Implement Sci. 8: 35 .

Franz-Odendaal T. A., Hall B. K. and Witten P. E. (2006). "Buried alive: How osteoblasts become osteocytes." Dev Dyn. 235: 176-90.

FRAX. (2019). "Calculation tool." from https://www.sheffield.ac.uk/FRAX/tool. asp $x$ ? country $=5$.

Fryback D. G. and Thornbury J. R. (1991). "The Efficacy of Diagnostic Imaging." Med Decis Making. 11: 88-94.

Gao L., Jiao T., Feng Q. and Wang W. (2021). “Application of artificial intelligence in diagnosis of osteoporosis using medical images: a systematic review and metaanalysis." Osteoporos Int. 32: 1279-86.

Geraets W. G., Van der Stelt P. F., Netelenbos C. J. and Elders P. J. (1990). "A new method for automatic recognition of the radiographic trabecular pattern." $J$ Bone Miner Res. 5: 227-33.

Geraets W. G., Van der Stelt P. F. and Elders P. J. (1993). "The radiographic trabecular bone pattern during menopause." Bone. 14: 859-64.

Geraets W. G., Van der Stelt P. F., Lips P. and Van Ginkel F. C. (1998). "The radiographic trabecular pattern of hips in patients with hip fractures and in elderly control subjects." Bone. 22: 165-73.

Geraets W. G., Verheij J. G. C., van der Stelt P. F., Horner K., Lindh C., NicopoulouKarayianni K., et al. Devlin H. (2007). "Prediction of bone mineral density with dental radiographs." Bone. 40: 1217-21. 
Geraets W. G., Verheij J. G., van der Stelt P. F., Horner K., Lindh C., NicopoulouKarayianni K., et al. Devlin H. (2008). "Selecting regions of interest on intraoral radiographs for the prediction of bone mineral density." Dentomaxillofac Radiol. 37: 375-79.

Geraets W. G., Lindh C. and Verheij H. (2012). "Sparseness of the trabecular pattern on dental radiographs: visual assessment compared with semi-automated measurements." Br J Radiol. 85: e455-60.

Geraets W. G., Jonasson G. and Hakeberg M. (2018). "Predicting fractures using trabecular patterns on panoramic radiographs." Clin Oral Investig. 22: 377-84.

Glaser B. G. and Strauss A. L. (1967). The discovery of grounded theory: strategies for qualitative research. New York, NY. Routledge.

Glob G. N. (2014). History and demography. Aging Bones: short history of osteoporosis. Baltimore, Maryland, USA, JHU Press: 1-24.

Graneheim U. H. and Lundman B. (2004). "Qualitative content analysis in nursing research: concepts, procedures and measures to achieve trustworthiness." Nurse Educ Today. 24: 105-12.

Greenberg B. L., Glick M., Frantsve-Hawley J. and Kantor M. L. (2010). "Dentists' attitudes toward chairside screening for medical conditions." J Am Dent Assoc. 141: 52-62.

Greenberg B. L. and Glick M. (2012). "Assessing Systemic Disease Risk in a Dental Setting: A Public Health Perspective." Dent Clin North Am. 56: 863-74.

Greenberg B. L., Kantor M. L., Jiang S. S. and Glick M. (2012). "Patients' attitudes toward screening for medical conditions in a dental setting." J Public Health Dent. 72: 28-35.

Grimes D. A. and Schulz K. F. (2005). "Refining clinical diagnosis with likelihood ratios." The Lancet. 365: 1500-05.

Groen J. J., Duyvensz F. and Halsted J. A. (1960). "Diffuse alveolar atrophy of the jaw (non-inflammatory form of paradental disease) and pre-senile osteoporosis." Gerontol Clin (Basel). 2: 68-86.

Grol R. and Wensing M. (2004). "What drives change? Barriers to and incentives for achieving evidence-based practice." Med J Aust. 180: S57-S60.

Grol R., Wensing M., Eccles M. and Davis D. (2013). Theories on implementation of change in healthcare. Improving Patient Care: The Implementation of Change in Health Care. Hoboken, United Kingdom, John Wiley \& Sons, Inc.: 18-40.

Grönbeck Lindén I., Hägglin C., Gahnberg L. and Andersson P. (2017). "Factors Affecting Older Persons' Ability to Manage Oral Hygiene: A Qualitative Study.” JDR Clin Trans Res. 2: 223-32.

Hanna T. N., Lamoureux C., Krupinski E. A., Weber S. and Johnson J.-O. (2018). "Effect of Shift, Schedule, and Volume on Interpretive Accuracy: A Retrospective Analysis of 2.9 Million Radiologic Examinations.” Radiology. 287: 205-12. 
Hart D., Wall B. F., Hillier M. C. and Shrimpton P. (2010). Frequency and collective dose of medical and dental X-ray examinations in the UK, 2008. Chilton, P. H. England.(https://www.gov.uk/government/publications/medical-and-dental-xrays-frequency-and-collective-doses-in-the-uk, Last accessed [21 June 2021]).

Hassani-Nejad A., Ahlqwist M., Hakeberg M. and Jonasson G. (2013). "Mandibular trabecular bone as fracture indicator in 80-year-old men and women." Eur J Oral Sci. 121: 525-31.

Hellén-Halme K., Johansson P. M., Håkansson J. and Petersson A. (2004). "Image quality of digital and film radiographs in applications sent to the Dental Insurance Office in Sweden for treatment approval." Swed Dent J. 28: 77-84.

Hellén-Halme K., Rohlin M. and Petersson A. (2005). "Dental digital radiography: a survey of quality aspects.” Swed Dent J. 29: 81-7.

Hellén-Halme K., Nilsson M. and Petersson A. (2007). "Digital radiography in general dental practice: a field study." Dentomaxillofac Radiol. 36: 249-55.

Hernlund E., Svedbom A., Ivergard M., Compston J., Cooper C., Stenmark J., et al. Kanis J. A. (2013). "Osteoporosis in the European Union: medical management, epidemiology and economic burden. A report prepared in collaboration with the International Osteoporosis Foundation (IOF) and the European Federation of Pharmaceutical Industry Associations (EFPIA).” Arch Osteoporos. 8: 136.

Horner K. and Devlin H. (1992). "Clinical bone densitometric study of mandibular atrophy using dental panoramic tomography." J Dent. 20: 33-37.

Horner K., Devlin H., Alsop C. W., Hodgkinson I. M. and Adams J. E. (1996). "Mandibular bone mineral density as a predictor of skeletal osteoporosis." $\mathrm{Br} \mathrm{J}$ Radiol. 69: 1019-25.

Horner K., Allen P., Graham J., Jacobs R., Boonen S., Pavitt S., et al. Devlin H. (2010). "The relationship between the OSTEODENT index and hip fracture risk assessment using FRAX." Oral Surg Oral Med Oral Pathol Oral Radiol Endod. 110: $243-49$.

Hsieh H. F. and Shannon S. E. (2005). "Three approaches to qualitative content analysis." Qual Health Res. 15: 1277-88.

Hubar J. S. (2017). Intraoral Technique Errors. Fundamentals of Oral and Maxillofacial Radiology, Wiley-Blackwell: 61-67.

Hugoson A., Koch G., Göthberg C., Helkimo A. N., Lundin S. A., Norderyd O., et al. Sondell K. (2005). "Oral health of individuals aged 3-80 years in Jönköping, Sweden during 30 years (1973-2003). I. Review of findings on dental care habits and knowledge of oral health." Swed Dent J. 29: 125-38.

ICRP (1973). Implications of Commission Recommendations that Doses be kept as Low as Readily Achievable. ICRP Publication 22. P. Press. Oxford.(https:// journals.sagepub.com/doi/pdf/10.1016/S0074-27407380004-2, Last accessed [21 june 2021]). 
International Osteoporosis Foundation (2021). “About osteoporosis.” Retrieved [21 april 2021], from https://www.osteoporosis.foundation/patients/aboutosteoporosis.

Johanen A., Jonasson G., Lund H., Bernhardsson S., Hagman J., Hange D., et al. Hakeberg M. (2021). "Trabecular bone patterns as a fracture risk predictor: a systematic review." Acta Odontol Scand: 1-10.

Johnell O. and Kanis J. (2005). "Epidemiology of osteoporotic fractures." Osteoporos Int. 16 Suppl 2: S3-7.

Jonasson G., Bankvall G. and Kiliaridis S. (2001). "Estimation of skeletal bone mineral density by means of the trabecular pattern of the alveolar bone, its interdental thickness, and the bone mass of the mandible." Oral Surg Oral Med Oral Pathol Oral Radiol Endod. 92: 346-52.

Jonasson G., Jonasson L. and Kiliaridis S. (2007). "Skeletal bone mineral density in relation to thickness, bone mass, and structure of the mandibular alveolar process in dentate men and women." Eur J Oral Sci. 115: 117-23.

Jonasson G. (2009). "Bone mass and trabecular pattern in the mandible as an indicator of skeletal osteopenia: a 10-year follow-up study." Oral Surg Oral Med Oral Pathol Oral Radiol Endod. 108: 284-91.

Jonasson G., Alstad T., Vahedi F., Bosaeus I., Lissner L. and Hakeberg M. (2009). "Trabecular pattern in the mandible as bone fracture predictor." Oral Surg Oral Med Oral Pathol Oral Radiol Endod. 108: e42-51.

Jonasson G., Sundh V., Ahlqwist M., Hakeberg M., Bjorkelund C. and Lissner L. (2011). "A prospective study of mandibular trabecular bone to predict fracture incidence in women: a low-cost screening tool in the dental clinic." Bone. 49: 873-79.

Jonasson G. and Billhult A. (2013). "Mandibular bone structure, bone mineral density, and clinical variables as fracture predictors: a 15-year follow-up of female patients in a dental clinic." Oral Surg Oral Med Oral Pathol Oral Radiol. 116: 362-68.

Jonasson G., Sundh V., Hakeberg M., Hassani-Nejad A., Lissner L. and Ahlqwist M. (2013). "Mandibular bone changes in 24 years and skeletal fracture prediction." Clin Oral Investig. 17: 565-72.

Jonasson G., Lindberg F., Jorge A., Alstad T. and Kashani H. (2014). "Mandibular trabecular bone structure in adults with Crohn's disease." Clin Oral Investig. 18: 423-28.

Jonasson G. and Rythén M. (2016). “Alveolar bone loss in osteoporosis: A loaded and cellular affair?” Clin Cosmet Investig Dent. 8: 95-103.

Kanis J. A. (2002). "Diagnosis of osteoporosis and assessment of fracture risk." The Lancet. 359: 1929-36.

Kanis J. A., Oden A., Johnell O., Johansson H., De Laet C., Brown J., et al. Yoshimura N. (2007). "The use of clinical risk factors enhances the performance of BMD in the prediction of hip and osteoporotic fractures in men and women." Osteoporos Int. 18: 1033-46. 
Kanis J. A., Johnell O., Oden A., Johansson H. and McCloskey E. (2008). "FRAX and the assessment of fracture probability in men and women from the UK." Osteoporos Int. 19: 385-97.

Kanis J. A., McCloskey E. V., Johansson H., Oden A., Melton L. J. and Khaltaev N. (2008). "A reference standard for the description of osteoporosis." Bone. 42: 467-75.

Kanis J. A., Oden A., Johansson H., Borgström F., Ström O. and McCloskey E. (2009). "FRAX® and its applications to clinical practice." Bone. 44: 734-43.

Karayianni K., Horner K., Mitsea A., Berkas L., Mastoris M., Jacobs R., et al. Devlin H. (2007). "Accuracy in osteoporosis diagnosis of a combination of mandibular cortical width measurement on dental panoramic radiographs and a clinical risk index (OSIRIS): the OSTEODENT project." Bone. 40: 223-29.

Khan M. E. and Manderson L. (1992). "Focus groups in tropical diseases research." Health Policy Plan. 7: 56-66.

Khanagar S. B., Al-ehaideb A., Maganur P. C., Vishwanathaiah S., Patil S., Baeshen H. A., et al. Bhandi S. (2021). "Developments, application, and performance of artificial intelligence in dentistry - A systematic review." J Dent Sci. 16: 508-22.

Kitzinger J. (1994). "The methodology of Focus Groups: the importance of interaction between research participants.” Sociol Health Illn. 16: 103-21.

Kottner J., Gajewski B. J. and Streiner D. L. (2011). "Guidelines for Reporting Reliability and Agreement Studies (GRRAS).” Int J Nurs Stud. 48: 659-60.

Kribbs P. J., Chesnut C. H., 3rd, Ott S. M. and Kilcoyne R. F. (1989). "Relationships between mandibular and skeletal bone in an osteoporotic population." J Prosthet Dent. 62: 703-07.

Kribbs P. J. (1990). "Comparison of mandibular bone in normal and osteoporotic women." J Prosthet Dent. 63: 218-22.

Krueger D., Fidler E., Libber J., Aubry-Rozier B., Hans D. and Binkley N. (2014). "Spine trabecular bone score subsequent to bone mineral density improves fracture discrimination in women." J Clin Densitom. 17: 60-65.

Landis J. R. and Koch G. G. (1977). "The measurement of observer agreement for categorical data." Biometrics. 33: 159-74.

Larsson B., Mellstrom D., Johansson L., Nilsson A. G., Lorentzon M. and Sundh D. (2018). "Normal Bone Microstructure and Density But Worse Physical Function in Older Women Treated with Selective Serotonin Reuptake Inhibitors, a CrossSectional Population-Based Study." Calcif Tissue Int. 103: 278-88.

Lee J.-S., Adhikari S., Liu L., Jeong H.-G., Kim H. and Yoon S.-J. (2019). "Osteoporosis detection in panoramic radiographs using a deep convolutional neural network-based computer-assisted diagnosis system: a preliminary study." Dentomaxillofac Radiol. 48: 20170344. 
Lee K.-S., Jung S.-K., Ryu J.-J., Shin S.-W. and Choi J. (2020). "Evaluation of Transfer Learning with Deep Convolutional Neural Networks for Screening Osteoporosis in Dental Panoramic Radiographs." J Clin Med. 9: 392.

Leeflang M. M. G. (2014). "Systematic reviews and meta-analyses of diagnostic test accuracy." Clin Microbiol Infect. 20: 105-13.

Leeflang M. M. G. and Allerberger F. (2019). "How to: evaluate a diagnostic test." Clin Microbiol Infect. 25: 54-59.

Leslie W. D., Johansson H., Kanis J. A., Lamy O., Oden A., McCloskey E. V. and Hans D. (2014). "Lumbar spine texture enhances 10-year fracture probability assessment." Osteoporos Int. 25: 2271-77.

Lin P.-J., Cangelosi M. J., Lee D. W. and Neumann P. J. (2013). "Willingness to Pay for Diagnostic Technologies: A Review of the Contingent Valuation Literature." Value Health. 16: 797-805.

Lindh C., Petersson A. and Rohlin M. (1996). “Assessment of the trabecular pattern before endosseous implant treatment: diagnostic outcome of periapical radiography in the mandible." Oral Surg Oral Med Oral Pathol Oral Radiol Endod. 82: 335-43.

Lindh C., Obrant K. and Petersson A. (2004). "Maxillary bone mineral density and its relationship to the bone mineral density of the lumbar spine and hip." Oral Surg Oral Med Oral Pathol Oral Radiol Endod. 98: 102-09.

Lindh C., Horner K., Jonasson G., Olsson P., Rohlin M., Jacobs R., et al. Devlin H. (2008). "The use of visual assessment of dental radiographs for identifying women at risk of having osteoporosis: the OSTEODENT project." Oral Surg Oral Med Oral Pathol Oral Radiol Endod. 106: 285-93.

Lorentzon M., Mellström D. and Ohlsson C. (2005). "Age of Attainment of Peak Bone Mass Is Site Specific in Swedish Men-The GOOD Study." J Bone Miner Res. 20: 1223-27.

Lorentzon M., Nilsson A. G., Johansson H., Kanis J. A., Mellstrom D. and Sundh D. (2019). "Extensive undertreatment of osteoporosis in older Swedish women." Osteoporos Int. 30: 1297-305.

Macfarlane A. (2005). What are the main factors that influence the implementation of disease prevention and health promotion programmes in children and adolescents? Copenhagen, WHO.(Health Evidence Network Report; http://www.euro.who.int/ Document/E86766.pdf, Last accessed [22 june 2021]).

Manolagas S. C. and Jilka R. L. (1995). "Bone Marrow, Cytokines, and Bone Remodeling - Emerging Insights into the Pathophysiology of Osteoporosis." $N$ Engl J Med. 332: 305-11.

Marshall D., Johnell O. and Wedel H. (1996). "Meta-analysis of how well measures of bone mineral density predict occurrence of osteoporotic fractures." BMJ. 312: 1254-59.

McMaster. (2021). "Textbook of Internal Medicine." Retrieved [22 April 2021], from https://empendium.com/mcmtextbook/image/B31.031_4288. 
MedCalc. (2021). "Diagnostic test evaluation calculator." from https://www.medcalc. org/calc/diagnostic_test.php.

Merlijn T., Swart K. M. A., van der Horst H. E., Netelenbos J. C. and Elders P. J. M. (2020). "Fracture prevention by screening for high fracture risk: a systematic review and meta-analysis." Osteoporos Int. 31: 251-57.

Mintz Y. and Brodie R. (2019). "Introduction to artificial intelligence in medicine." Minim Invasive Ther Allied Technol. 28: 73-81.

Mosekilde L. (1989). Knoglevaevets biologi. Fysiologiske, kliniske og farmakologiske aspekter af relationerne mellem struktur og funktion. Denmark. Nivås Grafiske Vaerksted.

Murray C. J., Barber R. M., Foreman K. J., Abbasoglu Ozgoren A., Abd-Allah F., Abera S. F., et al. Vos T. (2015). "Global, regional, and national disability-adjusted life years (DALYs) for 306 diseases and injuries and healthy life expectancy (HALE) for 188 countries, 1990-2013: quantifying the epidemiological transition." Lancet. 386: 2145-91.

NIH Consensus Development Panel on Osteoporosis Prevention, Diagnosis and Therapy (2001). "Osteoporosis prevention, diagnosis, and therapy." JAMA. 285: 785-95.

Nilsen P. (2010). Implementering: teori och tillämpning inom hälso- och sjukvård. Lund. Studentlitteratur.

Nilsson M., Sundh D., Mellstrom D. and Lorentzon M. (2017). "Current Physical Activity Is Independently Associated With Cortical Bone Size and Bone Strength in Elderly Swedish Women." J Bone Miner Res. 32: 473-85.

Norderyd O., Kochi G., Papias A., Kohler A. A., Helkimo A. N., Brahm C. O., et al. Frisk F. (2015). "Oral health of individuals aged 3-80 years in Jonkoping, Sweden, during 40 years (1973-2013). I. Review of findings on oral care habits and knowledge of oral health." Swed Dent J. 39: 57-68.

Pachêco-Pereira C., Almeida F. T., Chavda S., Major P. W., Leite A. and Guerra E. N. S. (2019). "Dental imaging of trabecular bone structure for systemic disorder screening: A systematic review." Oral Dis. 25: 1009-26.

Pan Y., Shi D., Wang H., Chen T., Cui D., Cheng X. and Lu Y. (2020). “Automatic opportunistic osteoporosis screening using low-dose chest computed tomography scans obtained for lung cancer screening." Eur Radiol. 30: 4107-16.

Pasco J. A., Seeman E., Henry M. J., Merriman E. N., Nicholson G. C. and Kotowicz M. A. (2006). "The population burden of fractures originates in women with osteopenia, not osteoporosis." Osteoporos Int. 17: 1404-09.

Pham D., Jonasson G. and Kiliaridis S. (2010). "Assessment of trabecular pattern on periapical and panoramic radiographs: a pilot study." Acta Odontol Scand. 68: 91-97.

Pothuaud L., Carceller P. and Hans D. (2008). "Correlations between grey-level variations in 2D projection images (TBS) and 3D microarchitecture: Applications in the study of human trabecular bone microarchitecture." Bone. 42: 775-87. 
Rabier B., Héraud A., Grand-Lenoir C., Winzenrieth R. and Hans D. (2010). “A multicentre, retrospective case-control study assessing the role of trabecular bone score (TBS) in menopausal Caucasian women with low areal bone mineral density (BMDa): Analysing the odds of vertebral fracture.” Bone. 46: 176-81.

Rajaraman V. (2014). "JohnMcCarthy — Father of artificial intelligence.” Resonance. 19: 198-207.

Rajpurkar P., Irvin J., Zhu K., Yang B., Mehta H., Duan T., et al. Ng A. Y. (2017). CheXNet: Radiologist-Level Pneumonia Detection on Chest X-Rays with Deep Learning. arXiv. EBSCOhost. (https://proxy.mau.se/login?url=https://search. ebscohost.com/login.aspx?direct=true \&db=edsarx\&AN=edsarx.1711.05225\&lan $\mathrm{g}=$ sv\&site=eds-live \&scope $=$ site)

Riggs B. L., Wahner H. W., Seeman E., Offord K. P., Dunn W. L., Mazess R. B., et al. Melton L. J., III (1982). "Changes in Bone Mineral Density of the Proximal Femur and Spine with Aging: Differences between the postmenopausal and senile osteoporosis syndromes." J Clin Invest. 70: 716-23.

Robert M., David W. D., Jane A. C. and David F. (2013). Osteoporosis. Osteoporosis. Amsterdam, Academic Press: 1017-35.

Rohlin M., Horner K., Lindh C. and Wenzel A. (2020). "Through the quality kaleidoscope: reflections on research in dentomaxillofacial imaging." Dentomaxillofac Radiol. 49: 20190484.

Sambrook P. and Cooper C. (2006). "Osteoporosis." Lancet. 367: 2010-18.

SBU (2003). Osteoporosis - prevention, diagnosis and treatment. Stockholm. Swedish Council on Health Technology Assessment in Health Care.

Shepstone L., Lenaghan E., Cooper C., Clarke S., Fong-Soe-Khioe R., Fordham R., et al. Mitchell N. (2018). "Screening in the community to reduce fractures in older women (SCOOP): a randomised controlled trial." Lancet. 391: 741-47.

Shepstone L. and McCloskey E. (2018). "A closer look at SCOOP: screening for fracture prevention - Authors' reply." Lancet. 392: 552-53.

Sklan J. E., Plassard A., Fabbri D. and Landman B. (2015). Toward content-based image retrieval with deep convolutional neural networks. SPIE.

Socialstyrelsen (2012). Nationella riktlinjer för rörelseorganens sjukdomar. Osteoporos, artros, inflammatorisk ryggsjukdom och ankyloserande spondylit, psoriasisartrit och reumatoid artrit. Stöd för styrning och ledning.(https://www. socialstyrelsen.se/globalassets/sharepoint-dokument/artikelkatalog/nationellariktlinjer/2012-5-1.pdf, Last accessed [21 august 2021]).

Standring S. e., Borley N. R. e. and Gray H. (2008). Gray's anatomy : the anatomical basis of clinical practice. Churchill Livingstone.

Stangroom J. (2018). "Social Science Statistics." Retrieved [26 May 2021], from https://www.socscistatistics.com/tests/chisquare/default2.aspx.

Stern R. H. (2012). “Individual risk.” J Clin Hypertens (Greenwich). 14: 261-4. 
Sundh V., Hange D., Ahlqwist M., Hakeberg M., Lissner L. and Jonasson G. (2017). "FRAX and mandibular sparse trabeculation as fracture predictors: a longitudinal study from 1980 to 2002." Eur J Oral Sci. 125: 135-40.

Svenson B., Eriksson T., Kronström M. and Palmqvist S. (1995). "Quality of intraoral radiographs used for prosthodontic treatment planning by general dentists in the public dental health service." Swed Dent J. 19: 47-54.

Svenson B., Ståhlnacke K., Karlsson R. and Fält A. (2018). “Dentists' use of digital radiographic techniques: Part I - intraoral X-ray: a questionnaire study of Swedish dentists." Acta Odontol Scand. 76: 111-18.

Taguchi A., Tanimoto K., Suei Y., Ohama K. and Wada T. (1996). "Relationship between the mandibular and lumbar vertebral bone mineral density at different postmenopausal stages." Dentomaxillofac Radiol. 25: 130-35.

Tausch A. P. and Menold N. (2016). "Methodological Aspects of Focus Groups in Health Research:Results of Qualitative Interviews With Focus Group Moderators." Glob Qual Nurs Res. 3: 2333393616630466.

Turner D. A., Khioe R. F. S., Shepstone L., Lenaghan E., Cooper C., Gittoes N., et al. Team t. S. S. (2018). "The Cost-Effectiveness of Screening in the Community to Reduce Osteoporotic Fractures in Older Women in the UK: Economic Evaluation of the SCOOP Study." J Bone Miner Res. 33: 845-51.

Tversky A. and Kahneman D. (1974). "Judgment under Uncertainty: Heuristics and Biases." Science. 185: 1124-31.

Ujgare N. S. and Baviskar S. P. (2013). "Conversion of DICOM Image in to JPEG, BMP and PNG Image Format.” Int J Comput Appl. 62: 22.

Varma D. R. (2012). "Managing DICOM images: Tips and tricks for the radiologist." Indian J Radiol Imaging. 22: 4-13.

Vartiainen E., Seppälä T., Lillsunde P. and Puska P. (2002). "Validation of self reported smoking by serum cotinine measurement in a community-based study." $J$ Epidemiol Community Health. 56: 167-70.

Verheij J. G., Geraets W. G., van der Stelt P. F., Horner K., Lindh C., NicopoulouKarayianni K., et al. Devlin H. (2009). "Prediction of osteoporosis with dental radiographs and age." Dentomaxillofac Radiol. 38: 431-37.

von Wowern N. and Stoltze K. (1978). "Histoquantitation on small jaw specimens." Scand J Dent Res. 86: 193-99.

Västra Götalands Regionen. (2021, 2021-06-15). “Osteoporosvård.” Retrieved [23 july 2021].

Waite S., Scott J., Gale B., Fuchs T., Kolla S. and Reede D. (2017). "Interpretive Error in Radiology." Am J Roentgenol Radium Ther. 208: 739-49.

Walter S. D., Macaskill P., Lord S. J. and Irwig L. (2012). "Effect of dependent errors in the assessment of diagnostic or screening test accuracy when the reference standard is imperfect." Stat Med. 31: 1129-38. 
Webster M. “Definition: ‘Artificial Intelligence'.” Retrieved [27 May 2021], from https://www.merriam-webster.com/dictionary/artificial\%20intelligence.

Wenzel A. and Hintze H. (1999). "The choice of gold standard for evaluating tests for caries diagnosis.” Dentomaxillofac Radiol. 28: 132-36.

White S. C. and Rudolph D. J. (1999). "Alterations of the trabecular pattern of the jaws in patients with osteoporosis." Oral Surg Oral Med Oral Pathol Oral Radiol Endod. 88: 628-35.

White S. C., Cohen J. M. and Mourshed F. A. (2000). "Digital analysis of trabecular pattern in jaws of patients with sickle cell anemia." Dentomaxillofac Radiol. 29: $119-24$.

White S. C. (2002). "Oral radiographic predictors of osteoporosis." Dentomaxillofac Radiol. 31: 84-92.

White S. C., Atchison K. A., Gornbein J. A., Nattiv A., Paganini-Hill A., Service S. K. and Yoon D. C. (2005). "Change in mandibular trabecular pattern and hip fracture rate in elderly women." Dentomaxillofac Radiol. 34: 168-74.

WHO (1984). Health Promotion: A Discussion Document on the Concept and Principles. Copenhagen, WHO, Last accessed [21 june 2021]).

WHO (1994). "Assessment of fracture risk and its application to screening for postmenopausal osteoporosis. Report of a WHO Study Group." World Health Organ Tech Rep Ser. 843: 1-129.

Williams H. (2019, 23 June 2019). "What is artificial intelligence all about anyway?" Toward data science. Retrieved [19 June 2021], from https://towardsdatascience. com/what-is-artificial-intelligence-all-about-anyway-b57c7eb75f5f.

Wårdh I., Axelsson S. and Tegelberg Å. (2009). "Which Evidence has an Impact on Dentists' Willingness to Change Their Behavior?" J Evid Based Dent Pract. 9: 197-205.

Zebaze R. M. D., Ghasem-Zadeh A., Bohte A., Iuliano-Burns S., Mirams M., Price R. I., et al. Seeman E. (2010). "Intracortical remodelling and porosity in the distal radius and post-mortem femurs of women: a cross-sectional study." Lancet. 375: 1729-36. 
I 



\title{
Osteoporosis risk assessment in primary dental care-The attitudes of Swedish dentists, patients and medical specialists
}

\author{
Joanna Gullberg ${ }^{1}$ (D) | Christina Lindh ${ }^{1}$ | Björn Axtelius ${ }^{1}$ | Keith Horner ${ }^{2}$ | \\ Hugh Devlin ${ }^{2}$ | Lene Povlsen ${ }^{3}$
}

${ }^{1}$ Faculty of Odontology, Malmö University, Malmö, Sweden

${ }^{2}$ Division of Dentistry, School of Medical Sciences, University of Manchester, Manchester, UK

${ }^{3}$ Unit for Health Promotion Research, University of Southern Denmark, Esbjerg, Denmark

\section{Correspondence}

Joanna Gullberg, Faculty of Odontology, Malmö University, Malmö, Sweden. Email: joanna.gullberg@mau.se

Funding information CO Henrikson Stiftelse

\begin{abstract}
Objective: To explore and identify the attitudes of dentists, patients and medical specialists regarding implementation of osteoporosis risk assessment into Swedish primary dental care.

Background: Osteoporosis is a major health problem leading to fragility fractures. As shown in academic-based research, dental radiological examination can be used for osteoporosis risk assessment. A substantial number of patients undergo radiographic examinations in primary dental care each year, but little is known about implementation of osteoporosis risk assessment in this setting.

Materials and methods: A qualitative research approach using focus group discussions and manifest content analysis was applied. Five focus groups with dentists and representatives from patient support groups and a single individual interview with one medical specialist were included in the sample.

Results: From the manifest content analysis, three categories emerged: (a) barriers to change in practice, (b) benefits to change in practice, and (c) needs and requirements prior to change in practice. Most participants felt that there was insufficient knowledge of osteoporosis as well as a heavy existing workload. A concern was expressed about medical practitioners' willingness to take on responsibility for patients referred by dentists. Representatives from patient support groups highlighted a lack of knowledge about osteoporosis among both the general public and the medical professionals. Clear guidelines and improved communication channels between stakeholders would have to be established to ensure a smooth treatment path for patients.

Conclusion: Despite interest in osteoporosis risk assessment in primary dental care, there are political, workflow and educational barriers that must be overcome for successful implementation.

KEYWORDS

osteoporosis, primary dental care, qualitative study, risk assessment
\end{abstract}

This is an open access article under the terms of the Creative Commons Attribution-NonCommercial License, which permits use, distribution and reproduction in any medium, provided the original work is properly cited and is not used for commercial purposes.

(c) 2020 The Authors. Gerodontology published by Gerodontology Association and John Wiley \& Sons Ltd. 


\section{1 | INTRODUCTION}

Osteoporosis is a disease of bone causing its microstructural deterioration and loss of mass ${ }^{1}$ leading to weakening of the skeleton and increased risk of fragility fractures, particularly so of the vertebrae, forearm, hip and proximal humerus. ${ }^{2}$ The economic burden of fragility fractures in Europe has been estimated at $€ 37$ billion, and the costs are expected to increase by $25 \%$ by 2025 . $^{3}$

A major challenge in managing osteoporosis is the difficulty in identifying affected individuals before the condition is established and fracture has occurred. At present, the diagnosis of osteoporosis mainly relies on measurement of bone mineral density (BMD) at the hip and spine by dual-energy $X$-ray absorptiometry (DXA). ${ }^{2}$ The principal difficulty with this method is that BMD based on DXA alone in prediction of fracture risk has high specificity but low sensitivity. The performance characteristics of the test can, however, be improved by the concurrent consideration of risk factors (eg age, low body mass index and previous fragility fracture) that operate independently of BMD. ${ }^{3}$

Dental radiographs show not only the teeth but also part or all of the bone tissue in the jaws. Results achieved in a well-controlled academic environment indicate that these radiographs may be used as part of an osteoporosis risk assessment. ${ }^{4}$ Much interest has focused upon the cortical bone layer at the lower border of the mandible on panoramic radiographs. ${ }^{5}$ Mandibular cortical thickness measured on panoramic radiographs was shown to be the single most efficacious measurement in identifying women with osteoporosis in a large European multicentre study. ${ }^{6}$ Also, assessment of trabecular pattern using intraoral ${ }^{7}$ and panoramic radiographs ${ }^{8}$ has shown statistical validity in identifying individuals with osteoporosis.

A substantial number of patients undergo dental radiographic examinations each year. ${ }^{9}$ Given that the radiographs are taken for dental diagnostic and treatment purposes, an opportunity exists to incorporate osteoporosis risk assessment into dental clinical practice using dental radiographs already taken in the dental setting.

Few studies have been published reporting attitudes towards dentists performing health promotion activities or tests for medical conditions. The feasibility of blood glucose testing by dentists for diagnosis and monitoring of diabetes has been investigated by means of either questionnaires ${ }^{10,11}$ or in-depth interviews. ${ }^{12}$ Attitudes towards smoking cessation by dentists have been investigated through surveys ${ }^{13,14}$ or semi-structured interviews by phone ${ }^{15}$ but to our knowledge not through a focus group approach. None of the studies explored all stakeholders but rather chose to focus on either dentists $^{13,14}$ or patients. ${ }^{11,16}$

This study is part of a larger project titled "Implementation of osteoporosis and fracture risk assessment in primary dental care" inspired by quality implementation framework. ${ }^{17}$ The overriding goal of the project is to implement an innovative technique, and this study is part of the self-assessment strategy in order to investigate the needs, fit and readiness. Implementation of new types of patient management in clinical practice may be influenced by factors such as cognitive-behavioural barriers, attitudinal barriers and professional barriers. ${ }^{18}$ It is essential to explore the attitudes of all stakeholders on what might obstruct or facilitate the process, before implementing it, and thus increase its chance of success by adjusting the implementation strategy.

The aim of this study was therefore to explore and identify the attitudes of dentists, patients and medical specialists regarding benefits and barriers to the assessment and the implementation of osteoporosis detection into Swedish primary dental care.

\section{MATERIALS AND METHODS}

\section{1 | Ethical considerations}

The Regional Ethical Review Board in Lund was contacted in 2014. According to the instructions received, ethical approval was not required given that no identifying features were reported. The study followed the ethical considerations of the Declaration of Helsinki. Participation was voluntary and information about the study, formulated according to the general outlines provided by the Regional Ethical Review Board, was provided prior to the interviews. Informed consent was signed by all participants.

\subsection{Study setting and participants}

To gather the participants' thoughts and experiences on the subject area, an inductive qualitative approach was chosen based on focus group discussions (FGDs) and manifest content analysis. The study was conducted in southern Sweden over a 12-month period starting in the autumn of 2014. Representatives of Swedish general dental practitioners (GDPs), patients and medical specialists were recruited, with a total of 17 participants ( 14 women and 3 men). After this, no new insights were provided ${ }^{19}$ and no further focus groups were therefore considered necessary.

We recruited GDPs from private as well as from public clinics because both sectors have equal prevalence in Sweden and are subsidised to the same extent by the state. Since there are minor differences between counties in the organisation of public dental care, we recruited GDPs from three different counties in Sweden.

As recommended in other studies, we deliberately chose participants who knew or worked with each other in order to ease the conversation and make the participants feel comfortable. ${ }^{20,21}$ We contacted the heads of clinics via email, and they forwarded the invitation to participate in the focus groups together with information about the study to all practitioners in their clinics. Four GDPs from a private clinic formed the first focus group, four GDPs from a public clinic formed the second focus group, while the third focus group consisted of four heads of different public clinics in one county (unrelated to participants of the previous two focus groups). In the last group, however, one of the participants withdrew from the study due to a family emergency. 
Patients were selected through purposive sampling and consisted of representatives from local osteoporosis patient support groups from different parts of Sweden. We considered these representatives to be well-informed on the topic and their input valuable. Chairs of the support groups were contacted via email, and the invitation to participate in the focus groups was forwarded to all members of the organisations. All who agreed to take part were women above the age of 70 years. We scheduled meetings with two focus groups, each consisting of four participants, but eventually one dropped out from the first group and two from the second due to health issues, resulting in one group of three and one of two participants, respectively.

In terms of medical practitioners, our primary goal was to recruit physicians from primary healthcare clinics. However, after multiple attempts of reaching out to general practitioners (GPs) from different clinics in different parts of the country without success, we instead invited medical specialists in the field of osteoporosis. Since there are very few such experts in Sweden, we were only able to perform a single individual interview with one representative for this group, using the same interview guide as for the focus groups.

\subsection{Data collection}

We chose focus group discussions because we were looking for exchange of opinions on a specific topic (ie implementation of osteoporosis risk assessment in primary dental care) with minimal facilitation and interaction of the research team in the process. ${ }^{22}$ Five focus groups were performed based on a semi-structured interview guide that consisted of open-ended questions and was developed using relevant literature and consultations with public health experts. The guide was pre-tested on the first focus group of dentists. This only resulted in minor changes of the probing questions, and we therefore decided to include the data collected in the study.

Focus group discussions were conducted by a moderator (author JG, dentist) and an observer (author CL, professor who has specialised in the topic of osteoporosis risk assessment in dentistry). The moderator was responsible for tape recording the discussions and asking questions from the interview guide. The observer took notes and ensured that the discussions progressed smoothly and that all topics were covered. To ensure that participants felt free to express themselves openly, only the moderator, the observer, and persons who were part of the FGD were present during the discussions. Focus groups with dentists from private and public practices were held in their home clinics, while the one with heads of the clinics was held in the regional headquarters. Representatives from patient support groups came from different parts of southern Sweden, so we chose to arrange the first focus group at Malmö University and the second at a conference centre in Gothenburg. The single interview with the medical specialist from the field of osteoporosis was carried out in a private hospital setting.

Prior to the FGD, all participants received an e-mail with an information letter explaining the topic, objective of the study and latest research findings. The letter also included a short description of focus groups. Every FGD began by the researchers greeting, welcoming and thanking the participants for their contribution. We briefly repeated the content of the information letter to ensure that all participants understood the principles of the study and clarified any uncertainties. We asked the participants to contribute to the discussion and to take turns so that everyone could express their thoughts. We encouraged them to explain their views openly and in their own words. ${ }^{23}$

Discussions focused on the participants' perceptions about the introduction of osteoporosis and fracture risk assessment into primary dental care, with regard to the benefits and barriers as well as to the referral pathway and arrangement of the workflow. We started with a few general questions such as "What do you think about introducing osteoporosis and fracture risk assessment into general dental practice? Do you see any advantages? Might there be any difficulties?", and let the participants interact. Probing and follow-up questions were asked if needed. The individual single interview with the medical specialist followed the same procedure. All focus groups and the single interview were conducted in Swedish and lasted for approximately 40 minutes.

\section{4 | Analysis}

The transcriptions were analysed through manifest content analysis. ${ }^{24,25}$ The first author (JG) transcribed the interviews verbatim. Quality control of the transcripts was performed by listening to the recording while reading the text of the transcripts. The audio tapes and the transcriptions were reviewed and thoroughly discussed by author JG and author CL before the analysis started. The manifest content analysis was performed in three phases. ${ }^{24,25}$ In the first phase, all transcriptions were analysed directly after each focus group, commencing with thorough reading several times to get an overview of the whole text. In the second phase, meaning units, that is words and phrases meaningful to the aim of the study were identified in the text and highlighted. After identification of all meaning units, these were condensed into codes without changing the original meaning. The first phase and second phase of the analysis were performed by author JG alone, but the findings which emerged during the analysis were regularly discussed with author CL. In the third phase, the codes from all the transcriptions were gathered for comparison. They were then sorted by authors JG and CL together into three categories. Special attention was paid to establishing clear differences between (external homogeneity) and similarities within the categories (internal homogeneity). ${ }^{24}$ Two of three categories each had three subcategories. An example of the analysis process is presented in Table 1. An experienced qualitative researcher (author LP) was consulted as required.

Translation of the quotations for the purpose of citation in the manuscript was conducted by author JG. Actual speech was translated word by word. The native English-speaking co-authors were consulted when necessary. 
TABLE 1 Illustration of the analysis process

\begin{tabular}{|c|c|c|c|}
\hline Raw data & Codes & Subcategories & Category \\
\hline $\begin{array}{l}\text {...what are we supposed to say about the panoramic x-rays? } \\
\text { Are we supposed to comment on it, are we not supposed to } \\
\text { comment? Is the licensing course enough for it? }\end{array}$ & $\begin{array}{l}\text { Lack of knowledge and } \\
\text { routine }\end{array}$ & Work-related obstacles & $\begin{array}{l}\text { Barriers to change } \\
\text { in practice }\end{array}$ \\
\hline $\begin{array}{l}\text {...question is if it falls under our license, I don't know that. } \\
\text { We are not allowed to diagnose it, but are we supposed to } \\
\text { comment on it in some way in the future? }\end{array}$ & $\begin{array}{l}\text { Uncertainty about future } \\
\text { responsibilities }\end{array}$ & $\begin{array}{l}\text { Additional challenges } \\
\text { and responsibilities }\end{array}$ & \\
\hline
\end{tabular}

\section{3 | RESULTS}

Overall, the participants were eager to share their views and expressed their opinions openly. Opinions differed between general dental practitioners from private and public sectors. The medical specialist in osteoporosis shared views and thoughts, which were mostly in line with those of the private dental clinicians. The representatives from different support groups expressed quite similar experiences and opinions, and little variation emerged between representatives from different counties.

The findings of the manifest content analysis are described in three categories relating to the main topics covered in the discussions: (a) barriers to change in practice, (b) benefits of change in practice, and (c) needs and requirements prior to change in practice. Quotations are presented in the text to provide the reader with an opportunity to examine the original data and thereby establish confirmability.

\section{1 | Barriers to change in practice}

This category includes the subcategories: knowledge gaps on osteoporosis, work-related obstacles, and additional challenges and responsibilities.

\subsection{1 | Knowledge gaps on osteoporosis}

Most of the dentists from public practice did not feel confident in their ability to provide the risk assessment or counselling on osteoporosis due to insufficient knowledge of what osteoporosis is, how it is diagnosed and treated, and its consequences. They stated that they had never heard of or learned about any research showing that dental X-rays could be used to detect individuals with osteoporosis and risk for fracture.

Why did no one tell us about this earlier? It would have been good if we had learnt about this during our dental education, but it was barely discussed.

(dentist from public practice)

Dentists from both public practice and private practice expressed concerns about the consequences of implementing osteoporosis risk assessment in dental practice since knowledge on the topic is lacking and almost entirely limited to academia. The medical specialist expressed the same concern about primary healthcare centres and identified knowledge gaps also among primary healthcare practitioners.

Osteoporosis is still unfortunately a disease that people don't think that much about, until it causes serious problems. It is an underdiagnosed condition and you can have osteoporosis for many years without knowing, until you get compression fractures

(medical specialist)

The representatives of the patient support groups expressed similar opinions. They mentioned that osteoporosis is a disease that is widely unknown to the public. Some of them only learned about it because they had suffered from an osteoporosis-related fracture. Others learned about it by coincidence or were asked about it by acquaintances directly affected by the disease. According to them, the lack of knowledge about osteoporosis is not only a problem among the general public but also among medical professionals.

A dream situation would be (to have) osteoporosis clinics. Sending someone to a healthcare centre, where the doctor does not know too much about it, is just a waste of time and resources

(representative from patient support group)

\subsection{2 | Work-related obstacles}

Dentists from public practice felt pressured by time. Moreover, they were already involved in several other general health promotion activities such as tobacco control or cessation, diabetes prevention and high blood pressure prevention.

We already feel overwhelmed by everything that needs to be included in the dental examination. A lot of steps have to be completed. I can only imagine how people are going to react when they learn there is another thing to add to the list

(head of a public clinic)

Dentists from public practice and heads of public clinics in particular had other revenue requirements and felt it would be 
hard to incorporate osteoporosis risk assessment into the dental examination if they did not receive any compensation for it. Any additional task was perceived as "very tiresome." Their solution was to charge for the service, which would allow them to prolong the visit.

On the other hand, representatives from patient groups were concerned that they would have to pay more for a visit they already considered to be expensive. They would prefer that the new service was included within the existing price of dental examination. If that were not possible, they were prepared to pay an additional cost no greater than $€ 10-12$.

If it was billed as a patient fee within the healthcare system it would be great, exactly as PSA (Prostate Specific Antigen) and similar stuff are. We pay 100 SEK ( $\approx € 10$ at the time of the study) for a mammography examination, which is a reasonable amount

(representative from patient support group)

Another issue concerned licensing and scope of practice. Due to limited knowledge about osteoporosis, GDPs expressed a worry on how the workflow including osteoporosis risk assessment using dental radiographs should be structured.

The general opinion was that the referral system to medical clinics might also be an obstacle to any change of practice. Some dental professionals had already tried to introduce osteoporosis risk assessment locally in their practice but considered it hard to refer patients at risk to a doctor. They felt medical professionals were not taking them seriously. At present, there is no formal referral path between dental clinics and medical centres. Moreover, there is no digitalised communication, so patients who are found to be at risk of osteoporosis as part of a dental examination would be handed a report of the result from the dentist and were then supposed to search for medical help on their own.

Representatives from patient support groups did not consider it a good idea that they would need to search for medical help on their own. They expressed a worry that many patients would not have the energy for it. They had the experience that medical centres could be hard to reach and said that patients have to be stubborn to get through. They might also feel neglected and perceive that their problems were underestimated.

One thing I can say with all certainty is that you have to fight for attention (...) It is tough for those who are old and do not have anybody to take care of them. I don't know how they manage it

(representative from patient support group)

\subsection{3 | Additional challenges and responsibilities}

Due to the lack of a functional workflow and referral path in the scope of practice, dental practitioners were concerned about taking additional responsibility for the patients. They required clear guidelines that specified who should take responsibility for different parts of the risk assessment and treatment process for osteoporosis. Previous experiences of health promotion programmes, which required collaboration between dental and medical care, had been unsuccessful. Thus, if osteoporosis risk assessment was implemented in the future, dental professionals expressed concern that they would be forced to take major responsibility for patients at risk.

\begin{abstract}
...the question is if it falls under our license; I don't know that. We are not allowed to diagnose it, but are we supposed to comment on it in some way in the future?
\end{abstract}

(public clinic dentist)

The alternative would be to leave the responsibility to the patient, even though this might not be an optimal solution. Some patients at risk might not seek health care. On the other hand, being adults and informed by dental practitioners, patients should be able to do so.

Both dental practitioners and the medical specialist were concerned about general medical practitioners' unwillingness to take on responsibility for patients referred by dentists. The osteoporosis specialist described medical healthcare centres as being like "small islands" where some doctors were very interested and active in cooperation with other professions, while others were not and thus might not appreciate new patients being referred by dentists.

\subsection{Benefits to change in practice}

Participants discussed the benefits of the proposed change of practice and agreed that preventing osteoporosis-related fractures would be beneficial for society, as well as for the individual person. Heads of dental clinics expressed a hope that the proposed change of practice would bring dental and medical fields closer together and help improve communication between dental practice and primary healthcare centres that was at present missing.

Dental practitioners considered that osteoporosis risk assessment could benefit their practice for different reasons. Public practitioners saw it as a potential source of additional income, as they expected to receive compensation for it. Private practitioners, on the other hand, were more willing to include it in the current price of the dental examination and saw it as a competitive attribute in attracting more patients.

Every time we talk about it more patients come and ask for it. If it were to become widely known, then it would probably be of great interest I think among many older people. It is really very rewarding to do it, both this (osteoporosis risk assessment) and other health promoting initiatives. One would gain a lot of good will from it (dentist from private practice) 
Representatives from the patients support groups expressed similar views. They considered the initiative to be of high value due to the clear benefit to society, directly related to lowering healthcare costs in the long run, but also considered it a personal benefit. They had all joined the support group after being diagnosed with osteoporosis or after suffering a fracture. Since osteoporosis is a silent disease, they had not been diagnosed until after receiving several low-trauma fractures, in the majority of cases. Those fractures caused different levels of impairment which, in the participants' opinions, could have been avoided if they had been diagnosed sooner. Patients expressed their belief in a better future if osteoporosis risk assessment by dentists succeeded. This was based partly on their previous experiences but also on their trust in the skills and interest of dental professionals.

I think it is a brilliant way of discovering osteoporosis if the dentists really can see it (diagnose osteoporosis), because many more (people) go regularly for check-ups to the dentist but never visit their doctors for osteoporosis. You just have no idea that you have it (representative from patient support group)

\subsection{Needs and requirements prior to change in practice}

This category includes the subcategories: political changes to the healthcare system, filling educational and motivational gaps, and routines concerning workflow.

\subsubsection{Political changes to the healthcare system}

In order for the implementation process to be successful, changes in the political system were considered necessary. The discussions extended from decisions taken at national level to those made at county level. For example, dental practitioners required clear guidelines from the Swedish National Board of Health and Welfare that would specify who should take responsibility for different parts of the osteoporosis risk assessment, diagnosis and treatment process. County councils, however, should decide on the division of resources to permit osteoporosis and fracture risk assessment to take place in primary dental care.

\subsection{2 | Filling knowledge and motivational gaps}

Participants also emphasised the need for education of dental and medical professionals as well as the general public, about osteoporosis and its impact on fracture risk. Dental practitioners from both private practice and public practice asked for more detailed courses or workshops about the disease itself and the software to be applied on dental radiographs to identify patients at risk of osteoporosis fractures, so they could fully understand the impact on the patients affected.
I attended a lecture on osteoporosis and it really affected me. I had no idea. They talked about how much quality of life declines after an osteoporosis-related fracture (...) how handicapped you can become. And if you can prevent this...everyone should know

(dentist from private practice)

Dental practitioners from private practice on the whole appeared very motivated towards implementing the concept of osteoporosis and fracture risk assessment, whereas practitioners from public practice needed to be allowed to charge for this extra service, due to the previously mentioned revenue implications. Participants agreed that a low compensation at the level of $€ 10-20$ would be sufficient to compensate for the extra time spent performing the assessment.

It is a lot of goodwill for us, we do not need specific payment for it (...) because we can incorporate it into our budget estimation.

(dentist from private practice)

\subsection{3 | Routines concerning workflow}

Dental practitioners expressed the view that the process of assessing risk for osteoporosis should be incorporated into the dental examination as easily as possible. It should be automated to reduce time implications. In addition, it would be necessary to establish a proper referral pathway so that each practitioner understood his or her responsibilities. A connection between dental practices, primary healthcare centres and hospitals needed to be established so that the patient could smoothly move along the subsequent stages of the examination and treatment pathway. The connection should preferably be digital, since too much paperwork would require additional time and resources. Dental practitioners favoured the use of predetermined referral templates that could be efficiently completed. Moreover, all information to the patient and respective practitioners after particular steps in the referral pathway were expected to be fully automated.

(It should be) as easy as just uploading a regular dental $x$-ray and then a window pops up with an answer or a warning, to embed it in the examination

(dentist from public practice)

\section{4 | DISCUSSION}

The present study aimed to explore and identify factors that dentists, doctors and representatives from osteoporosis patient support groups in Sweden considered crucial in the process of implementation of osteoporosis risk assessment in primary dental care. An inductive qualitative research approach primarily using focus group discussions was applied. To the authors' knowledge, this is the first study in the field. No organised implementation of osteoporosis risk 
assessment and evaluation of attitudes has previously taken place in Swedish primary dental care. Implementation of academic findings into everyday practice is a necessary but relatively new field of science.

Seventeen participants gave their opinions on the issues related to potential obstacles and benefits to implementation of dental osteoporosis risk assessment, 16 in five focus group discussions and one in the single interview. Moreover, they made suggestions on needs and requirements prior to a potential change in practice, just as they considered local factors in the context of broader society. We chose to work with pre-existing groups such as colleagues or friends who already knew each other through working or socialising together. On one hand, such approach is discouraged by standard market research as it is argued that familiarity tends to inhibit disclosure and that previously established relationships could have negative influence on the discussion and group dynamics. ${ }^{26,27}$ On the other hand, there are several publications that support such practice. ${ }^{20,21}$ Using pre-existing groups gives the possibility of observing interactions approximated to naturally occurring data. Some studies explicitly recommend use of such natural groups. ${ }^{21}$ The fact that research participants already know each other has the additional advantage that friends and colleagues can relate to each other's comments and encourage each other to elaborate their thoughts.

Dental professionals expressed the desire to conduct osteoporosis risk assessment side by side with their daily activities, which agrees with previous results on other health-promoting interventions in a dental setting. ${ }^{10,14}$ There was, however, clear frustration due to work burdens and perceived poor cooperation and support from medical professionals in primary healthcare centres. Providing incentives might help change these issues. Studies on dentists' attitudes towards smoking cessation confirm that lack of confidence, lack of time and lack of reimbursement were considered the main barriers to the implementation process. ${ }^{14}$ On the other hand, it has also been shown that incentive-based performance improvements over the long term may be challenging. ${ }^{28}$ As is common with monetary incentives, they may weaken the intrinsic motivation for performing a task. One way in which both dentists' and patients' intrinsic motivation may not be undermined is to introduce fees that just cover the costs of the provided service. ${ }^{29,30}$

Our study identified three major issues that were of crucial importance for the implementation process to succeed. First, the political setup of the healthcare system should be addressed. Second, the incorporated intervention should be preceded by education of all involved health professionals, just as educational support material for the general public should be provided. Third, the workflow in the referral pathway should be adapted into the scope of practice of the general dental practitioner.

We used a qualitative research design with FGD and manifest content analysis to acquire knowledge on a previously unexplored subject. The insights provided by this study highlight the value of a qualitative research design in exploring and understanding implementation of new and modern techniques in the field of dentistry. Focus groups using an interview guide with open-ended questions provided a deeper understanding of the implementation process and the broader socio-political context of the Swedish healthcare environment. Moreover, it allowed the participants to express themselves freely in their own words with minimum interaction from the research team. ${ }^{22,23}$ Use of this methodology enabled us to capture a richer, in-depth knowledge of the participants' perspective on the subject. Using the same interview guide throughout the study enabled us to compare the findings, since the extracted meaningful units from all transcriptions could be coded and grouped into subcategories and categories together. ${ }^{31} \mathrm{~A}$ similar research approach was successfully used to investigate oral health professionals' experiences on tooth brushing techniques ${ }^{32}$ and the ability of the elderly to maintain their oral hygiene. ${ }^{33}$

An information letter covering the topic and aim of the study as well as the latest research findings provided a good basis for the participants to further discuss the issues and position themselves in relation to the statements. The information letter together with the interview guide contributed to the dependability of the study. Among the strengths was the use of two independent analysts and data triangulation, which enhanced the credibility of the results. By describing the research process in detail, we strived to facilitate transferability. ${ }^{24}$

As in the case of all qualitative studies, responses generated in the current study are typical of the participants, but not necessarily of dentists, patients and medical specialists in other parts of Sweden. Therefore, it is not known if the findings can be transferred to other groups or settings. Still, they may provide healthcare professionals and educators with deeper insight and knowledge. Second, we did not reach the goal of involving 4-5 participants in each focus group. A small number of employed GDPs at the selected clinics defined the limits of the size of the focus groups. Some participants' medical conditions made travel difficult. The fact that the focus groups were smaller than desirable may have limited the dynamic of the focus groups and the nature of the data collected. ${ }^{34}$ Third, the primary goal was to recruit physicians from primary healthcare centres, but after multiple attempts we had to settle for an individual interview with a single medical specialist in the field of osteoporosis. This issue was confirmed by a study exploring general practitioners' and dentists' experiences and expectations of interprofessional collaboration, which concluded that while dentists were interested in extending collaboration, most GPs saw no need for collaboration. ${ }^{35}$ Another issue that needs addressing is our observation that participants appeared to have more to say about obstacles rather than about benefits, even though the pitfall of researcher bias was actively addressed throughout the study. The interview guide was constructed through cooperation between two main authors using relevant literature and consisted of open-ended questions to avoid leading the participants to simply agreeing or disagreeing. To avoid influencing participants' responses, the researchers present strived for minimal interaction in the ongoing discussions between 
the participants. Lastly, the authors did not consult dental educational programs. Implementation of techniques from already practicing clinicians is but one aspect of the implementation process. Education and training of clinicians within educational programs may alter the perspectives of clinicians; however, such programs may be barriers in uptake.

\section{CONCLUSION}

From the general perspective of Swedish dental practitioners and patients, it is feasible to implement osteoporosis risk assessment in primary dental care using dental radiographs already taken for dental purposes. However, implementation processes require that they are continuously adapted as needed. The present study shows that barriers concerning workflow, education and the current arrangement of the Swedish healthcare system must be overcome for a successful implementation of osteoporosis risk assessment in primary dental care. Furthermore, clear guidelines and improved communication channels between stakeholders must be established to ensure a smooth treatment path for patients.

\section{AUTHOR CONTRIBUTIONS}

All the authors participated in designing the outlay of the study. Joanna Gullberg and Christina Lindh performed the focus groups interviews and the interpretation of data. Lene Povlsen and Björn Axtelius who are both experts on qualitative research design were regularly consulted. All the authors contributed to drafting the paper as well as revising it critically after both submissions to Gerodontology. Moreover, Keith Horner and Hugh Devlin who are both native English speakers performed language check of the manuscript. All authors have approved the revised version of the manuscript.

\section{ORCID}

Joanna Gullberg (iD https://orcid.org/0000-0002-1895-3366

\section{REFERENCES}

1. Peck WA, Burckhardt P, Christiansen C, et al. Consensus development conference: diagnosis, prophylaxis, and treatment of osteoporosis. Am J Med. 1993;94(6):646-650.

2. WHO. Assessment of fracture risk and its application to screening for postmenopausal osteoporosis. Report of a WHO Study Group. World Health Organ Tech Rep Ser. 1994;843:1-129.

3. Hernlund E, Svedbom A, Ivergard M, et al. Osteoporosis in the European Union: medical management, epidemiology and economic burden. A report prepared in collaboration with the international osteoporosis foundation (IOF) and the European Federation of Pharmaceutical Industry Associations (EFPIA). Arch Osteoporos. 2013;8:136.

4. Devlin H, Allen P, Graham J, et al. The role of the dental surgeon in detecting osteoporosis: the OSTEODENT study. Br Dent $\mathrm{J}$. 2008;204(10): E16-discussion 560-561.

5. Calciolari E, Donos N, Park JC, Petrie A, Mardas N. Panoramic measures for oral bone mass in detecting osteoporosis: a systematic review and meta-analysis. J Dent Res. 2015;94(3 Suppl):17S-27S.
6. Karayianni K, Horner K, Mitsea A, et al. Accuracy in osteoporosis diagnosis of a combination of mandibular cortical width measurement on dental panoramic radiographs and a clinical risk index (OSIRIS): the OSTEODENT project. Bone. 2007;40(1):223-229.

7. Lindh C, Horner K, Jonasson $\mathrm{G}$, et al. The use of visual assessment of dental radiographs for identifying women at risk of having osteoporosis: the OSTEODENT project. Oral Surg Oral Med Oral Pathol Oral Radiol Endod. 2008;106(2):285-293.

8. Jonasson G, Sundh V, Hakeberg M, Hassani-Nejad A, Lissner L, Ahlqwist M. Mandibular bone changes in 24 years and skeletal fracture prediction. Clin Oral Investig. 2013;17(2):565-572.

9. Tanner R, Wall B, Shrimpton P, Hart D, Bungay D. Frequency of Medical and Dental X-ray Examinations in the UK 1997/98. NRPB-R320:52. London: National Radiological Protection Board; 2000.

10. Barasch A, Safford MM, Qvist V, Palmore R, Gesko D, Gilbert $\mathrm{GH}$. Random blood glucose testing in dental practice: a community-based feasibility study from the dental practice-based research network. J Am Dent Assoc. 2012;143(3):262-269.

11. Creanor S, Millward BA, Demaine A, et al. Patients' attitudes towards screening for diabetes and other medical conditions in the dental setting. Br Dent J. 2014;216(1):E2.

12. Rosedale MT, Strauss SM. Diabetes screening at the periodontal visit: patient and provider experiences with two screening approaches. Int J Dent Hyg. 2012;10(4):250-258.

13. Prakash P, Belek MG, Grimes B, et al. Dentists' attitudes, behaviors, and barriers related to tobacco-use cessation in the dental setting. J Public Health Dent. 2013;73(2):94-102.

14. Albert DA, Severson H, Gordon J, Ward A, Andrews J, Sadowsky D. Tobacco attitudes, practices, and behaviors: a survey of dentists participating in managed care. Nicotine Tob Res. 2005;7(Suppl. 1):S9-S18.

15. Nowlin JP, Lee JGL, Wright WG. Implementation of recommended tobacco cessation systems in dental practices: a qualitative exploration in Northeastern North Carolina. J Dent Educ. 2018;82(5):475-482.

16. Yahya NA, Saub R, Nor MM, Yusoff N. Dental patient knowledge about the effects of smoking and attitudes about the role of dentists in smoking cessation. Southeast Asian J Trop Med Public Health. 2017;48(2):473-484.

17. Meyers DC, Durlak JA, Wandersman A. The quality implementation framework: a synthesis of critical steps in the implementation process. Am J Community Psychol. 2012;50(3-4):462-480.

18. Cochrane LJ, Olson CA, Murray S, Dupuis M, Tooman T, Hayes S. Gaps between knowing and doing: understanding and assessing the barriers to optimal health care. J Contin Educ Health Prof. 2007;27(2):94-102.

19. Glaser BG, Strauss AL. The Discovery of Grounded Theory: Strategies for Qualitative Research. New York, NY: Routledge; 1967.

20. Kitzinger J. The methodology of focus groups: the importance of interaction between research participants. Sociol Health IIIn. 1994;16(1):103-121.

21. Khan ME, Manderson L. Focus groups in tropical diseases research. Health Policy Plan. 1992;7(1):56-66.

22. Morgan DL. The Focus Group Guidebook. Thousand Oaks, CA: SAGE Publications, Inc; 1997.

23. Hallberg LR. Introduction and aims of the book - health, public health and research on public health. In: Hallberg LR-M, ed. Qualitative Methods in Public Health Research: Theoretical Foundations and Practical Examples. Lund: Studentlitteratur; 2002:13-34.

24. Graneheim UH, Lundman B. Qualitative content analysis in nursing research: concepts, procedures and measures to achieve trustworthiness. Nurse Educ Today. 2004;24(2):105-112.

25. Hsieh HF, Shannon SE. Three approaches to qualitative content analysis. Qual Health Res. 2005;15(9):1277-1288. 
26. Smith JM. Interviewing in Market and Social Research. London: Routledge/Thoemmes Press; 1972.

27. Krueger RA, Casey MA. Focus Groups: A Practical Guide for Applied Research (5th ed.). California, CA: Sage Publications; 2015.

28. Brocklehurst P, Price J, Glenny AM, et al. The effect of different methods of remuneration on the behaviour of primary care dentists. Cochrane Database Syst Rev. 2013;11(11):CD009853.

29. Grytten J. Payment systems and incentives in dentistry. Community Dent Oral Epidemiol. 2017;45(1):1-11.

30. Christell H, Gullberg J, Nilsson K, Heidari Olofsson S, Lindh C, Davidson T. Willingness to pay for osteoporosis risk assessment in primary dental care. Health Econ Rev. 2019;9(1):14.

31. Morgan DL. Successful Focus Groups: Advancing the State of the Art. Thousand Oaks, CA: SAGE Publications Ltd; 1993.

32. Jensen O, Gabre P, Sköld U, Birkhed D, Povlsen L. 'I take for granted that patients know'-oral health professionals' strategies, considerations and methods when teaching patients how to use fluoride toothpaste. Int J Dental Hygiene. 2014;12(2):81-88.

33. Gronbeck Linden I, Hagglin C, Gahnberg L, Andersson P. Factors affecting older persons' ability to manage oral hygiene: a qualitative study. JDR Clin Trans Res. 2017;2(3):223-232.
34. Stalmeijer RE, Mcnaughton N, Van Mook WNKA. Using focus groups in medical education research: AMEE guide no. 91. Med Teach. 2014:36(11):923-939.

35. Sippli K, Rieger MA, Huettig F. GPs' and dentists' experiences and expectations of interprofessional collaboration: findings from a qualitative study in Germany. BMC Health Serv Res. 2017;17(1):179.

How to cite this article: Gullberg J, Lindh C, Axtelius B, Horner K, Devlin H, Povlsen L. Osteoporosis risk assessment in primary dental care-The attitudes of Swedish dentists, patients and medical specialists. Gerodontology. 2020;37:208-216. https://doi.org/10.1111/ger.12462 

II 



\title{
Willingness to pay for osteoporosis risk assessment in primary dental care
}

\author{
Helena Christell ${ }^{1,2^{*}}$, Joanna Gullberg ${ }^{1}$, Kenneth Nilsson' ${ }^{1}$ Sofia Heidari Olofsson ${ }^{1}$, Christina Lindh ${ }^{1}$ and \\ Thomas Davidson ${ }^{3}$
}

\begin{abstract}
Background: Fragility fracture related to osteoporosis among postmenopausal women is a significant cause of morbidity. The care and aftercare of these fractures are associated with substantial costs to society. A main problem is that many individuals suffer from osteoporosis without knowing it before a fracture happens. Dentists may have an important role in early identification of individuals with osteoporosis by assessment of dental radiographs already included in the dental examination. The aim of this study was therefore to investigate postmenopausal women's preferences for an osteoporosis risk assessment in primary dental care.

Results: Most respondents (129 of 144 (90\%)) were willing to pay for an osteoporosis risk assessment in primary dental care. The overall mean willingness to pay (WTP) including respondents that denoted none or zero WTP was $44.60 €(\mathrm{Cl} 95 \%$ 38.46-50.74 €) (median $34.75 €$ ). A majority (80.6\%) of the respondents that denoted WTP also gave a motivation for their answer. The two most common reasons denoted for being willing to pay for osteoporosis risk assessment were the importance of early diagnosis and preventive care to avoid fractures (41.0\%) and the importance of knowledge of a risk of osteoporosis (26.4\%). A majority of respondents (67.8\%) considered it valuable if dental clinics would offer osteoporosis risk assessment.
\end{abstract}

Conclusions: Postmenopausal women seem to find it valuable to be offered osteoporosis risk assessment in primary dental care and are willing to pay for such a risk assessment. From a societal perspective early diagnosis of osteoporosis by risk assessment in primary dental care could prevent osteoporotic related fractures and benefit women's health and quality of life, as well as have a major impact on the health-care budget in terms of costsavings.

Keywords: Dental clinics, Health economics, Medico economic, Osteoporosis, Patient acceptance of health care, willingness to pay

JEL: $\mid 10$

\section{Introduction}

Osteoporosis is a metabolic disease characterised by progressive reduction in bone mass and changes in the micro architectural structure of bone. The disease leads to an increased risk of fractures, most commonly affecting the spine, forearm, and hip [1]. At the age of 50, the lifetime risk of one of these fractures is $22 \%$ and $46 \%$ in

\footnotetext{
*Correspondence: Helena.Christell@mau.se

${ }^{1}$ Faculty of Odontology, Malmö University, Box 50500, 20250 Malmö, Sweden

2Department of Radiology, Helsingborg Hospital, 25187 Helsingborg, Sweden

Full list of author information is available at the end of the article
}

men and women, respectively [2]. The total cost burden of osteoporosis and its related fractures in Europe was estimated to 30.7 billion euros in 2010 and expected to increase to 38.5 billion euros by 2025 [3]. Consequently, osteoporosis is a major health problem that imposes a growing financial burden on health services and the burden becomes even greater when taking the Quality Adjusted Life Years (QALYs) lost into account [2].

Osteoporosis is diagnosed based on bone mineral density (BMD) derived from Dual-energy-X-ray Absorptiometry (DXA) [4]. Although there are risk factors other than low BMD, a major challenge in managing 
osteoporosis is the difficulty in identifying affected individuals before the condition is established and fracture has occurred [4-6]. Research has shown that assessment of bone tissue in radiographs obtained at dental clinics may disclose findings that constitute a risk factor for skeletal fracture [7]. Dental radiographs are probably the most commonly performed radiographic examination in the world [8]. These radiographs show the teeth as well as a varying amount of bone tissue which makes them a potential diagnostic tool for early identification of risk indicators of osteoporosis and consequently of fractures. Extended use of dental radiographs for risk assessment of osteoporosis, could make dentists possible 'gate-keepers' of bone health and contribute to reduce the huge socioeconomic burden that this condition means.

Dentists' attitudes towards chairside medical screening has been investigated and it was found that dentists considered medical screening important and were willing to implement this into their practice $[9,10]$. Results from other studies indicate that a majority of patients were willing to undergo medical screening in a dental setting as they considered this important [11, 12]. Gullberg et al. 2018 [13] investigated the attitudes of Swedish dentists, patients, and medical specialists towards osteoporosis risk assessment in primary dental care using qualitative study design. Several barriers at the individual level and within the healthcare system were identified as possible obstacles to optimal implementation of osteoporosis risk assessment at dental clinics. One of these barriers was the extra time, and thus additional cost, required for supplementary assessment of dental radiographs.

All interventions in health care should be deemed cost-effective in order to effectively use the scarce resources. For this reason, health economic evaluations are used, most commonly for pharmaceuticals, but also for diagnostic procedures and medical devices [14]. Cost benefit analysis is one type of economic evaluation that enables a direct answer of whether the benefits of a method exceeds its costs, thus having a positive net social benefit, indicating that the method is worthwhile. The benefits of any method for screening, diagnosis or treatment could be estimated in terms of willingness to pay (WTP) [15], using contingent valuation. In the context of osteoporosis risk assessment in a primary dental care setting WTP would reveal the strength of individual preferences for this method to be applied. According to our knowledge there are no previous studies addressing WTP of osteoporosis risk assessment in primary dental care.

The aim of this study was therefore to investigate postmenopausal women's preferences for an osteoporosis risk assessment in primary dental care using a self-administered questionnaire to assess WTP.

\section{Material and methods}

Data was collected between May and August 2013 in two primary dental clinics in southern Sweden, one public clinic and one private. Female patients over 50 years of age that could read and comprehend Swedish were consecutively invited to participate.

\section{Information booklet and questionnaire}

A booklet (Appendix I) was produced containing information about osteoporosis, its risk factors, prevalence, and possible consequences. The scenario of identifying women with osteoporosis risk was illustrated in two steps with i) risk assessment of women over 50 years based on current dental radiographs at the dental clinic and the possible diagnostic accuracy for such a method and ii) the procedure of referring women at risk of osteoporosis for further investigation with DXA.

A questionnaire (Appendix II) was developed in consultation with a health economist. The first section of the questionnaire aimed to measure the respondents' WTP for an osteoporosis risk assessment at the dental clinic using a payment scale. To enhance the probability of receiving a true value of the WTP the respondents were asked to denote the maximum amount that they were willing to pay as well as to cross out the amounts that exceeded this. The WTP question was followed by an open-ended question where the respondents were asked to write down a motivation for their answer to the first question. The respondents were also asked if they considered it valuable to be offered an osteoporosis risk assessment in connection with a dental visit. The dental staff was instructed to consecutively distribute the questionnaires and the information booklet to female patients in association with their dental visit and to encourage the patients to read the information booklet before completing the questionnaire. The information booklet was only distributed to the patients at the public clinic.

\section{Focus group}

Prior to distribution of the questionnaire to the dental clinics, a focus group interview was performed with participation of four postmenopausal women, between 50 and 84 years of age. The women were asked to read the information booklet and answer the questionnaire. During the subsequent discussion they were asked to give feedback regarding their understanding and interpretation of the booklet and survey questions. A minor revision of the questionnaire and booklet was then made according to the results from the focus group interview.

\section{Statistical calculations}

For statistical calculations IBM SPSS statistics 24 software for Windows (SPSS Corporation, Chicago, Illinois, 
USA) was used. The data were subjected to descriptive statistics including 95\% confidence intervals (CI). Correlation between mean WTP and any of the variables was analysed with one-way ANOVA. $P<0.05$ was considered statistically significant. The dependent variable was willingness to pay for osteoporosis risk assessment in primary dental care and the independent variables were: osteoporosis diagnosis, osteoporotic fracture, a relative with a diagnosis of osteoporosis or osteoporotic fracture, age, educational level, occupation, and annual income.

The study followed the ethical considerations of the Declaration of Helsinki according to which no ethical approval was necessary as participation in the interviews was voluntary, anonymous and no data can be traced back to the respondents. Information about the study, formulated according to the general outlines provided by the Regional Ethical Review Board, Lund, Sweden was provided in the information booklet administered together with the questionnaire. The costs were based on cost-year 2013 when one euro averaged 8.6 SEK.

\section{Results}

In total 144 women answered the questionnaire. Table 1 presents demographic characteristics of the respondents. Figure 1 illustrates how the age distribution of the eight age groups between 50 and $85+$ correspond to the population of Sweden 2013 [16].

\section{Willingness to pay}

Most respondents (129 of 144 (90\%)) were willing to pay for an osteoporosis risk assessment in primary dental care. The overall mean WTP including respondents that denoted none or zero WTP was $44.60 €$ (CI 95\% 38.46$50.74 €$ ) (median $34.75 €$ ) (Table 2 ). A majority (80.6\%) of the respondents that denoted WTP also gave a motivation for their answer. Twelve respondents denoted WTP zero and three answers regarding WTP were missing. The two most common reasons denoted for being willing to pay for osteoporosis risk assessment were the importance of early diagnosis and preventive care to avoid fractures (41.0\%) and the importance of knowledge of a risk of osteoporosis (26.4\%). A majority of respondents $(67.8 \%)$ considered it valuable if dental clinics could offer osteoporosis risk assessment.

There was no statistically significant association between income and WTP, thus no income elasticity (Table 2). None of the variables age, education level, occupation, osteoporosis diagnosis, osteoporotic fracture, having a relative with osteoporosis diagnosis or osteoporotic fracture, showed any statistically significant influence on the respondents' WTP when controlled using one-way ANOVA (Table 3). Mean WTP was slightly lower for those who already had an osteoporosis
Table 1 Demographic characteristics of the respondents (in total $n=144$ )

\begin{tabular}{|c|c|c|}
\hline & & $\mathrm{n}$ \\
\hline \multirow[t]{9}{*}{ Age (years) } & $50-54$ & 32 \\
\hline & $55-59$ & 23 \\
\hline & $60-64$ & 26 \\
\hline & $65-69$ & 24 \\
\hline & $70-74$ & 18 \\
\hline & 75-79 & 12 \\
\hline & $80-84$ & 3 \\
\hline & $>85$ & 3 \\
\hline & No answer & 3 \\
\hline \multirow[t]{4}{*}{ Education } & Primary & 34 \\
\hline & Secondary & 39 \\
\hline & College & 68 \\
\hline & No answer & 3 \\
\hline \multirow[t]{7}{*}{ Occupation } & Full time & 46 \\
\hline & Part time & 34 \\
\hline & Retired & 59 \\
\hline & Student & 1 \\
\hline & Unemployed & 0 \\
\hline & Other & 1 \\
\hline & No answer & 3 \\
\hline \multirow[t]{6}{*}{ Annual income (Euro) } & $0-22,999$ & 40 \\
\hline & $23,000-34,999$ & 34 \\
\hline & $35,000-45,999$ & 39 \\
\hline & $46,000-57,999$ & 8 \\
\hline & $>58,000$ & 3 \\
\hline & No answer & 20 \\
\hline \multirow[t]{4}{*}{ Osteoporosis diagnosis } & Yes & 19 \\
\hline & No & 121 \\
\hline & Do not know & 1 \\
\hline & No answer & 3 \\
\hline
\end{tabular}

diagnosis or had suffered from an osteoporosis-related fracture, while it was somewhat higher for those who had relatives diagnosed with osteoporosis or had suffered from an osteoporosis-related fracture. The lower WTP from respondents that had already been diagnosed with osteoporosis was in most cases motivated in the answer by the fact that there was no need for diagnosis. Most respondents diagnosed with osteoporosis and/ or with relatives diagnosed with osteoporosis that denoted high WTP stated the importance of early diagnosis.

\section{Net social benefit}

The benefits related to the costs can be expressed as the net social benefit (NSB) $[15,17]$. NSB for osteoporosis risk assessment in primary dental care can be calculated 


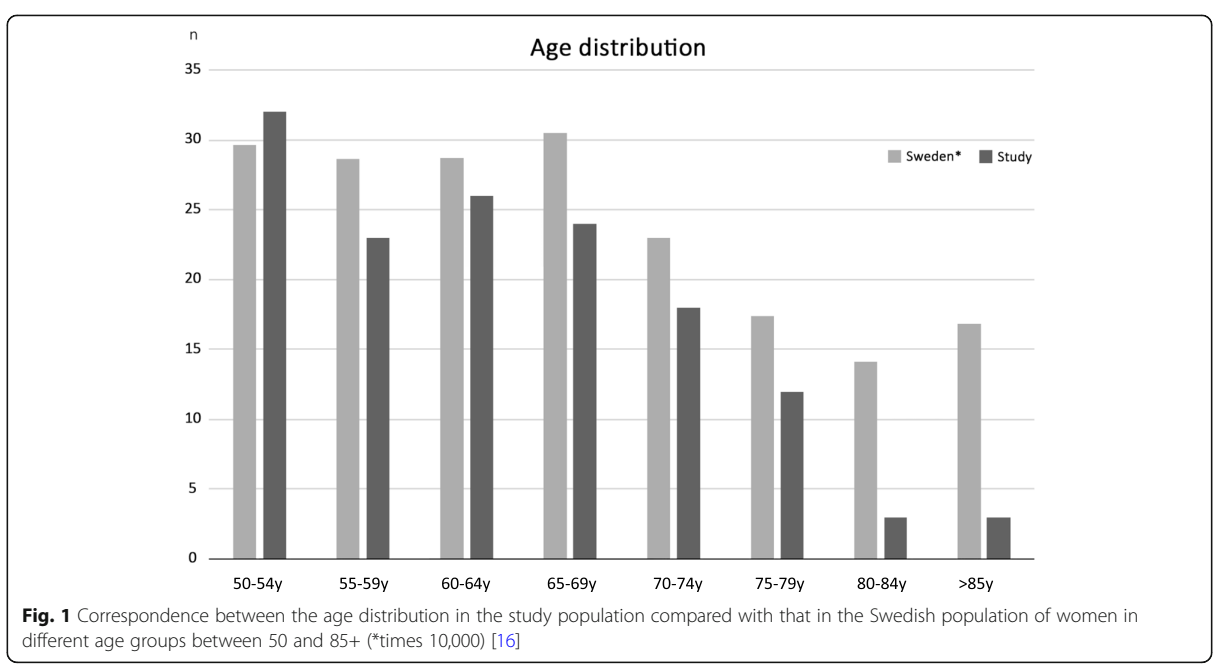

as the WTP (a) minus the cost for the dentist's working time (b). The expected revenue per hour in 2013 for a general dentist was around $220 €(3.67 €$ per minute) and the working time for a dentist to perform an osteoporosis risk assessment is estimated to be ten minutes. The average WTP (a) of $44.60 €$ minus a cost for ten minutes of a dentists working-time (b) of $36.68 €$ would result in a positive NSB. Any patient-related cost for transport to the clinic and the time to get to the clinic can be estimated to zero as this is already included in the cost for the dental visit and the cost of the patient's time for the actual risk assessment can be assumed to be negligible.

There is a well-known weakness in cost-benefit analyses in that the respondents may denote a higher WTP than the amount of money they would pay for an intervention in real life. Hence there is a risk that the resulting value of WTP is overestimated. The patient-fee for visiting a medical specialist in 2013 in Sweden, thus the cost a patient would normally have to pay to get an assessment of osteoporosis, was around $25 \%$ lower than the estimated average WTP in this study. In countries where medical care is paid for by the patients themselves or by private insurances the WTP for such risk assessment would be expected to be higher. With a $25 \%$ lower value for WTP, however, risk assessment of osteoporosis in primary dental care would still be resources well-invested in a long-term perspective as the benefits from early detection of osteoporosis would include reduced future health-care costs for osteoporotic-related fractures.

\section{Discussion}

The results showed that most respondents denoted a WTP indicating that women over 50 years of age are willing to pay for osteoporosis risk assessment and find

Table 2 Number of respondents ( $n=141$ of 144 due to no answer of WTP for three respondents) divided into different groups of annual income and median willingness to pay (WTP), mean WTP and 95\% Cl of mean WTP in Euro ( $€$ ).

\begin{tabular}{lllll}
\hline Annual income & $n$ (total $n=141)$ & Median WTP & Mean WTP & Cl 95\% of mean WTP \\
\hline $0-22,999$ & 39 & 34.75 & 36.49 & $27.22-45.87$ \\
$23,000-34,999$ & 33 & 34.75 & 48.77 & $34.40-63.25$ \\
$35,000-45,999$ & 39 & 57.92 & 53.17 & $39.39-66.96$ \\
$46,000-57,999$ & 8 & 46.34 & 53.63 & $16.22-90.94$ \\
$>58,000$ & 3 & 34.75 & 54.10 & $-81.90-190.10$ \\
No answer of income & 19 & 23.17 & 31.05 & $20.39-41.82$ \\
Overall results & & 34.75 & 44.60 & $38.46-50.74$ \\
\hline
\end{tabular}


Table 3 The number of respondents that answered the question if they had been diagnosed with osteoporosis, had an osteoporotic fracture, had a relative with osteoporosis or a relative that had an osteoporotic fracture related to their denoted willingness to pay (WTP) ( $n=141$ of 144 due to no answer of WTP for three respondents) $(P>0.05)$ in Euro $(€)$

\begin{tabular}{|c|c|c|c|c|c|c|c|c|}
\hline & \multicolumn{2}{|c|}{ Diagnosed with osteoporosis } & \multicolumn{2}{|c|}{ Osteoporotic fracture } & \multicolumn{2}{|c|}{ Relative with osteoporosis } & \multicolumn{2}{|c|}{ Relative with osteoporotic fracture } \\
\hline & $n$ & mean WTP & $n$ & mean WTP & $n$ & mean WTP & $n$ & mean WTP \\
\hline Yes & 17 & 43.62 & 7 & 39.73 & 15 & 48.67 & 10 & 57.94 \\
\hline No & 120 & 45.00 & 131 & 45.20 & 106 & 43.40 & 111 & 42.38 \\
\hline Do not know & 1 & 57.92 & 2 & 39.62 & 18 & 49.58 & 19 & 52.48 \\
\hline No answer of these questions & 3 & 30.93 & 1 & 11.58 & 2 & 34.75 & 1 & 11.58 \\
\hline ANOVA Sig. level & & 0.932 & & 0.919 & & 0.741 & & 0.284 \\
\hline
\end{tabular}

50-54y 55-59y 60-64y 65-69y 70-74y 75-79y 80-84y >85y

it valuable to be offered this at dental clinics. The average WTP overrated the estimated cost for osteoporosis risk assessment meaning that there is a positive net social benefit indicating that the method for risk assessment is worthwhile. This agrees with the results of another study where a majority of women aged 60 and older indicated preference for osteoporosis screening [18]. Only women over 50 years of age were included because postmenopausal women are at an increased risk of osteoporosis and this selection of respondents that have been diagnosed with the examined disease is in line with most other studies regarding WTP for diagnostic technologies [19]. The number of respondents was comparable with that in other WTP-studies in dentistry ranging from 36 to 611 respondents [17, 20-23].

WTP has proven to be influenced by study design and elicitation methods [19]. Studies using face-to-face interviews allow for communication with the respondents, which can avoid misunderstandings of the questions resulting in a higher validity than studies based on self-administered questionnaires [24, 25]. Payment scale implies a risk that the respondents are guided by the range of bid and many respondents tend to choose a higher value when the payment scale is long, i.e. including higher values [25]. According to two recent systematic reviews, face-to-face interviews were used in a majority of studies of WTP in oral health care [26] while most WTP-studies of diagnostic methods in medical care used self-administered questionnaires [19]. In present study a self-administered questionnaire with closed-ended questions and a payment-scale to elicit the WTP-question was constructed according to examples found in the literature [27]. The response rate was excellent with all respondents but three completing the WTP-question. According to Donaldson et al. (1997) using payment scale rather than an open-ended approach increases the likelihood that the WTP-question will be answered [27]. Furthermore, it is less time-consuming to use self-administered questionnaires instead of face-to face interviews thus enabling a larger study sample and minimising biased WTP-answers due to influence from an interviewer.

Describing a realistic scenario is fundamental in WTP-studies as it makes the respondents feel bound to their denoted value for WTP and that this value is in level with their budget [24] but it is one of the main difficulties in contingent valuation [15]. A realistic scenario when evaluating a method for diagnosis or risk assessment includes information of health gains, duration, diagnostic accuracy and risks. Such information regarding osteoporosis risk assessment was included in the booklet that was distributed to the respondents in the public clinic. The scenarios in WTP-studies often mean that the patients are asked if they are willing to pay for an intervention that is not (yet) available (a medicine or treatment that is being researched) or for medical healthcare that is normally paid for by taxes or included in the medical insurance. This could make the scenario difficult to understand which may lead to opposition of the survey in terms of a protest answer. Hence, the respondents denote a WTP that equals zero or is unreasonably high which obstructs the possibility of proper estimation of the WTP. All 15 respondents that denoted zero or non-response also motivated their answers, which were interpreted to reflect a true WTP. The WTP-method has been criticised for placing monetary value on health benefits or the saving of a life. For most patients in dental care, however, the WTP-scenario would seem realistic as they are used to being confronted with cost proposals for different treatments with specific health benefits. Furthermore, as opposed to medical care, the lion's share of dental care is paid for by the patients and this makes the WTP-instrument applicable for valuation of the benefits of any intervention in dentistry.

In contingent valuation the optimal validation would be to compare the estimated WTP with the corresponding value of a reference method. In present study, it would mean a comparison of the measured WTP with the amount of money women over 50 years of age would really pay for an osteoporosis risk 
assessment in primary dental care. In most cases such comparisons are not possible as the intervention being investigated is not (yet) used in healthcare or dental care. It is recommended that one controls the measured WTP with higher income, education, disease severity, family history, and a more accurate test as WTP increases with these variables. This is a well-known weakness in contingent valuation [15]. Most studies of WTP of diagnostic methods report correlation, significant or non-significant, between WTP and the variables above [19]. The systematic review of WTP of methods in dental care found that income elasticity was tested in only 11 of 26 studies whereof eight reported a statistic correlation between WTP and income and three studies showed a tendency for higher WTP at higher income [24].

In the present study, there was an association between income level and WTP but with no statistical significance. This result is similar to several other studies of costs related to benefits in terms of WTP in dental care $[17,22,23]$. Most patients in the private clinic were over 65 years old and retired whilst most of the respondents in the public clinic were in the age range 50-64 and still working. Despite this, the respondents in the private clinic denoted a slightly higher mean WTP compared with respondents in the public clinic (not statistically significant). It is possible that some of the respondents who stated a high WTP also had real estate or bank savings and that inclusion of a question about other assets than income would have resulted in income elasticity. Furthermore, the literature background information on the disease and method for diagnosis as well as on the WTP-instrument is considered important when estimating WTP $[15,24]$. Due to a misunderstanding by the staff in the private clinic, these respondents did not receive such information and it is possible that had they been given such information it would have resulted in a higher mean WTP for the respondents in the private clinic. Nineteen respondents had previously been diagnosed with osteoporosis whereof 16 denoted WTP. According to the results of other studies, there is no clear correlation between WTP and earlier diagnosis [19]. Nevertheless, a majority (13 of 19) of these respondents motivated the denoted WTP in a way that indicated that they had a positive attitude towards osteoporosis risk assessment at dental clinics whether or not they had specified any WTP. Another way to validate the estimated WTP was to have a follow-up question where respondents were asked to motivate their stated WTP, and almost all respondents gave a motivation that was logical and thus corresponding to the level of WTP. The respondents who had already been diagnosed with osteoporosis denoted either relatively low or relatively high values for WTP. The most common motivation for a low WTP was that the respondent personally would not benefit from a risk assessment of osteoporosis. A high WTP was denoted with the motivation that it was important for (other) women to be given the opportunity for this type of risk assessment of osteoporosis as early detection leads to less severe consequences.

According to a systematic review of WTP of diagnostic methods from 2013, most studies reported a median WTP below \$ 100 [19]. The median WTP of $34.75 €$ in the present study correspond well to the WTP in other studies of screening of osteoporosis [19]. Furthermore, the patient-cost for a specialist in medical care in 2013 in southern Sweden was $35 €$, thus the cost that the patients expect to pay. To enhance the probability of a realistic WTP the respondents were asked to mark the amount they were willing to pay and to cross out all the amounts exceeding their WTP but few respondents completed this question. Nevertheless, most respondents denoted a logical explanation for their WTP, which indicates a high validity. Most publications of contingent valuations focus on validation of the WTP-instrument instead of performing a full evaluation [15]. This might be due to inherent difficulties in measuring WTP and the ongoing debate concerning different ways of asking the questions and who should ask them. Incorporating WTP-studies into economic evaluation, however, requires identification of the opportunity cost of the new intervention [15]. Currently, there is no risk assessment for osteoporosis thus it would be a complex task to estimate the opportunity cost and the health benefits foregone for using this screening method. Consequently, the measured value for WTP can be assumed to represent the incremental value of risk assessment for osteoporosis compared with no risk assessment as the value of the latter could be considered non-existent. The result of a positive NSB where the estimated WTP was higher than the estimated costs indicates that risk assessment of osteoporosis is worthwhile. For comparison, a model study that assessed screening using DXA with subsequent hormone replacement concluded that DXA and treatment with Alendronate was the most cost-effective approach with \$ 55,000 per QALY [28]. Another model study concluded that the most cost-effective screening strategy would be to use DXA -2.5 with re-screening every five years for a cost of less than $\$ 50,000$ per QALY [29].

\section{Conclusions}

A majority of postmenopausal women find osteoporosis risk assessment in primary dental care valuable and are also willing to pay for such a risk assessment. Their main reasons for being willing to pay are the importance of an early diagnosis and preventive care to avoid fractures. To ensure that risk patients receive adequate 
treatment, dentists' preferences of conducting osteoporosis risk assessments as well as the referral pathways and communication between primary dental care and general healthcare should be assessed.

Osteoporosis risk assessment in primary dental care could identify disease at an early stage and avoid osteoporotic fractures, which would free resources that are currently designated to treatment and rehabilitation. Future research should further assess benefits in terms of health and cost of examinations in primary dental care lying beyond the oral cavity in order to increase knowledge of extended collaboration with the general healthcare.

\section{Abbreviations}

BMD: Bone mineral density; DXA: Dual energy $x$-ray absorptiometry; NSB: Net social benefit; QALY: Quality adjusted life years; WTP: Willingness to pay

\section{Acknowledgements \\ Non applicable.}

Funding

Non applicable.

\section{Availability of data and materials}

Data will be shared on request to Helena.Christell@mau.se

\section{Authors' contributions}

HC: Planning and designing the study, data processing and writing manuscript. JG: Processing data and writing manuscript. KN: Planning and designing the study, collecting and processing data and writing manuscript. SHO: Planning and designing the study, collecting and processing data and writing manuscript. CL: Planning and designing the study, collecting and processing data and writing manuscript. TD: Planning and designing the study, processing data and writing manuscript. All authors read and approved the final manuscript.

\section{Competing interests}

Non applicable.

\section{Publisher's Note}

Springer Nature remains neutral with regard to jurisdictional claims in published maps and institutional affiliations.

\section{Author details}

${ }^{1}$ Faculty of Odontology, Malmö University, Box 50500, 20250 Malmö, Sweden. ${ }^{2}$ Department of Radiology, Helsingborg Hospital, 25187 Helsingborg, Sweden. ${ }^{3}$ Centre for Medical Technology Assessment, Department of Medical and Health Sciences, Linköping University, 58183 Linköping, Linköping, Sweden.

\section{Received: 4 November 2018 Accepted: 14 May 2019}

Published online: 24 May 2019

\section{References}

1. Consensus development conference: diagnosis, prophylaxis, and treatment of osteoporosis. Am J Med. 1993;94:646-50.

2. Hernlund E, Svedbom A, Ivergard M, Compston J, Cooper C, Stenmark J, McCloskey EV, Jönsson B, Kanis JA. Osteoporosis in the European Union: medical management, epidemiology and economic burden. A report prepared in collaboration with the international Osteoporosis Foundation (IOF) and the European Federation of Pharmaceutical Industry Associations (EFPIA). Arch Osteoporos. 2013;8:136.

3. Ström O, Borgström F, Kanis JA, Compston J, Cooper C, McCloskey EV, Jönsson B. Osteoporosis: burden, health care provision and opportunities in the EU. Osteoporosis: a report prepared in collaboration with the international Osteoporosis Foundation (IOF) and the European Federation of Pharmaceutical Industry Associations (EFPIA). Arch Osteoporos. 2011;6: 59-155.

4. WHO. Assessment of fracture risk and its application to screening for postmenopausal osteoporosis. WHO study group. World Health Organ Tech Rep Ser. 1994;843:1-129

5. European Commission: Report on osteoporosis in the European Community. Strasbourg: European Community. 1998.

6. Royal College of Physicians: Osteoporosis: clinical guidelines for the prevention and treatment. London: Royal College of Physicians. 1999.

7. Horner K, Allen P, Graham J, Jacobs R, Boonen S, Pavitt S, Nackaerts O,

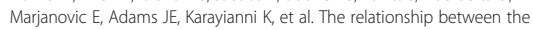
OSTEODENT index and hip fracture risk assessment using FRAX. Oral Surg Oral Med Oral Pathol Oral Radiol Endod. 2010;110:243-9.

8. United Nations Scientific Committee on the effects of Atomic Radiation (UNSCEAR): Hereditary effects of radiation. UNSCEAR 2001 Report to the General Assembly, with Scientific Annex. http://www.unscear.org/docs/ publications/2001/UNSCEAR_2001_Report.pdf. Accessed 13 September 2018.

9. Greenberg BL, Glick M, Frantsve-Hawley J, Kantor ML. Dentists' attitudes toward chairside screening for medical conditions. J Am Dent Assoc. 2010; 141:52-62.

10. Laurence B. Dentists consider medical screening important and are willing to incorporate screening procedures into dental practice. J Evid Based Dent Pract. 2010;10:254-6.

11. Greenberg BL, Kantor ML, Jiang SS, Glick M. Patients' attitudes toward screening for medical conditions in a dental setting. J Public Health Dent. 2012;72:28-35.

12. Creanor S, Millward BA, Demaine A, Price L, Smith W, Brown N, Creanor SL. Patients' attitudes towards screening for diabetes and other medical conditions in the dental setting. Br Dent J. 2014;216:E2.

13. Gullberg J, Axtelius B, Horner K, Devlin H, Lindh C, Poulsen L. Osteoporosis risk assessment in primary dental care - the attitudes of Swedish dentists, patients and medical specialists. Submitted to Gerodontology 2019.

14. Heintz E, Gerber-Grote A, Ghabri S, Hamers FF, Rupel VP, Slabe-Erker R, Davidson T. EUnetHTA. Is there a european view on health economic evaluations? Results from a synopsis of methodological guidelines used in the EUnetHTA partner countries. Pharmacoeconomics. 2016;34:59-76.

15. Drummond M, Sculpher M, Torrance G, O'Brien B, Stoddard G. Methods for the economic evaluation of health care programmes. 4th ed. Oxford: Oxford University Press; 2015

16. Statistics Sweden (SCB): population after age and year. http://www. statistikdatabasen.scb.se/pxweb/sv/ssd/START_BE_BE0101_BE0101A BefolkningNy/table/tableViewLayout1/?rxid=e963be29-5c21-4bf5-9a6448c0b47d85a8. Accessed 2018.

17. Oscarson N, Lindholm L, Källestål C. The value of caries preventive care among 19-year olds using the contingent valuation method within a costbenefit approach. Community Dent Oral Epidemiol. 2007:35:109-17.

18. Nayak S, Roberts MS, Greenspan SL. Osteoporosis screening preferences of older adults. J Clin Densitom. 2009;12:279-86.

19. Lin PJ, Cangelosi MJ, Lee DW, Neumann PJ. Willingness to pay for diagnostic technologies: a review of the contingent valuation literature. Value Health. 2013;16:797-805.

20. Cunningham SJ, Hunt NP. Relationship between utility values and willingness to pay in patients undergoing orthognathic treatment community dent health, vol. 17; 2000. p. 92-6.

21. Birch S, Sohn W, Ismail Al, Lepkowski JM, Belli RF. Willingness to pay for dentin regeneration in a sample of dentate adults. Community Dent Oral Epidemiol. 2004;32:210-6.

22. van Steenberghe $D$, Bercy $P$, De Boever J, Adriaens P, Geers $L_{\text {, Hendrickx } E_{f}}$ Adriaenssen C, Rompen E, Malmenäs M, Ramsberg J. Patient evaluation of a novel non-injectable anesthetic gel: a multicenter crossover study comparing the gel to infiltration anesthesia during scaling and root planing J Periodontol. 2004;75:1471-8

23. Esfandiari S, Lund JP, Penrod JR, Savard A, Thomason JM, Feine JS. Implant overdentures for edentulous elders: study of patient preference. Gerodontology. 2009;26:3-10.

24. Olsen JA, Smith RD. Theory versus practice: a review of 'willingness-to-pay' in health and health care. Health Econ. 2001;10:39-52.

25. Whynes DK, Wolstenholme JL, Frew E. Evidence of range bias in contingent valuation payment scales. Health Econ. 2004;13:183-90.

26. Tan SHX, Vernazza CR, Nair R. Critical review of willingness to pay for clinical oral health interventions. J Dent. 2017;46:1-12. 
27. Donaldson C, Thomas R, Torgerson DJ. Validity of open-ended and payment scale approaches to eliciting willingness to pay. Appl Econ. 1997;29:79-84.

28. Mobley LR, Hoerger TJ, Wittenborn JS, Galuska DA, Rao JK. Cost-

effectiveness of osteoporosis screening and treatment with hormone replacement therapy, raloxifene, or alendronate. Med Decis Mak. 2006;26: 194-206.

29. Nayak S, Roberts MS, Greenspan SL. Cost-effectiveness of different screening strategies for osteoporosis in postmenopausal women. Ann Intern Med. 2011;155:751-61.

- fast, convenient online submission

- thorough peer review by experienced researchers in your field

- rapid publication on acceptance

- support for research data, including large and complex data types

- gold Open Access which fosters wider collaboration and increased citations

- maximum visibility for your research: over 100M website views per year

At $B M C$, research is always in progress.

Learn more biomedcentral.com/submission 
III 



\title{
RESEARCH ARTICLE The challenge of applying digital image processing software on intraoral radiographs for osteoporosis risk assessment
}

\author{
${ }^{1}$ Joanna Gullberg, ${ }^{2}$ Ayman Al-Okshi, ${ }^{1}$ Dalia Homar Asan, ${ }^{1}$ Anita Zainea, ${ }^{3}$ Daniel Sundh, \\ ${ }^{3,4,5}$ Mattias Lorentzon and ${ }^{1}$ Christina Lindh \\ ${ }^{1}$ Faculty of Odontology, Malmö University, Malmö, Sweden; ${ }^{2}$ Department of Oral Medicine and Radiology, Faculty of Dentistry, \\ Sebha University, Sebha, Libya; ${ }^{3}$ Sahlgrenska Osteoporosis Centre, Department of Internal Medicine and Clinical Nutrition, \\ Institute of Medicine, University of Gothenburg, Gothenburg, Sweden; ${ }^{4}$ Region Västra Götaland, Department of Geriatric \\ Medicine, Sahlgrenska University Hospital, Mölndal, Sweden; ${ }^{5}$ Mary MacKillop Institute for Health Research, Australian \\ Catholic University, Melbourne, VIC, Australia
}

Objectives: The purpose of this study was to evaluate rater agreement and the accuracy of a semi-automated software and its fully automated tool for osteoporosis risk assessment in intraoral radiographs.

Methods: A total of 567 intraoral radiographs was selected retrospectively from women aged 75-80 years participating in a large population-based study (SUPERB) based in Gothenburg, Sweden. Five raters assessed participants' risk of osteoporosis in the intraoral radiographs using a semi-automated software. Assessments were repeated after 4 weeks on 121 radiographs $(20 \%)$ randomly selected from the original 567 . Radiographs were also assessed by the softwares' fully automated tool for analysis.

Results: Overall interrater agreement for the five raters was 0.37 (95\% CI $0.32-0.41)$, and for the five raters with the fully automated tool included as 'sixth rater' the overall Kappa was 0.34 $(0.30-0.38)$. Intrarater agreement varied from moderate to substantial according to the Landis and Koch interpretation scale. Diagnostic accuracy was calculated in relation to reference standard for osteoporosis diagnosis which is T-score values for spine, total hip and femoral neck and presented in form of sensitivities, specificities, predictive values, likelihood ratios and odds ratios. All raters' mean sensitivity, including the fully automated tool, was $40,4 \%$ (range 14,3\%-57,6\%). Corresponding values for specificity was 69,5\% (range 59,7\%-90,4\%). The diagnostic odds ratios ranged between 1 and 2.7 .

Conclusion: The low diagnostic odds ratio and agreement between raters in osteoporosis risk assessment using the software for analysis of the trabecular pattern in intraoral radiographs shows that more work needs to be done to optimise the automation of trabecular pattern analysis in intraoral radiographs.

Dentomaxillofacial Radiology (2021) 50, 20210175. doi: 10.1259/dmfr.20210175

Cite this article as: Gullberg J, Al-Okshi A, Homar Asan D, Zainea A, Sundh D, Lorentzon M, et al. The challenge of applying digital image processing software on intraoral radiographs for osteoporosis risk assessment. Dentomaxillofac Radiol 2021; 50: 20210175.

Keywords: Dental Digital Radiography; Computer-Assisted Image Analysis; Data Accuracy; Osteoporosis; Risk assessment

\section{Introduction}

In 1994, osteoporosis was defined by WHO as a systematic skeletal disease characterised by low bone mass

Correspondence to: Mrs Joanna Gullberg, E-mail: joanna.gullberg@mau.se

Received 12 April 2021; revised 08 June 2021; accepted 06 July 2021 and microstructural deterioration of bone tissue with a consequent increase in bone fragility and susceptibility to fracture. ${ }^{1}$ Osteoporotic fractures are common and approximately $50 \%$ of females over 50 years of age will sustain a fragility fracture during their remaining 
lifetime. ${ }^{2}$ In 2010, three and a half million osteoporotic fractures occurred in the EU at an annual cost of 37 billion Euro. ${ }^{3}$ The number of fractures is expected to rise to four and a half million and cost 46.8 billion Euro by $2025 .{ }^{3}$ In females, the increase is most prominent after the age of 70 . In Sweden, the annual number of osteoporotic fractures is almost 70,000 and vertebral fractures are the most common. ${ }^{4}$

Osteoporosis is one risk factor for fracture and the diagnosis of osteoporosis mainly relies on the measurement of bone mineral density (BMD) by dual-energy X-ray absorptiometry (DXA). ${ }^{5}$ The operational definition of osteoporosis is based on the T-score for BMD assessed by DXA at the femoral neck or spine and is defined as a value for BMD 2.5 SD or more below the young female adult mean. ${ }^{6}$ A major challenge in managing osteoporosis is identifying affected individuals before the condition is established and fracture has occurred. Even though bone density measurement plays a vital role in examining individuals with multiple risk factors in order to predict their fracture risk, there is currently no scientific evidence to support the use of bone density measurement as a screening method in healthy, middle-aged individuals. ${ }^{7}$

It is known that a correlation exists between BMD of the jaws and other skeletal sites, ${ }^{8-11}$ and studies have also shown that patients with osteoporosis have an altered trabecular pattern in the jaws compared with normal subjects. ${ }^{12}$ Based on these conclusions, methods have been developed and applied on intraoral dental radiographs, with the goal of identifying individuals at risk of or with osteoporosis. Visual assessment, categorising the trabecular patter into dense homogeneous, heterogeneous, or sparse homogeneous in intraoral radiographs of the premolar region of both upper and lower jaw showed a potential to identify females at risk of having osteoporosis $^{13}$ as well as for prediction of skeletal fractures. $^{14}$ Most adults in Sweden frequently visit their dentist where radiographs are taken on a regular basis ${ }^{15}$ for diagnostic purposes, and an opportunity exists to incorporate osteoporosis risk assessment into dental clinical practice using radiographs already taken in the dental setting.

Visual assessments have the drawback of being rater dependent which means they rely on human perception, and thus some degree of error is likely inevitable even with experienced raters. ${ }^{16}$ Digital image processing software have been applied to overcome this issue in an attempt to automate the process of analysis of trabecular pattern in intraoral dental radiographs. ${ }^{12,17-20}$ However, most software are based on a semi-automated approach where a rater applies the region of interest on a specific part of the image. As little as $0.10 \mathrm{~cm}^{2}$ of interdental bone of the premolar area on intraoral dental radiographs has been proved to be large enough to enable prediction of femoral and spinal BMD and thus osteoporosis. ${ }^{21}$
Most studies are performed on radiographs obtained under controlled conditions within academic research projects and not on radiographs obtained during everyday clinical work in a primary dental setting..$^{13,18}$ Furthermore, as for all diagnostic methods, agreement and accuracy are important concepts and agreement studies using digital image analysis software are infrequently reported.22 Even though an image processing algorithm is applied, these are often based on a semiautomated approach that does not entirely neglect the influence of its user. To the best of our knowledge, no study has evaluated rater agreement when using software for analysis of the trabecular bone pattern in intraoral dental radiographs. Therefore, this study aimed to investigate rater agreement and the diagnostic accuracy of one semi-automated software and its fully automated tool in osteoporosis risk assessment based on the analysis of trabecular pattern in intraoral dental radiographs obtained in a primary dental setting.

\section{Methods and materials}

This is a retrospective rater-based study on agreement and reliability when using semi-automated software for analyses of bone tissue in intraoral radiographs. It was conducted, analysed, and reported in accordance with the Guidelines for Reporting Reliability and Agreement Studies (GRRAS). ${ }^{23}$

\section{Subjects}

A population-based, prospective study (Sahlgrenska University hospital Prospective Evaluation of Risk of Bone fractures-The SUPERB study) was based in Gothenburg, Sweden, between the years 2013 and 2016. A national population register was used to identify females aged 75-80 years living within the greater Gothenburg area. Those who were ambulant, able to follow instructions in Swedish and had at least one hip that could be evaluated for BMD were included in the study. ${ }^{24,25}$ The study included 3028 elderly females. All study subjects gave their informed consent, and the study protocol was approved by the Ethical Review Board at the University of Gothenburg (Dnr T297-15/ Ad 929-12).

\section{Dual-energy X-ray absorptiometry}

Areal (a) BMD of the hip and spine was measured by dual-energy X-ray absorptiometry (DXA) device, Hologic Discovery A (S/N 86491) (Waltham, MA) on most participants $(n=2995)$. The National Health and Nutrition Examination Survey (NHANES) III reference database for femoral neck and total hip in 20-29 year-old Caucasian females as well as the Hologic material for lumbar spine consisting of 30-year-old Caucasian American females were used to calculate the corresponding T-scores. ${ }^{26}$ Due to machine failure, a small proportion of females $(n=33)$ was measured with 


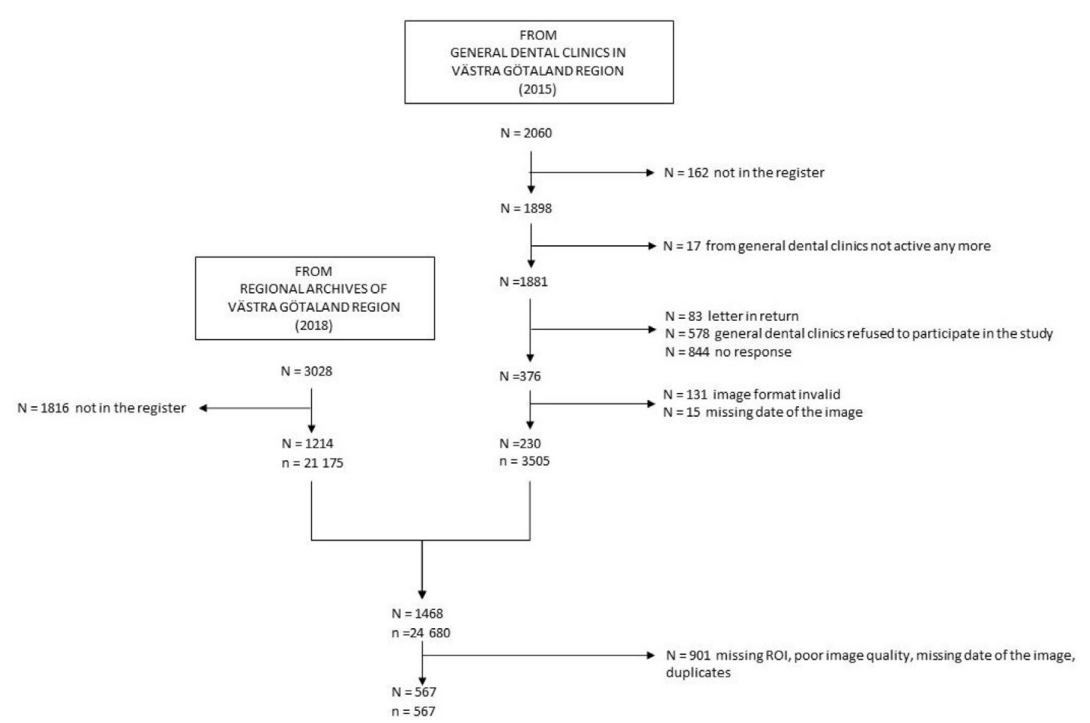

Figure 1 Flow chart of participant recruitment and data collection. $N$, number of study participants; $n$, number of dental radiographs; ROI, region of interest

another Hologic Discovery A DXA device (Waltham, MA). The potential discrepancy between the two machines was taken into account by performing a crosscalibration described elsewhere. ${ }^{27}$

\section{Collection of dental radiographs}

A flow chart illustrating the collection of images is shown in Figure 1. In 2015, data on 2060 participants out of 3028 from the SUBERB study ${ }^{27}$ were available. The social security numbers of these study participants were sent to the Swedish National Insurance Agency requesting data on dental examinations during 2010-2015 in the Västra Götaland region of Sweden, including dental radiographic examinations. A total of 9303 dental examinations were found on 1898 participants from 337 clinics. Letters with lists of patients were sent to the clinics requesting that they send digital as well as analogue radiographs obtained as part of a dental examination. Radiographs from 376 patients were collected from 83 responding clinics. Invalid image format and missing date on the images reduced the amount to 230 study participants, 3505 images. Due to poor response rates from the clinics in the first round of collection of images in 2015, data on all 3028 participants from the SUPERB study were also requested from the regional archives of Västra Götaland that stores data for public healthcare clinics in 2018. We received images from 1214 patients and as we received all radiographic images from all examinations performed of the patient at the clinic, regardless of our inclusion criteria, this gave us a total of 21,175 images. Duplicates of images from the first and second data collection were removed. Thereafter, a selection of images took place according to the following criteria: (a) vertical bitewing and/or periapical image including ROI between roots of premolars in the lower jaw (b) acceptable image quality including projection geometry, resolution, sharpness and contrast (c) image taken within 3 years before or after DXA examination. First, a rough selection was performed by the first author. The most common reasons for excluding images from the analysis were missing region of interest, poor image quality, image too old, or unknown date. Two authors made the second selection of images based on image quality and closest in date to DXA examination. After the final selection 567 images, from the same number of patients remained for analysis. All DICOM images were converted to JPG format using Image J software (Rasband, W.S., Image J, U. S. National Institutes of Health, Bethesda, Maryland, 1997-2018). Analogue images were scanned with 1000 dpi using UMAX Mirage IIse (Umax Technologies, Inc., Hsinchu, Taiwan) flatbed scanner.

Digital image analysis software

The software (Boneprox ${ }^{\circ}$, Gothenburg, Sweden) is based on a bilinear filter where the reference size is chosen to be small enough to remove noise but still retain the trabecular pattern to be assessed automatically. The 


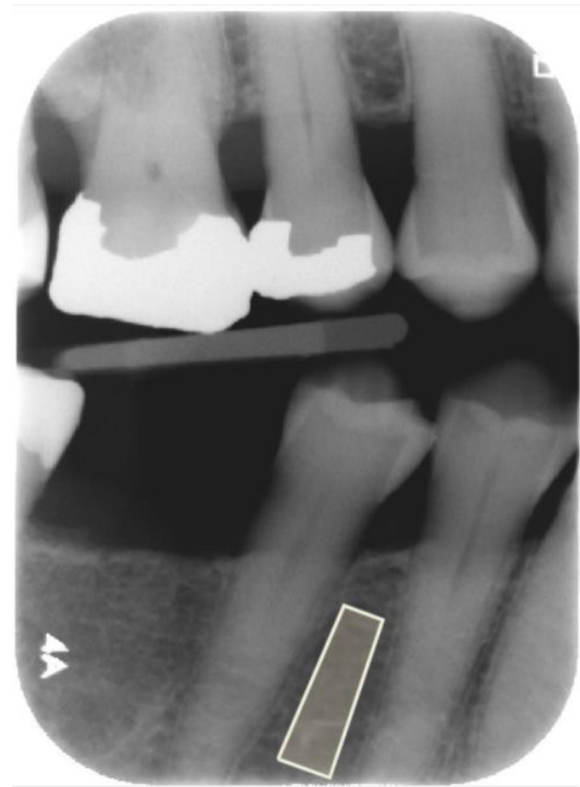

Figure 2 An example of a dental radiograph uploaded to the software with the trapezoid marker symbolising ROI manually placed between the roots/apices of premolar area in the lower jaw. ROI, region of interest.

grey levels in the image are reduced to 8-bit data and linearly stretched to cover all intensities. A median filter minimises noise in the image. The analysis progresses by identifying the minimum and mean value within a $9 \times$ 9 neighbourhood to every pixel and focusing only on the bone tissue. The software searches for a pattern to recognise trabecula and separates them from the voids. If too many pixels are classified as a trabecula (and thus too little space) the threshold is reduced, and the process repeated. The threshold value was chosen from the reference material. ${ }^{13}$ Afterwards, the distance transform is applied, first to measure from each pixel within every trabecula the closest bone space and then measure the size of the space between trabeculae. The largest intertrabecular space is identified, after that the second largest, until the 20 largest spaces are found. The assessed trabecular pattern is enclosed within a trapezoid marker symbolising ROI (Figure 2) that needs to be manually placed in order to perform the analysis. The marker is fixed in size and shape but could be moved and rotated. Only pixel data within the area of the marker are considered for the analysis. The area within the marker is resampled in size to make the resulting image match a fixed reference size. A novel technology has been introduced to the software that fully automates the whole process from placement of the trapezoid marker to the analysis of the trabecular pattern within. In other words, the fully automated tool removes the method's dependency on its user. The details of this technology are a corporate secret and cannot be included in this paper. The final resulting value represents the sum of the sizes and intensities of the spaces between the trabeculae. Values are between approximately 3000 (dense bone structure) and 9500 (sparse bone structure, i.e. large gaps between trabeculae). Values higher than 6500 denoted risk of osteoporosis according to the manufacturer's manual.

\section{Analyses}

Five raters performed analyses of the intraoral images using semi-automated software. Of the five raters one is a specialist in dental and maxillofacial radiology with 30 years of experience. The second rater was a general dental practitioner with 6 years of clinical experience and a postdoc in dental and maxillofacial radiology. The third rater was a general dental practitioner with 5 years of clinical experience and a PhD student. The last two raters were recently graduated general dental practitioners with less than 1 year of clinical experience. In addition to the analysis performed by the raters, the images were subjected to analysis with a fully automated tool provided by the most recent version of the software.

Prior to the analyses, an information session on the purpose of the study and a calibration exercise took place with all the raters. The assessment instructions were specified both verbally and in writing. All raters were familiar with the handling of the software.

The images were uploaded to the software in JPEG (Joint Photographic Experts Group), TIFF (Tagged Image File Format) or BMP format (Bitmap image file format; 8-bit greyscale). A trapezoid marker symbolising ROI was manually placed with the raters between the roots/apices of the premolar area in the lower jaw (Figure 2). In the case of analysis by the fully automated tool the trapezoid marker was placed by the software itself. The trabecular pattern was assessed by the algorithm provided in the software.

All raters performed the analyses independently of each other at their own location using computer screens with resolution $1920 \times 1080$. The observation rooms were dimly lit as recommended by the American Association of Physicists in Medicine Task Group. ${ }^{28}$ The distance to the screen was approximately $50 \mathrm{~cm}$. There was no restriction regarding observation time. All raters were blinded to clinical features such as the patients' age, previous medical history and individual DXA results. Software developed for the purpose performed a random selection of 121 images $(20 \%)$ for the second round of observations performed by all raters, except for the fully automated tool, after 4 weeks.

\section{Statistical methods}

Rater agreement for categorical data was established through $\kappa$ value using SPSS software v. 24.0 for Windows 
(IBM Corp., Armonk, NY). Pairwise interrater agreement was calculated to define the reliability between the investigator's evaluation for each case. Intrarater agreement was calculated based on the reliability of the individual investigators between the first and the second analysis. Fleiss' $\kappa$ was used to calculate the rater agreement between all the raters with and without the fully automated tool. Fleiss' $\kappa$ was calculated using STATA software v. 16 for Windows (StataCorp LLC, College Station, TX). Sensitivity, specificity, predictive values as well as likelihood ratios and accuracy were calculated using the online statistical calculator MedCalc ${ }^{\mathbb{B}}(\mathrm{Med}-$ Calc Software, Ostend, Belgium). ${ }^{29}$ To examine differences between groups for dichotomised variables we used $\chi 2$ test calculated using Chi-Square Calculator. ${ }^{30}$

\section{Results}

In this study, 567 radiographs that met the inclusion criteria were selected through consensus reached between the two authors. One radiograph was chosen for each participant.

The results acquired from the analyses were dichotomised into low and high risk of osteoporosis with a threshold value of 6500 units in agreement with the manufacturer's manual. The distribution of raters and the fully automated tool assessments into two groups according to the subjects' risk for osteoporosis is presented in Table 1. The number of subjects assessed as having high risk of osteoporosis ranged between 52 and 211. There was a difference between the raters in the number of radiographs excluded due to being deemed not possible to assess. Rater 1 did not exclude any radiographs, while Rater 4 excluded 149 out of 567 radiographs.

Tables 2 and 3 present $\kappa$ values for pairwise inter- and intrarater agreement, respectively. Following Landis and $\mathrm{Koch}^{31}$ interpretation scale, pairwise agreement between the five raters varies from fair to moderate. Agreement between the five raters and the softwares' fully automated tool is mostly fair. Intrarater agreement varies from moderate to substantial. ${ }^{31}$ Overall interrater agreement $\kappa$ values for the five raters was $0.37(95 \% \mathrm{CI}$

Table 1 Distribution of assessments dichotomised into low and high risk of osteoporosis with the threshold value of 6500 units for five raters and the fully automated tool (Auto.tool)

\begin{tabular}{lcrr}
\hline Rater & $\begin{array}{l}\text { Low risk of } \\
\text { osteoporosis } \\
(<6500)\end{array}$ & $\begin{array}{l}\text { High risk of } \\
\text { osteoporosis } \\
(\geq 6500)\end{array}$ & $\begin{array}{l}\text { Missing } \\
\text { values }\end{array}$ \\
\hline 1 & 423 & 144 & 0 \\
2 & 446 & 52 & 69 \\
3 & 351 & 211 & 5 \\
4 & 255 & 163 & 149 \\
5 & 332 & 201 & 34 \\
Auto.tool & 290 & 204 & 73 \\
\hline
\end{tabular}

$0.32-0.41$ ), and for the five raters with the fully automated tool included as a "sixth rater", the overall $\kappa$ was $0.34(0.30-0.38)$.

Figure 3, Table 4 show the diagnostic accuracy of osteoporosis risk assessment by five raters using the software as well as for the fully automated tool. The diagnostic accuracy was presented as means of specificity, sensitivity, predictive values, likelihood and odds ratio. The analysis was performed on dichotomised data with the threshold value of 6500 units in agreement with the manufacturers' manual. Accuracy was calculated in relation to reference standard for osteoporosis diagnosis which is T-score values for spine, total hip and femoral neck, respectively where values lower than -2.5 were denoted osteoporotic. With values higher than 6500 units as an indicator of high risk of osteoporosis in intraoral radiography, the mean sensitivity of all raters' including the fully automated tool was $40,4 \%$ (range $14,3-57,6 \%$ ). The corresponding value for specificity was $69,5 \%$ (range 59,7-90,4\%). There are large differences between the five raters. Rater 2 stood out in comparison to the others with low sensitivity values $(18.4 \%, 22.6 \%$ and 14. $3 \%$ for T-score spine, T-score total hip and T-score femoral neck, respectively) and high specificity $(90.4 \%$, $90.4 \%$ and $90.1 \%$ ). The fully automated tool sensitivity varies from $45.6 \%$ for $\mathrm{T}$-score spine, $57.6 \%$ for T-score total hip to $49.3 \%$ for T-score femoral neck. Specificity of the fully automated tool for T-score spine was $68.8 \%$ which was higher than its specificity for T-score total hip and femoral neck (59.7 and 59.9\%). The diagnostic odds ratios vary between 1 and 2.7.

Because the interval for collection of radiographs was relatively wide ( \pm 3 years from DXA examination) in order to control for the possibility of influence on the bone tissue and thus the results of the analysis, we performed a $\chi 2$ test for the analysis between groups based on their previous history of medication with antiosteoporotic drugs. We investigated if there was a difference between the group of study participants who either had been treated with osteoporosis medication before the study or at the start of the study with the group of study participants who never underwent osteoporosis treatment. The results were only statistically significant in two cases of specificity for two raters (Rater 2 and Rater 5 ) and the fully automated tool. There was no significant difference in sensitivity between the groups.

\section{Discussion}

The findings of this study show that even when a computer-based tool for assessment of trabecular bone pattern is used, there is variation among raters regarding where to apply the tool and subsequently the result of the assessments varies. We chose to evaluate one computer-based tool that is currently marketed to general dental practitioners as a way of identifying individuals with osteoporosis or at risk of developing osteoporosis. 
Table 2 Pairwise interrater agreement calculated as unweighted $\kappa$ for five raters and the fully automated tool (Auto.tool) with $95 \% \mathrm{CI}$

\begin{tabular}{lcrrr}
\hline$\kappa$ & Rater 2 & Rater 3 & Rater 4 & Rater 5 \\
\hline Rater 1 & $0,29(0,19-0,38)$ & $0,39(0,31-0,46)$ & $0,42(0,33-0,51)$ & $0,44(0,36-0,51)$ \\
Rater 2 & & $0,21(0,14-0,28)$ & $0,24(0,16-0,31)$ & $0,25(0,18-0,32)$ \\
Rater 3 & & $0,41(0,32-0,50)$ & $0,16(0,09-0,23)$ \\
Rater 4 & & & $0,46(0,38-0,53)$ \\
Rater 5 & & & $0,28(0,20-0,37)$ \\
\hline
\end{tabular}

CI, confidence interval.

The software algorithm used in this study can be classified as artificial intelligence (AI). Although there is no straightforward definition, $\mathrm{AI}$ is considered to be the capability of a machine to imitate intelligent human behaviour. ${ }^{32}$ Image processing and computer vision are both examples of AI applied in the field of medicine. Image processing is defined as a mathematical process enhancing an image to retrieve specific information like pattern measurements. Computer vision is defined as the processing of an image to enable identification of the image input and to provide an appropriate output. ${ }^{33}$ Boneprox software algorithm falls perfectly under these definitions. However, its limitation lies in the fact that it has been developed and trained on the same small set of radiographs. While there are techniques that have been proved to successfully fine-tune a softwares' capability of recognising specific patterns using a limited amount of data ${ }^{34}$ the results of this study show that the software for trabecular pattern analysis in intraoral radiographs requires further work. Possibly Boneprox algorithm could improve its skills by training on a larger, more versatile volume of images and using a convolutional neural network (CNN), another form of AI. CNN has yielded impressive results in diagnosis and prediction within other fields of odontology, ${ }^{35}$ such as diagnosing caries or periapical lesions. ${ }^{36-38}$

It has been suggested that the digitalisation of dental offices, including dental radiography, might lead to the development of software for trabecular pattern analysis on a large scale. Such a tool could be well suited for identifying individuals with or at risk of developing osteoporosis performed on a large number of radiographs already collected for diagnostic reasons ${ }^{39}$ Several digital image processing techniques have been designed to measure and describe the structure of the trabecular pattern. Algorithms based on a binary, skeletonised

Table 3 Intrarater agreement calculated as unweighted $\kappa$ for five raters with $95 \% \mathrm{CI}$

\begin{tabular}{lc}
\hline Rater & Intrarater agreement \\
\hline 1 & $0,57(0,40-0,73)$ \\
2 & $0,73(0,48-0,98)$ \\
3 & $0,49(0,33-0,66)$ \\
4 & $0,70(0,53-0,87)$ \\
5 & $0,65(0,50-0,80)$ \\
\hline
\end{tabular}

CI, confidence interval. version of the image have been constructed for the sole purpose of analysing morphological variables of trabecular bone tissue, including trabecula and the intertrabecular spaces. These structures were chosen as they were considered to be related to each other (together they fill up the image) but with different properties that could influence the outcome of the analysis. Software were applied on among others iliac crest, ${ }^{40,41}$ femoral
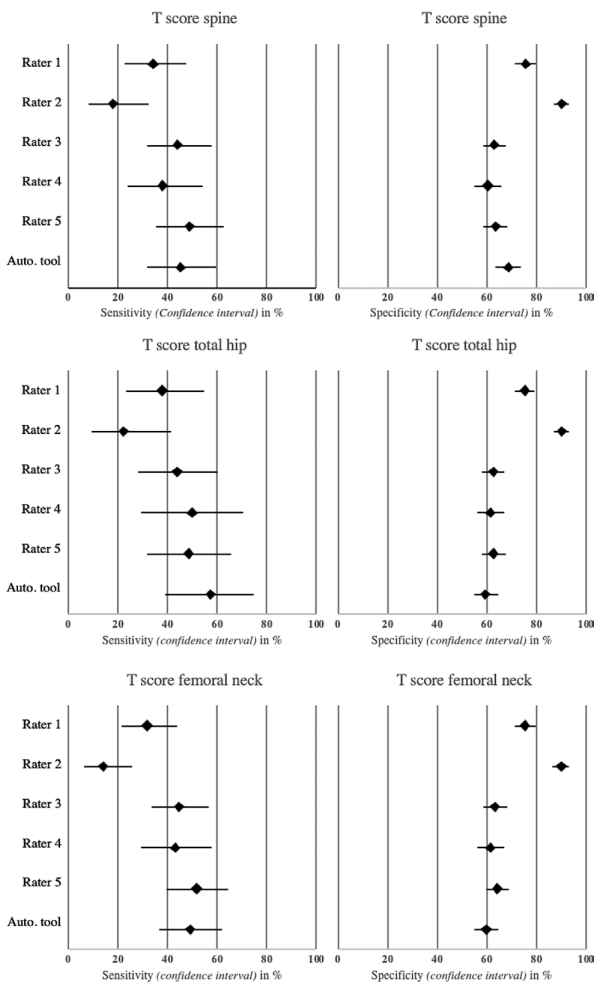

Figure 3 Sensitivity and specificity for five raters and the fully automated tool (Auto.tool) using the cut-off value of 6500 units indicating osteoporosis. 
Table 4 Diagnostic accuracy for five raters and the fully automated tool (Auto.tool) for osteoporosis risk assessment in intraoral radiographs calculated as sensitivities, specificities, positive and negative predictive values with $95 \%$ CI and positive and negative likelihood ratios and odds ratio

\begin{tabular}{|c|c|c|c|c|c|c|c|c|c|c|c|c|}
\hline T-score & Rater & \multicolumn{2}{|c|}{ Sensitivity [\%] } & \multicolumn{2}{|c|}{ Specificity [\%] } & \multicolumn{4}{|c|}{ Predictive values [\%] } & \multicolumn{2}{|c|}{ Likelihood ratio } & Odds ratio \\
\hline & 1 & 34,4 & $23,0-47,3$ & 75,9 & $71,9-79,5$ & 15,4 & $11,1-20,9$ & 90,1 & $88,3-91,6$ & 1,4 & 0,9 & 1,6 \\
\hline \multirow[t]{4}{*}{ Spine } & 3 & 44,4 & $31,9-57,5$ & 63,4 & $59,0-67,6$ & 13,3 & $10,2-17,2$ & 90,0 & $87,7-91,9$ & 1,2 & 0,9 & 1,4 \\
\hline & 4 & 38,3 & $24,5-53,6$ & 60,8 & $55,6-65,8$ & 11,0 & $7,8-15,4$ & 88,6 & $85,9-90,8$ & 1,0 & 1,0 & 1,0 \\
\hline & 1 & 38,1 & $23,6-54,4$ & 75,6 & $71,7-79,2$ & 11,1 & $7,6-15,9$ & 93,8 & $92,3-95,1$ & 1,6 & 0,8 & 1,9 \\
\hline & 2 & 22,6 & $9,6-41,1$ & 90,4 & $87,3-92,9$ & 13,5 & $7,1-24,0$ & 94,6 & $93,6-95,5$ & 2,3 & 0,9 & 2,7 \\
\hline \multirow[t]{3}{*}{ Hip } & 3 & 43,9 & $28,5-60,3$ & 62,9 & $58,6-67,1$ & 8,5 & $6,1-11,8$ & 93,4 & $91,5-95,0$ & 1,2 & 0,9 & 1,3 \\
\hline & 4 & 50,0 & $29,9-70,1$ & 61,7 & $56,7-66,6$ & 8,0 & $5,5-11,5$ & 94,9 & $92,6-96,5$ & 1,3 & 0,8 & 1,6 \\
\hline & 2 & 14,3 & $6,8-25,4$ & 90,1 & $86,9-92,8$ & 17,3 & $9,7-29,0$ & 88,0 & $86,7-89,0$ & 1,5 & 1,0 & 1,5 \\
\hline \multirow[t]{4}{*}{ Femoral neck } & 3 & 45,0 & $33,9-56,5$ & 63,6 & $59,1-67,9$ & 17,1 & $13,6-21,2$ & 87,4 & $84,9-89,6$ & 1,2 & 0,9 & 1,4 \\
\hline & 4 & 43,4 & $29,8-57,7$ & 61,6 & $56,4-66,7$ & 14,1 & $10,5-18,7$ & 88,2 & $85,4-90,6$ & 1,1 & 0,9 & 1,2 \\
\hline & 5 & 52,1 & $40,0-63,9$ & 64,5 & $59,9-68,9$ & 18,9 & $15,3-23,1$ & 89,4 & $86,8-91,6$ & 1,5 & 0,7 & 2,0 \\
\hline & Auto.tool & 49,3 & $36,8-61,8$ & 59,9 & $55,1-64,6$ & 16,3 & $12,9-20,3$ & 88,2 & $85,4-90,6$ & 1,2 & 0,9 & 1,5 \\
\hline
\end{tabular}

CI, confidence interval.

neck, ${ }^{42}$ vertebrae ${ }^{43}$ and distal radius. ${ }^{44,45}$ An equivalent method was applied on intraoral periapical radiographs in search for signs of osteoporosis showing architectural changes in the trabecular bone in osteoporotic individuals in comparison to healthy counterparts. ${ }^{12,17,18,46}$ Within the jaws, the premolar region of the lower jaw has been of particular interest due to little variation in anatomy and the lack of major muscular fibre insertion in this region. ${ }^{47}$ Another advantage of this region is that when no teeth are present, the mental foramen serves as a landmark for the region to assess. However, the method applied on intraoral radiographs was never taken to the next step of being tested in a large-scale population study. Another approach of automated analysis of trabecular pattern called Jax-X method, was also applied on intraoral radiographs with focus on identification of the analysis of intertrabecular spaces instead. ${ }^{48,49}$ The software investigated in this study is the next generation of the Jaw-X method. It is difficult to establish in detail what the similarities or differences between the software are since the algorithm is either developed and applied locally or protected by patent or trade secret.

Another issue with previous studies is that the study samples were usually small, with the smallest sample consisting of 23 individuals. ${ }^{12}$ Only one study presented a sample size big enough $(=671)$ to draw a reliable conclusion. ${ }^{18}$ We intended to analyse images from a big sample, which is why we decided to select images from patients taking part in the SUBERB study ${ }^{27}$ with 3028 participants. Due to difficulties in obtaining images from the clinics and image quality in many cases being too poor to allow analyses, the final number of radiographs available for analysis was 567 from the same number of patients, a sample size still superior to that used in several other studies.

On one hand, a prerequisite for any method, visual or computer-based, is that image quality regarding projection and exposure settings is close to optimal. In wellplanned prospective research projects, image quality is more likely to be optimal. On the other hand, a previous study has shown that many of the morphologic variables of trabecular bone are robust enough to withstand variation in exposure angle and image brightness (optical density). ${ }^{39}$ With this being our hypothesis and the fact that the software under investigation in this study is already being marketed to general dental practitioners in Sweden, we concluded that the method should be tested on radiographs obtained during routine clinical work in general dental practice. Therefore, we analysed radiographs collected retrospectively and taken in ordinary clinical settings.

It is tempting to believe that if using a computerbased tool, the influence of its user will be eliminated. However, unless fully automated, the impact of human interaction cannot be neglected. In this study, we used five raters to explore any differences in results between and within raters when using a computer-based digital 
image processing software. In addition, we applied a fully automated version of that software that was to be used without human interaction. When, for any reason, analyses or measurements are performed in radiographs, both agreement and reliability are important concepts as they provide information about the quality of measurements. ${ }^{23}$

To the best of our knowledge, no other study has compared rater agreement using semi-automated software for trabecular pattern analysis in dental radiographs. The degree of agreement between the raters in this study being only fair to moderate is comparable with the agreement between raters in previous studies using visual assessment method to assess trabecular pattern. ${ }^{13}$ Moreover, the degree of experience and expertise of raters in this study varied considerably, whilst in the study using a visual assessment approach, four out of five raters were highly trained in the field of oral radiology and had more than 20 years of experience. Additionally, the image acquisition in that study was more standardised and obtained in the controlled environment of specialist clinics. With that in mind, our study showed that the evaluated software achieved similar levels of inter- and intrarater agreement used on radiographs attained retrospectively from unknown conditions and analysed by raters with different levels of clinical experience. However, the fully automated tool built into the software to eliminate the user's influence showed only slight to fair agreement with the five raters, which indicates it needs further improvement before it can be recommended for commercial use.

Software accuracy has also been investigated through sensitivity and specificity analysis in relation to participants T-score values in spine, hip and femoral neck. In general, sensitivity was lower than the specificity for most raters and the fully automated tool. This agrees with previous studies investigating the same software sensitivity and specificity. ${ }^{48}$ The fully automated tools' sensitivity varied between 45.6 and $57.9 \%$ and specificity between 59.8 and $68.8 \%$, which means that its ability to identify individuals with risk of osteoporosis and individuals without risk of osteoporosis is almost equal. In other words, the fully automated tool would generate many false-positive and false-negative results at the general dental clinic. False-positive results are unwanted because it not acceptable to worry dental patients unnecessarily and refer them for DXA measurements. In contrast, false-negative results keep the patients unaware of a condition they might have that may lead to serious health issues such as fragility fracture.

A number of strengths and limitations of this study must be considered. One limitation of this study was the difficulty of collecting radiographs from general dental practitioners. We tried to retrieve images from general dental practices by contacting the clinics directly, however, with limited outcome. When using retrospectively collected images from different clinics, the information regarding image acquisition is limited. Different technologies for image acquisition (analogue radiographs scanned, digital radiographs) and various file formats (DICOM converted to JPEG, JPEG, TIFF and BMP) could also be a potential source of bias. Inclusion criteria for the radiographs followed previously established image quality criteria as well as the softwares' general requirements regarding ROI. Although clear quality criteria had been set before the assessments, there was a difference between the raters in how they judged the quality of a single radiograph to be sufficient for assessment. On one hand, this could be perceived as another source of bias, but it should also be seen as a strength of this study as it reflects the reality of general dental practice. Another limitation is that it was not possible to investigate the reproducibility of the fully automated tool. This tool could only be handled by the manufacturer and despite several inquiries we could not get the assistance.

The strength of this study is that it was part of a large population study which made it possible to acquire a large amount of material for analysis compared to many previous studies. Also, unique for this study is that the cohort (SUPERB) had a rather narrow age span (75-80 years) and that all participants underwent DXA examination, which enabled us to evaluate the accuracy of the software

\section{Conclusions}

The low diagnostic odds ratio and agreement between raters in osteoporosis risk assessment using the investigated software leads to the conclusion that more work needs to be done to optimise the automation process of analysis of the trabecular pattern in intraoral radiographs.

\section{Acknowledements}

Ingvar Kamprad Foundation, C O Henriksson Foundation and Swedish Dental Association financially supported the research for this paper. There is no conflict of interest. We gratefully acknowledge technical support from Michael Gullberg.

\section{Funding}

Ingvar Kamprad Foundation, C O Henriksson Foundation, Swedish Dental Association 


\section{REFERENCES}

1. Peck WA, Burckhardt P, Christiansen C, Fleisch HA, Genant HK, Gennari C. Consensus development conference: diagnosis, prophylaxis, and treatment of osteoporosis. Am J Med 1993; 94: 646-50. doi: https://doi.org/10.1016/0002-9343(93)90218-e

2. Sambrook P, Cooper C. Osteoporosis. Lancet 2006; 367: 2010-8. doi: https://doi.org/10.1016/S0140-6736(06)68891-0

3. Hernlund E, Svedbom A, Ivergård M, Compston J, Cooper C, Stenmark J, et al. Osteoporosis in the European Union: medica management, epidemiology and economic burden. A report prepared in collaboration with the International osteoporosis Foundation (IOF) and the European Federation of pharmaceutical industry associations (EFPIA. Arch Osteoporos 2013; 8: 136 doi: https://doi.org/10.1007/s11657-013-0136-1

4. Kanis JA, Johnell O, Oden A, Sembo I, Redlund-Johnell I, Dawson A, et al. Long-Term risk of osteoporotic fracture in Malmö. Osteoporos Int 2000; 11: 669-74. doi: https://doi.org/10.1007/ s001980070064

5. WHO Assessment of fracture risk and its application to screening for postmenopausal osteoporosis. Report of a who Study Group. World Health Organ Tech Rep Ser 1994; 843: 1-129.

6. Kanis JA, Cooper C, Rizzoli R, Reginster JY. Scientific Advisory Board of the European Society for $\mathrm{C}$, economic aspects of $\mathrm{O}$, et al. European guidance for the diagnosis and management of osteoporosis in postmenopausal women. Osteoporos Int 2019; 30 3-44.

7. SBU.Osteoporosis - prevention, diagnosis and treatment. Stockholm: Swedish Council on Health Technology Assessment in Health Care; 2003.

8. Horner K, Devlin H. Clinical bone densitometric study of mandibular atrophy using dental panoramic tomography. J Den 1992; 20: 33-7. doi: https://doi.org/10.1016/0300-5712(92)90007-y

9. Horner K, Devlin H, Alsop CW, Hodgkinson IM, Adams JE. Mandibular bone mineral density as a predictor of skeletal osteoporosis. Br J Radiol 1996; 69: 1019-25. doi: https://doi.org/10. 1259/0007-1285-69-827-1019

10. Taguchi A, Tanimoto K, Suei Y, Ohama K, Wada T. Relationship between the mandibular and lumbar vertebral bone mineral density at different postmenopausal stages. Dentomaxillofac Radiol 1996; 25: 130-5. doi: https://doi.org/10.1259/dmfr.25.3. 9084261

11. Lindh C, Obrant K, Petersson A. Maxillary bone mineral density and its relationship to the bone mineral density of the lumbar spine and hip. Oral Surg Oral Med Oral Pathol Oral Radiol Endod 2004; 98: 102-9. doi: https://doi.org/10.1016/s1079-2104(03) 00460-8

12. White SC, Rudolph DJ. Alterations of the trabecular pattern of the jaws in patients with osteoporosis. Oral Surg Oral Med Oral Pathol Oral Radiol Endod 1999; 88: 628-35. doi: https://doi.org/ 10.1016/s1079-2104(99)70097-1

13. Lindh C, Horner K, Jonasson G, Olsson P, Rohlin M, Jacobs R, et al. The use of visual assessment of dental radiographs for identifying women at risk of having osteoporosis: the OSTEODENT project. Oral Surg Oral Med Oral Pathol Oral Radiol Endod 2008; 106: 285-93. doi: https://doi.org/10.1016/j.tripleo. 2007.09.008

14. Jonasson G, Alstad T, Vahedi F, Bosaeus I, Lissner L, Hakeberg M Trabecular pattern in the mandible as bone fracture predictor. Oral Surg Oral Med Oral Pathol Oral Radiol Endod 2009; 108 e42-51. doi: https://doi.org/10.1016/j.tripleo.2009.05.018

15. Norderyd O, Kochi G, Papias A, Kohler AA, Helkimo AN, Brahm CO. Oral health of individuals aged 3-80 years in Jonkoping, Sweden, during 40 years (1973-2013). I. Review of findings on oral care habits and knowledge of oral health. Swed Dent J 2015; 39: $57-68$.

16. Waite S, Scott J, Gale B, Fuchs T, Kolla S, Reede D. Interpretive error in radiology. Am J Roentgenol Radium Ther 2017; 208: 739-49.

17. White SC, Cohen JM, Mourshed FA. Digital analysis of trabecular pattern in jaws of patients with sickle cell anemia. Dentomax- illofac Radiol 2000; 29: 119-24. doi: https://doi.org/10.1038/sj/ $\mathrm{dmfr} / 4600516$

18. Verheij JGC, Geraets WGM, van der Stelt PF, Horner K, Lindh C, Nicopoulou-Karayianni K, et al. Prediction of osteoporosis with dental radiographs and age. Dentomaxillofac Radiol 2009; 38: 431-7. doi: https://doi.org/10.1259/dmfr/ 55502190

19. Licks R, Licks V, Ourique F, Radke Bittencourt H, Fontanella V. Development of a prediction tool for low bone mass based on clinical data and periapical radiography. Dentomaxillofac Radiol 2010; 39: 224-30. doi: https://doi.org/10.1259/dmfr/23760876

20. Geraets WGM, Lindh C, Verheij H. Sparseness of the trabecular pattern on dental radiographs: visual assessment compared with semi-automated measurements. Br J Radiol 2012; 85: e455-60. doi: https://doi.org/10.1259/bjr/32962542

21. Geraets WGM, Verheij JGC, van der Stelt PF, Horner K, Lindh C, Nicopoulou-Karayianni $\mathrm{K}$, et al. Selecting regions of interest on intraoral radiographs for the prediction of bone mineral density. Dentomaxillofac Radiol 2008; 37: 375-9. doi: https://doi.org/10. $1259 / \mathrm{dmfr} / 29966973$

22. Farzin B, Gentric J-C, Pham M, Tremblay-Paquet S, Brosseau L, Roy C, et al. Agreement studies in radiology research. Diagn Interv Imaging 2017; 98: 227-33. doi: https://doi.org/10.1016/j.diii.2016. 05.014

23. Kottner J, Gajewski BJ, Streiner DL Guidelines for reporting reliability and agreement studies (GRRAS). Int J Nurs Stud 2011; 48: 659-60. doi: https://doi.org/10.1016/j.ijnurstu.2011.01.017

24. Larsson B, Mellström D, Johansson L, Nilsson AG, Lorentzon M, Sundh D. Normal bone microstructure and density but worse physical function in older women treated with selective serotonin reuptake inhibitors, a cross-sectional population-based study. Calcif Tissue Int 2018; 103: 278-88. doi: https://doi.org/10.1007/ s00223-018-0427-z

25. Nilsson AG, Sundh D, Johansson L, Nilsson M, Mellström D, Rudäng R, et al. Type 2 diabetes mellitus is associated with better bone microarchitecture but lower bone material strength and poorer physical function in elderly women: a population-based study. J Bone Miner Res 2017; 32: 1062-71. doi: https://doi.org/ $10.1002 / \mathrm{jbmr} .3057$

26. Looker AC, Wahner HW, Dunn WL, Calvo MS, Harris TB, Heyse SP, et al. Updated data on proximal femur bone mineral levels of US adults. Osteoporos Int 1998; 8: 468-89. doi: https:// doi.org/10.1007/s001980050093

27. Lorentzon M, Nilsson AG, Johansson H, Kanis JA, Mellström D, Sundh D. Extensive undertreatment of osteoporosis in older Swedish women. Osteoporos Int 2019; 30: 1297-305. doi: https://doi.org/10.1007/s00198-019-04872-4

28. Samei E, Badano A, Chakraborty D, Compton K, Cornelius C, Corrigan K, et al. Assessment of display performance for medical imaging systems: Executive summary of AAPM TG18 report. Med Phys 2005; 32: 1205-25. doi: https://doi.org/10.1118/1. 1861159

29. MedCalc.Diagnostic test evaluation calculator. 2021. Available from: https://www.medcalc.org/calc/diagnostic_test.php.

30. Stangroom J. Social Science Statistics. 2018. Available from: https://www.socscistatistics.com/tests/chisquare/default2.aspx.

31. Landis JR, Koch GG. The measurement of observer agreement for categorical data. Biometrics 1977; 33: 159-74.

32. Webster M. Definition: 'Artificial Intelligence. Available from: https://www.merriam-webster.com/dictionary/artificial\%20intelligence.

33. Mintz Y, Brodie R. Introduction to artificial intelligence in medicine. Minim Invasive Ther Allied Technol 2019; 28: 73-81. doi: https://doi.org/10.1080/13645706.2019.1575882

34. Lee K-S, Jung S-K, Ryu J-J, Shin S-W, Choi J. Evaluation of transfer learning with deep Convolutional neural networks for screening osteoporosis in dental panoramic radiographs. $J$ Clin Med 2020; 9: 392. doi: https://doi.org/10.3390/jcm9020392 
35. Schwendicke F, Golla T, Dreher M, Krois J Convolutional neural networks for dental image diagnostics: a scoping review. J Dent 2019; 91: 103226. doi: https://doi.org/10.1016/j.jdent.2019.103226

36. Lee J-H, Kim D-H, Jeong S-N, Choi S-H. Detection and diagnosis of dental caries using a deep learning-based convolutional neural network algorithm. J Dent 2018; 77: 106-11. doi: https:// doi.org/10.1016/j.jdent.2018.07.015

37. Pauwels R, Brasil DM, Yamasaki MC, Jacobs R, Bosmans H, Freitas DQ, et al. Artificial intelligence for detection of periapical lesions on intraoral radiographs: comparison between convolutional neural networks and human observers. Oral Surg Oral Med Oral Pathol Oral Radiol 2021; 131: 610-6. doi: https://doi.org/10. 1016/j.oooo.2021.01.018

38. Karatas O, Cakir NN, Ozsariyildiz SS, Kis HC, Demirbuga S, Gurgan CA. A deep learning approach to dental restoration classification from bitewing and periapical radiographs. Quintessence Int 2021; 52: 568-74. doi: https://doi.org/10.3290/j.qi.b1244461

39. White S. Influence of X-ray beam angulation and exposure on morphologic features of trabecular bone. Int J Oral Biol 1999; 24: $17-23$.

40. Compston JE, Mellish RW, Garrahan NJ. Age-Related changes in iliac crest trabecular microanatomic bone structure in man. Bone 1987; 8: 289-92. doi: https://doi.org/10.1016/8756-3282(87)900044

41. Croucher PI, Garrahan NJ, Compston JE. Structural mechanisms of trabecular bone loss in primary osteoporosis: specific disease mechanism or early ageing? Bone Miner 1994; 25: 111-21. doi: https://doi.org/10.1016/s0169-6009(08)80253-x

42. Geraets WG, Van der Stelt PF, Lips P, Van Ginkel FC. The radiographic trabecular pattern of hips in patients with hip fractures and in elderly control subjects. Bone 1998; 22: 165-73. doi: https:// doi.org/10.1016/s8756-3282(97)00233-0

43. Caligiuri P, Giger ML, Favus MJ, Jia H, Doi K, Dixon LB. Computerized radiographic analysis of osteoporosis: preliminary evaluation. Radiology 1993; 186: 471-4. doi: https://doi.org/10. 1148/radiology. 186.2.8421753

44. Geraets WG, Van der Stelt PF, Netelenbos CJ, Elders PJ. A new method for automatic recognition of the radiographic trabecular pattern. J Bone Miner Res 1990; 5: 227-33. doi: https://doi.org/10. 1002/jbmr.5650050305

45. Geraets WG, Van der Stelt PF, Elders PJ. The radiographic trabecular bone pattern during menopause. Bone 1993; 14: 859-64. doi: https://doi.org/10.1016/8756-3282(93)90315-2

46. Lee BD, White SC. Age and trabecular features of alveolar bone associated with osteoporosis. Oral Surg Oral Med Oral Pathol Oral Radiol Endod 2005; 100: 92-8. doi: https://doi.org/10.1016/ j.tripleo.2004.11.020

47. von Wowern N, Stoltze K. Histoquantitation on small jaw specimens. Scand J Dent Res 1978; 86: 193-9. doi: https://doi.org/10. 1111/j.1600-0722.1978.tb01931.x

48. Hassani-Nejad A, Ahlqwist M, Hakeberg M, Jonasson G Mandibular trabecular bone as fracture indicator in 80-year-old men and women. Eur J Oral Sci 2013; 121: 525-31. doi: https:/l doi.org/10.1111/eos.12087

49. Jonasson G, Billhult A. Mandibular bone structure, bone mineral density, and clinical variables as fracture predictors: a 15 -year follow-up of female patients in a dental clinic. Oral Surg Oral Med Oral Pathol Oral Radiol 2013; 116: 362-8. doi: https://doi.org/10. 1016/j.oooo.2013.06.009 


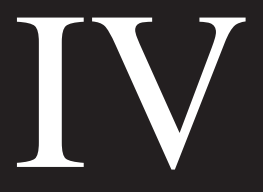





\section{TITLE:}

The outcome of an automated assessment of trabecular pattern in intraoral radiographs as a fracture risk predictor

\section{Authors list:}

Joanna Gullberg ${ }^{1}$, Daniel Sundh ${ }^{2}$, Lisa Johansson ${ }^{2,3}$, Per-Erik Isberg ${ }^{4}$, Mattias Lorentzon ${ }^{2,5,6}$, Christina Lindh $^{1}$

${ }^{1}$ Faculty of Odontology, Malmö University, Malmö, Sweden

${ }^{2}$ Sahlgrenska Osteoporosis Centre, Institute of Medicine, Sahlgrenska Academy, University of Gothenburg, Gothenburg, Sweden

${ }^{3}$ Region Västra Götaland, Department of Orthopaedics, Sahlgrenska University Hospital, Mölndal, Sweden

${ }^{4}$ Department of Statistics, Lund University School of Economics and Management, Lunds University, Lund, Sweden

${ }^{5}$ Mary MacKillop Institute for Health Research, Australian Catholic University, Melbourne, Australia.

${ }^{6}$ Region Västra Götaland, Geriatric Medicine, Sahlgrenska University Hospital, Mölndal, Sweden.

*Corresponding author: Joanna Gullberg, Faculty of Odontology, Malmö University, SE 20506 Malmö Sweden E-mail: Joanna.gullberg@mau.se

Conflicts of interest: Joanna Gullberg, Christina Lindh, Per-Erik Isberg, Daniel Sundh, Lisa Johansson and Mattias Lorentzon declare that they have no conflict of interest. 


\section{Abstract}

Purpose: This study aims to investigate if automated analyses of the trabecular pattern in intraoral radiographs independently contribute to fracture risk assessment when other risk factors incorporated in the Fracture Risk Assessment Tool (FRAX) are taken into account. A secondary aim is to explore the correlation between the automated trabecular pattern assessment in intraoral radiographs and Trabecular Bone Score (TBS).

Methods: A total of 567 intraoral radiographs from older women participating in a large population-based study (SUPERB) based in Gothenburg, Sweden, were selected for analysis of trabecular pattern using semi-automated and fully-automated software. Associations between trabecular pattern analysis and incident fractures were studied using Cox proportional hazard model, unadjusted and adjusted for FRAX risk factors (previous fracture, family history of hip fracture, smoking, corticosteroids, rheumatoid arthritis, without and with bone mineral density (BMD) of the femoral neck). Correlation between trabecular pattern analysis and TBS of the lumbar spine was investigated using Pearson correlation analysis.

Results: Neither the unadjusted nor the adjusted trabecular pattern analysis in intraoral radiographs was significantly associated with any fracture or major osteoporotic fracture (MOF). A weak correlation was found between semi-automated trabecular pattern analysis and TBS. No correlation was found between the fullyautomated trabecular pattern analysis and TBS.

Conclusion: The present study shows that semi-automated and fully-automated digital analyses of the trabecular pattern in intraoral radiographs do not contribute to fracture risk prediction. Furthermore, the study shows a weak correlation between semi-automated trabecular pattern analysis and TBS.

Keywords: Dental Digital Radiography; Computer-Assisted Image Analysis; Osteoporotic Fracture; Risk assessment 


\section{Introduction:}

Osteoporosis is defined as a systemic skeletal disease characterised by low bone mass and deterioration of bone tissue architecture, leading to an increased risk of fragility fractures [1]. Dual X-ray absorptiometry (DXA) is the validated reference standard for diagnosing osteoporosis. It gives bone mineral density (BMD) value, which is a major determinant of bone strength and fracture risk [2]. However, the method has its limitations [3], and considerable overlap exists between BMD values in patients with and without fractures [4], meaning that other factors influence bone strength. In an attempt to improve the estimation of 10-year fracture probability, a Fracture Risk Assessment (FRAX) tool was developed incorporating all recognised risk factors: sex, age, body mass index (BMI), previous fracture, a parent with hip fracture (heredity), current smoking, glucocorticoid use, rheumatoid arthritis (RA), secondary osteoporosis and alcohol intake [5, 6]. However, neither DXA nor FRAX can capture all skeletal determinants of bone strength. Trabecular Bone Score (TBS) is a novel tool created to reflect bone microarchitecture and is proposed to be used as a surrogate for bone strength $[7,8]$. TBS is applied directly on DXA machines and computed successively after the BMD measurement in the same region of interest (ROI) of the lumbar spine [8]. The method was first developed on micro-computed tomography $(\mu \mathrm{CT})$ slices and thereafter adapted for DXA images. A high TBS value reflects a dense trabecular microarchitecture and thus good mechanical strength of bone, while a low TBS value is associated with sparse microarchitecture [9]. Several studies confirm that TBS is an independent and significant risk factor for fragility fractures [10], and TBS has shown incremental improvement in fracture prediction when combined with FRAX [11], particularly for hip fracture outcomes.

Research has shown that a correlation exists between BMD of the jaws and other skeletal sites [12-15]. Furthermore, osteoporotic individuals have also demonstrated an altered trabecular pattern of the bone tissue in the jaws compared to healthy subjects [16]. Both visual assessment [17] and digital analyses [18] of the trabecular pattern In intraoral radiographs have shown the potential to identify women at risk of osteoporosis. Also, the possibility of using assessments of the trabecular pattern in intraoral radiographs to identify individuals at high risk of fracture has been proposed. Both visual assessments and assessments using different digital software $[19,20]$ showed promising results in predicting skeletal fractures. Most digital software is based on semi-automated applications where human influence cannot be neglected, but recently fully-automated software has been launched.

A majority of the Swedish population regularly visits their dentist for dental examinations, including radiographic examinations of the teeth and surrounding bone tissue [21]. The high frequency of visits to dental 
clinics is another reason why attempts have been made to use the resources available as an opportunity to incorporate osteoporosis and fracture risk assessment into dental clinical practice.

To the best of our knowledge, using a fully-automated software applied on intraoral radiographs and its possibility to predict skeletal fractures have not been investigated, neither has the correlation between TBS and trabecular pattern of the jaws.

Therefore, the present study aims to investigate if semi-automated and fully-automated digital analyses of the trabecular pattern in intraoral radiographs independently contribute to fracture risk assessment when other clinical risk factors incorporated in FRAX are taken into account. A secondary aim of this study is to explore the correlation between the automated trabecular pattern assessment in intraoral radiographs with TBS.

\section{Material and method}

This is a retrospective study on fracture risk assessment using semi-automated and fully-automated software to analyse bone tissue in intraoral radiographs.

\section{Subjects}

A total of 3028 older Swedish women (75-80 years) living within the greater Gothenburg area were recruited through a national population register for a population-based, prospective study (Sahlgrenska University hospital Prospective Evaluation of Risk of Bone fractures - The SUPERB study) between 2013-2016. Those who accepted and could participate (were ambulant and able to follow instructions in Swedish) were invited to a visit at the Osteoporosis Clinic, Department of Geriatrics, Sahlgrenska University Hospital, Mölndal, Sweden. [22, 23]. Prior to participation, all study subjects have given their informed consent. The Ethical Review Board approved the study protocol at the University of Gothenburg (Dnr T297-15/Ad 929-12).

\section{Dual-energy X-ray absorptiometry}

BMD measurements of total hip (TH), femoral neck (FN), lumbar spine $\mathrm{L}_{1}$ to $\mathrm{L}_{4}(\mathrm{LS})$ and $\mathrm{TBS}$ of $\mathrm{L}_{1}$ to $\mathrm{L}_{4}$ were performed by dual-energy X-ray absorptiometry (DXA) device, Hologic Discovery A (S/N 86491) (Waltham, MA, USA) on most participants of the SUPERB cohort $(n=2995)$. However, a small proportion of women $(n=$ 33) was measured with another Hologic Discovery A DXA device (Waltham, MA, USA) due to machine failure. The potential discrepancy between the two machines was considered by performing a cross-calibration study described elsewhere [24]. The BMD of the lumbar spine and TBS were calculated as the mean of L1 to L4, and any fractured vertebra or vertebra with osteosynthesis material was excluded. 


\section{Anthropometrics and questionnaire}

Body weight was measured to the nearest $0.1 \mathrm{~kg}$ using the same scale in all study participants. Body height was measured using a wall-mounted calibrated stadiometer. Data on clinical risk factors for fracture such as medical history, history of fracture, current smoking habits, parental history of hip fracture, oral glucocorticoids use for three months or more with prednisolone $5 \mathrm{mg}$ or equivalent, diabetes, rheumatoid arthritis, alcohol consumption were assessed by questionnaires. Self-reported fractures sustained after the age of 50 and at any location, except the skull and face, were included in the FRAX-score calculations. Current smoking was defined by a validated questionnaire [25]. A limit of 21 standard drinks per week was used as a definition of high alcohol consumption [26]. Medical history, including prior treatment for osteoporosis such as oral bisphosphonates (ongoing or within two years), zoledronic acid (ongoing or within three years), denosumab (ongoing or within one year), and teriparatide, was assessed by questionnaires.

\section{Incident fracture assessment}

Incident fractures were recorded using radiographs and radiology reports retrieved from the regional archive of Västra Götaland region. Research nurses initially reviewed the radiology reports and recorded all reported fractures. Then, an experienced orthopaedic surgeon examined all radiographs without available radiology reports or reports with uncertain fracture diagnoses. Major osteoporotic fractures (MOF) included clinical spine, hip, forearm, and proximal humerus fractures. All fractures included all incident fractures except for fractures of the skull and face.

\section{Collection of dental radiographs}

In 2015, during the ongoing SUPERB study, Swedish National Insurance Agency was asked for data on dental examinations (including dental radiographic examinations) from 2010-2015 on a subpopulation consisting of the first 2060 consecutively included women. A total of 1898 participants were found in the register. Letters requesting intraoral radiographs were sent to the involved clinics. Due to the poor response rate, a decision has been made not to claim data on the remaining study participants recruited in 2016. Instead, in 2017 data on all 3028 participants was requested from regional archives of Västra Götaland region resulting in 21175 dental radiographs from 1214 participants. Images from both rounds of data collection were put together, duplicates were removed, and a selection of images took place according to the following criteria: (a) vertical bitewing and/or periapical image including a ROI between roots of premolars in the lower jaw (b) acceptable image quality (image geometry, resolution, sharpness and contrast) (c) images obtained within three years before or after DXA examination. The first author performed the first rough selection, after which a consensus between two of the authors was reached for the final selection. A detailed description of the collection of radiographs was 
described previously[27]. The most common reason for excluding images from the analysis was a missing ROI, image quality, and the image's date. A total of 567 radiographs was chosen from the same number of patients. All DICOM images were converted to JPG format using Image J software (Rasband, W.S., ImageJ, U. S. National Institutes of Health, Bethesda, Maryland, USA, 1997-2018). Analogue images were scanned with 1000 dpi using UMAX Mirage IIse (Umax Technologies, Inc., Hsinchu, Taiwan) flatbed scanner.

\section{Boneprox (C) Software}

The Boneprox software (Boneprox, Gothenburg, Sweden) is the next generation of Jaw-X software (Crebone AB, Sundbyberg, Sweden) [28]. The Boneprox software creates a binary filtered image through digital imaging algorithms to automatically analyse trabecular patterns limited by a trapezoid marker. The marker can be placed and turned manually to perform the analysis. Grey levels in the image are reduced to 8 bit-data, and the application of histogram stretch allows for the grey levels to be linearly stretched to cover all intensities (dark areas become black and bright areas become white). The analysis progresses by identifying the largest intertrabecular space, followed by the next largest until the 20 largest spaces had been found. New technology has been introduced to the software that fully-automated the whole process from placement of the trapezoid marker to the analysis of the trabecular pattern within. The final resulting value represents the sum of the sizes and intensities of the spaces between the trabeculae. Scores for the automated analysis of trabecular pattern in intraoral radiographs range between 3000 (dense bone structure) and 9500 (sparse bone structure e large gaps between trabeculae) units. According to manufacturers' recommendations, values equal to or higher than 6500 denoted the risk of osteoporosis. The threshold value was chosen from the reference material. [17] However, there is no threshold value for the risk of fracture. Therefore we investigated if the dichotomisation of scores recommended for assessing osteoporosis also applies to fracture risk. We controlled the distribution of the scores for both semi-automated and fully-automated software in the group that sustained a fracture during the study follow-up and the one without a fracture (Fig.1). No difference was found between the groups ( $\mathrm{p}=0,876$ for semi-automated analysis and $\mathrm{p}=0,198$ for fully-automated analysis). Therefore, we chose to continue the analysis without the dichotomisation.

\section{Analyses}

One rater (first author) familiar with the analysis technique performed assessments of the intraoral radiographs using semi-automated software. The radiographs were also subject to analysis with fully-automated tool provided by the software developer. 
A trapezoid marker symbolising ROI was manually placed between the roots/apices of the premolar area in the lower jaw (Fig.2). In the case of analysis by fully-automated tool, the trapezoid marker was placed by the software itself. The trabecular pattern was assessed by the algorithm provided in the software.

The analysis took place using a screen with a resolution of 1920x1080 pixels. The observation room was dimly lit as recommended by the American Association of Physicists in Medicine Task Group [29]. The distance to the screen was approximately $50 \mathrm{~cm}$. There was no restriction in the observation time. The rater was blinded to clinical features such as the patient's age, previous medical history, and individual DXA results.

\section{Statistical methods}

All statistical analyses were performed using SPSS software version 26.0 for Windows (IBM Corp., Armonk, NY, USA). Descriptive statistics were used to present study sample characteristics. For continuous variables, independent sample t-tests were used to examine differences between groups, and for dichotomised variables, we used the $\chi^{2}$ test. Associations between trabecular pattern analysis in intraoral radiographs and incident fractures were studied using Cox proportional hazard model. Note that for ease of interpretation, Boneprox scores were expressed in thousands of units in these models. The analysis was performed unadjusted and adjusted for FRAX risk factors (previous fracture, family history of hip fracture, smoking, corticosteroids, rheumatoid arthritis, without and with femoral neck BMD). Because there were no cases of secondary osteoporosis and only two cases of high alcohol consumption in the whole study sample, they were not adjusted for in the model. Correlation between scores of semi- and fully-automated analysis of trabecular pattern in intraoral radiographs and TBS of lumbar spine was investigated using Pearson correlation analysis.

\section{Results}

\section{Baseline characteristics}

The characteristics of the population sample of older women participating in the study are presented in Table 1 . During a median follow-up of 3.6 years, 70 study participants sustained a MOF (12.3\%) and 101 any fractures (17.8\%). Trabecular pattern analysis was performed on all 567 intraoral radiographs using semi-automated software. The fully-automated tool, however, excluded 73 images.

\section{Predictive value of automated trabecular analysis in intraoral radiographs}

Incident fractures were divided into two groups: any fracture (included all incident fractures except for face and skull) and MOF. Neither the semi-automated nor the fully-automated analysis of trabecular pattern in intraoral radiographs, adjusted for the included covariates, were predictors of any fracture or MOF. In the analysis of survival probability until any incident fracture or MOF for the semi-automated and fully-automated analysis of 
trabecular pattern in intraoral radiographs, neither the unadjusted nor the adjusted model were significantly associated with any fracture or MOF (Table 2).

\section{Correlation with TBS}

A relatively weak correlation was found between intraoral radiographs' trabecular pattern analysis using semiautomated and TBS (Table 3). The significance of this correlation disappears when adjusted to the number of cases analysed by fully-automated method $(\mathrm{N}=493)$. Fully-automated analysis of the trabecular pattern in intraoral radiographs found no correlation to TBS.

\section{Discussion}

In the present study, we demonstrate that neither the semi-automated nor the fully-automated assessment of trabecular pattern in intraoral radiographs shows the predictive value for fragility fracture. Furthermore, the correlation with TBS was rather weak and only for the semi-automated software.

The subject of fracture prediction using dental radiographs has been under investigation since the correlation was established between the trabecular pattern of the jaws and osteoporosis [16]. Previous research indicates that individuals with a sparse trabecular pattern are at greater risk of osteoporosis [17]. However, osteoporosis is nowadays considered to be one of many risk factors increasing the risk of fracture. The majority of individuals with fragility fractures show BMD values within the normal or osteopenic range [30]. Therefore efforts have been directed to evaluate the predictive value of assessment of trabecular pattern in intraoral radiographs for fracture risk instead.

Already in 1987, the analysis of vertebral bone showed that the biomechanical competence of the trabecular bone was more closely related to age-related changes of the three-dimensional bone structure than to its mineral content [31]. While there is a relationship between BMD and fracture risk, evidence suggests that BMD measurements reflect only one component of bone strength [32]. Other factors than BMD influence bone strength and fracture risk, including microarchitectural deterioration of bone tissue [33]. A large variety of different modalities have been applied for assessment of skeletal microstructure, from histomorphometric analysis of transiliac crest bone biopsy, high- resolution peripheral quantitative computed tomography (HRpQCT) [34], microCT ( $\mu \mathrm{CT}$ ) [35], to Magnetic Resonance Imaging (MRI)[36]. However, these techniques are both costly, time-consuming and not always available in clinical routine. Moreover, they have been mainly used in peripheral sites and are not part of standardised imaging protocols yet [7]. Therefore, TBS was developed to meet the demand for an instrument assessing trabecular microarchitecture. Its proponents define TBS as a 
textural parameter that evaluates pixel grey-level variations in the DXA image [8]. Similarly, the trabecular structure of the jaw bone is revealed indirectly by periapical radiographs, which are considered high-resolution two-dimensional images. The diagnostic value of periapical radiographs for assessing bone tissue characteristics has been investigated [37]. Based on studies showing a correlation between BMD in the mandible and other skeletal sites, we found it interesting to investigate two methods, TBS and Boneprox, both based on evaluation of three-dimensional trabecular bone structure from two-dimensional images.

Assessment of trabecular pattern in dental radiographs for the purpose of prediction of fracture has been investigated previously. Only a few studies have a similar approach as our study. Visual index for assessment of trabecular pattern proposed by Lindh, et al. [17] applied on both intraoral [28, 38] and panoramic radiographs $[20,39]$ showed some promising results in the fracture risk prediction. Automated analysis of the trabecular pattern in intraoral radiographs is a rather novel method that has not been yet explored enough. Jonasson and Billhult [28] compared visual index for assessing trabecular pattern in intraoral radiographs with the analysis using semi-automated software (Jaw-X, Crebone AB, Sundbyberg, Sweden). Neither of the two methods in this study showed a significant correlation in the prediction of incident fractures. Even though the study's limitation is that their sample was relatively small $(\mathrm{N}=136)$, it agrees with our results. In a recent systematic review, it was concluded that based on low certainty of the evidence, trabecular bone evaluation on dental radiographs might predict fractures in adults without a prior diagnosis of osteoporosis, and based on very low certainty of the evidence, it is uncertain whether digital image analyses of trabecular bone can identify individuals who have osteoporosis [40]. These conclusions are, however, based on only three studies included in the final syntheses.

A number of strengths and limitations of this study must be considered. One limitation was difficulties in data collection. Even though we reached out to the general dental clinics in a structured manner, both by mail and phone, it resulted in very few responses. Another limitation originates from the retrospective study design, where the images were collected from many different clinics with no details regarding exposure parameters. The radiographs delivered to us were acquired with different technologies (analogue radiographs, digital radiographs) and various file formats (DICOM, JPEG, TIFF, and BMP), which could also be a considerable source of bias. Lastly, Boneprox software investigated in this study is the next generation of the software earlier referred to as Jaw-X. Because of the trade secret from the company owning the rights to the algorithm, it is not easy to establish in detail the similarities or differences between the previous and the current versions 
The main strength of our study is that it was part of a large cohort with a small age span (75-80 years) where the study participants underwent a thorough clinical examination and answered a detailed questionnaire which made it possible to acquire a large amount of data for analysis. Another strength of our study is that we used incident fracture as the outcome measure instead of BMD used by most studies of diagnostic or therapeutic protocols for osteoporosis. BMD limitation is that it is, after all, an imperfect surrogate of osteoporotic fracture.

\section{Conclusion}

The present study shows that semi-automated and fully-automated digital analyses of the trabecular pattern in intraoral radiographs do not contribute to fracture risk prediction. Furthermore, the study shows a weak correlation between semi-automated trabecular pattern analysis and TBS. 


\section{References}

1. WHO (1994) Assessment of fracture risk and its application to screening for postmenopausal osteoporosis.

Report of a WHO Study Group. World Health Organ Tech Rep Ser 843:1-129.

2. Johnell O, Kanis JA, Oden A, et al. (2005) Predictive value of BMD for hip and other fractures. J Bone Miner Res 20:1185-1194. https://doi.org/10.1359/jbmr.050304

3. Laskey MA (1996) Dual-energy X-ray absorptiometry and body composition. Nutrition 12:45-51. https://doi.org/10.1016/0899-9007(95)00017-8

4. Cummings SR (1985) Are patients with hip fractures more osteoporotic? Review of the evidence. Am J Med

78:487-494. https://doi.org/10.1016/0002-9343(85)90343-2

5. FRAX (2019) Calculation tool. https://www.sheffield.ac.uk/FRAX/tool.aspx?country=5

6. Kanis JA, Johnell O, Oden A, Johansson H, McCloskey E (2008) FRAX and the assessment of fracture probability in men and women from the UK. Osteoporos Int 19:385-397. https://doi.org/10.1007/s00198-0070543-5

7. Bousson V, Bergot C, Sutter B, Levitz P, Cortet B, the Scientific Committee of the G (2012) Trabecular bone score (TBS): available knowledge, clinical relevance, and future prospects. Osteoporos Int 23:1489-1501. https://doi.org/10.1007/s00198-011-1824-6

8. Pothuaud L, Carceller P, Hans D (2008) Correlations between grey-level variations in 2D projection images (TBS) and 3D microarchitecture: Applications in the study of human trabecular bone microarchitecture. Bone 42:775-787. https://doi.org/10.1016/j.bone.2007.11.018

9. Bousson V, Bergot C, Sutter B, et al. (2015) Trabecular Bone Score: Where are we now? Joint Bone Spine 82:320-325. https://doi.org/10.1016/j.jbspin.2015.02.005

10. McCloskey EV, Odén A, Harvey NC, et al. (2016) A Meta-Analysis of Trabecular Bone Score in Fracture Risk Prediction and Its Relationship to FRAX. J Bone Miner Res 31:940-948. https://doi.org/10.1002/jbmr.2734 11. Leslie WD, Johansson H, Kanis JA, Lamy O, Oden A, McCloskey EV, Hans D (2014) Lumbar spine texture enhances 10-year fracture probability assessment. Osteoporos Int 25:2271-2277. https://doi.org/10.1007/s00198014-2761-y

12. Horner K, Devlin H (1992) Clinical bone densitometric study of mandibular atrophy using dental panoramic tomography. J Dent 20:33-37. https://doi.org/10.1016/0300-5712(92)90007-Y

13. Horner K, Devlin H, Alsop CW, Hodgkinson IM, Adams JE (1996) Mandibular bone mineral density as a predictor of skeletal osteoporosis. Br J Radiol 69:1019-1025. https://doi.org/10.1259/0007-1285-69-827-1019 14. Taguchi A, Tanimoto K, Suei Y, Ohama K, Wada T (1996) Relationship between the mandibular and lumbar vertebral bone mineral density at different postmenopausal stages. Dentomaxillofac Radiol 25:130-135. https://doi.org/10.1259/dmfr.25.3.9084261

15. Lindh C, Obrant K, Petersson A (2004) Maxillary bone mineral density and its relationship to the bone mineral density of the lumbar spine and hip. Oral Surg Oral Med Oral Pathol Oral Radiol Endod 98:102-109. https://doi.org/10.1016/s1079-2104(03)00460-8

16. White SC, Rudolph DJ (1999) Alterations of the trabecular pattern of the jaws in patients with osteoporosis. Oral Surg Oral Med Oral Pathol Oral Radiol Endod 88:628-635. S1079-2104(99)70097-1 [pii]

17. Lindh C, Horner K, Jonasson G, et al. (2008) The use of visual assessment of dental radiographs for identifying women at risk of having osteoporosis: the OSTEODENT project. Oral Surg Oral Med Oral Pathol Oral Radiol Endod 106:285-293. https://doi.org/10.1016/j.tripleo.2007.09.008

18. Geraets WG, Verheij JGC, van der Stelt PF, Horner K, Lindh C, Nicopoulou-Karayianni K, Jacobs R, Harrison EJ, Adams JE, Devlin H (2007) Prediction of bone mineral density with dental radiographs. Bone 40:1217-1221. https://doi.org/10.1016/j.bone.2007.01.009

19. Sundh V, Hange D, Ahlqwist M, Hakeberg M, Lissner L, Jonasson G (2017) FRAX and mandibular sparse trabeculation as fracture predictors: a longitudinal study from 1980 to 2002. Eur J Oral Sci 125:135-140. https://doi.org/10.1111/eos.12341

20. Jonasson G, Sundh V, Ahlqwist M, Hakeberg M, Bjorkelund C, Lissner L (2011) A prospective study of mandibular trabecular bone to predict fracture incidence in women: a low-cost screening tool in the dental clinic. Bone 49:873-879. https://doi.org/10.1016/j.bone.2011.06.036

21. Hugoson A, Koch G, Göthberg C, Helkimo AN, Lundin SA, Norderyd O, Sjödin B, Sondell K (2005) Oral health of individuals aged 3-80 years in Jönköping, Sweden during 30 years (1973-2003). I. Review of findings on dental care habits and knowledge of oral health. Swed Dent J 29:125-138.

22. Larsson B, Mellstrom D, Johansson L, Nilsson AG, Lorentzon M, Sundh D (2018) Normal Bone

Microstructure and Density But Worse Physical Function in Older Women Treated with Selective Serotonin Reuptake Inhibitors, a Cross-Sectional Population-Based Study. Calcif Tissue Int 103:278-288.

https://doi.org/10.1007/s00223-018-0427-z

23. Nilsson AG, Sundh D, Johansson L, Nilsson M, Mellstrom D, Rudang R, Zoulakis M, Wallander M, Darelid A, Lorentzon M (2017) Type 2 Diabetes Mellitus Is Associated With Better Bone Microarchitecture But Lower 
Bone Material Strength and Poorer Physical Function in Elderly Women: A Population-Based Study. J Bone Miner Res 32:1062-1071. https://doi.org/10.1002/jbmr.3057

24. Lorentzon M, Nilsson AG, Johansson H, Kanis JA, Mellstrom D, Sundh D (2019) Extensive undertreatment of osteoporosis in older Swedish women. Osteoporos Int 30:1297-1305. https://doi.org/10.1007/s00198-01904872-4

25. Vartiainen E, Seppälä T, Lillsunde P, Puska P (2002) Validation of self reported smoking by serum cotinine measurement in a community-based study. J Epidemiol Community Health 56:167-170.

https://doi.org/10.1136/jech.56.3.167

26. Bergman H, Källmén H (2002) Alcohol use among Swedes and psychometric evaluation of the alcohol use disorders identification test. Alcohol Alcohol 37:245-251. https://doi.org/10.1093/alcalc/37.3.245

27. Gullberg J, Al-Okshi A, Homar Asan D, Zainea A, Sundh D, Lorentzon M, Lindh C The challenge of applying digital image processing software on intraoral radiographs for osteoporosis risk assessment. Dentomaxillofac Radiol 0:20210175. https://doi.org/10.1259/dmfr.20210175

28. Jonasson G, Billhult A (2013) Mandibular bone structure, bone mineral density, and clinical variables as fracture predictors: a 15-year follow-up of female patients in a dental clinic. Oral Surg Oral Med Oral Pathol Oral Radiol 116:362-368. https://doi.org/10.1016/j.oooo.2013.06.009

29. Samei E, Badano A, Chakraborty D, et al. (2005) Assessment of display performance for medical imaging systems: executive summary of AAPM TG18 report. Med Phys 32:1205-1225.

https://doi.org/10.1118/1.1861159

30. Pasco JA, Seeman E, Henry MJ, Merriman EN, Nicholson GC, Kotowicz MA (2006) The population burden of fractures originates in women with osteopenia, not osteoporosis. Osteoporos Int 17:1404-1409.

https://doi.org/10.1007/s00198-006-0135-9

31. Mosekilde L, Mosekilde L, Danielsen CC (1987) Biomechanical competence of vertebral trabecular bone in relation to ash density and age in normal individuals. Bone 8:79-85. https://doi.org/10.1016/8756-

3282(87)90074-3

32. Rubin CD (2005) Emerging concepts in osteoporosis and bone strength. Curr Med Res Opin 21:1049-1056. https://doi.org/10.1185/030079905x50525

33. Silva BC, Leslie WD, Resch H, Lamy O, Lesnyak O, Binkley N, McCloskey EV, Kanis JA, Bilezikian JP

(2014) Trabecular bone score: a noninvasive analytical method based upon the DXA image. J Bone Miner Res 29:518-530. https://doi.org/10.1002/jbmr.2176

34. Boutroy S, Bouxsein ML, Munoz F, Delmas PD (2005) In vivo assessment of trabecular bone microarchitecture by high-resolution peripheral quantitative computed tomography. J Clin Endocrinol Metab 90:6508-6515. https://doi.org/10.1210/jc.2005-1258

35. Genant HK, Engelke K, Prevrhal S (2008) Advanced CT bone imaging in osteoporosis. Rheumatology (Oxford) 47 Suppl 4:iv9-16. https://doi.org/10.1093/rheumatology/ken180

36. Krug R, Carballido-Gamio J, Banerjee S, Burghardt AJ, Link TM, Majumdar S (2008) In vivo ultra-highfield magnetic resonance imaging of trabecular bone microarchitecture at 7 T. J Magn Reson Imaging 27:854859. https://doi.org/10.1002/jmri.21325

37. Lindh C, Petersson A, Rohlin M (1996) Assessment of the trabecular pattern before endosseous implant treatment: diagnostic outcome of periapical radiography in the mandible. Oral Surg Oral Med Oral Pathol Oral Radiol Endod 82:335-343. https://doi.org/10.1016/S1079-2104(96)80363-5

38. Jonasson G, Alstad T, Vahedi F, Bosaeus I, Lissner L, Hakeberg M (2009) Trabecular pattern in the mandible as bone fracture predictor. Oral Surg Oral Med Oral Pathol Oral Radiol Endod 108:e42-51. https://doi.org/10.1016/j.tripleo.2009.05.018

39. Jonasson G, Sundh V, Hakeberg M, Hassani-Nejad A, Lissner L, Ahlqwist M (2013) Mandibular bone changes in 24 years and skeletal fracture prediction. Clin Oral Investig 17:565-572.

40. Johanen A, Jonasson G, Lund H, et al. (2021) Trabecular bone patterns as a fracture risk predictor: a systematic review. Acta Odontol Scand 1-10. https://doi.org/10.1080/00016357.2021.1886322 
Tables 


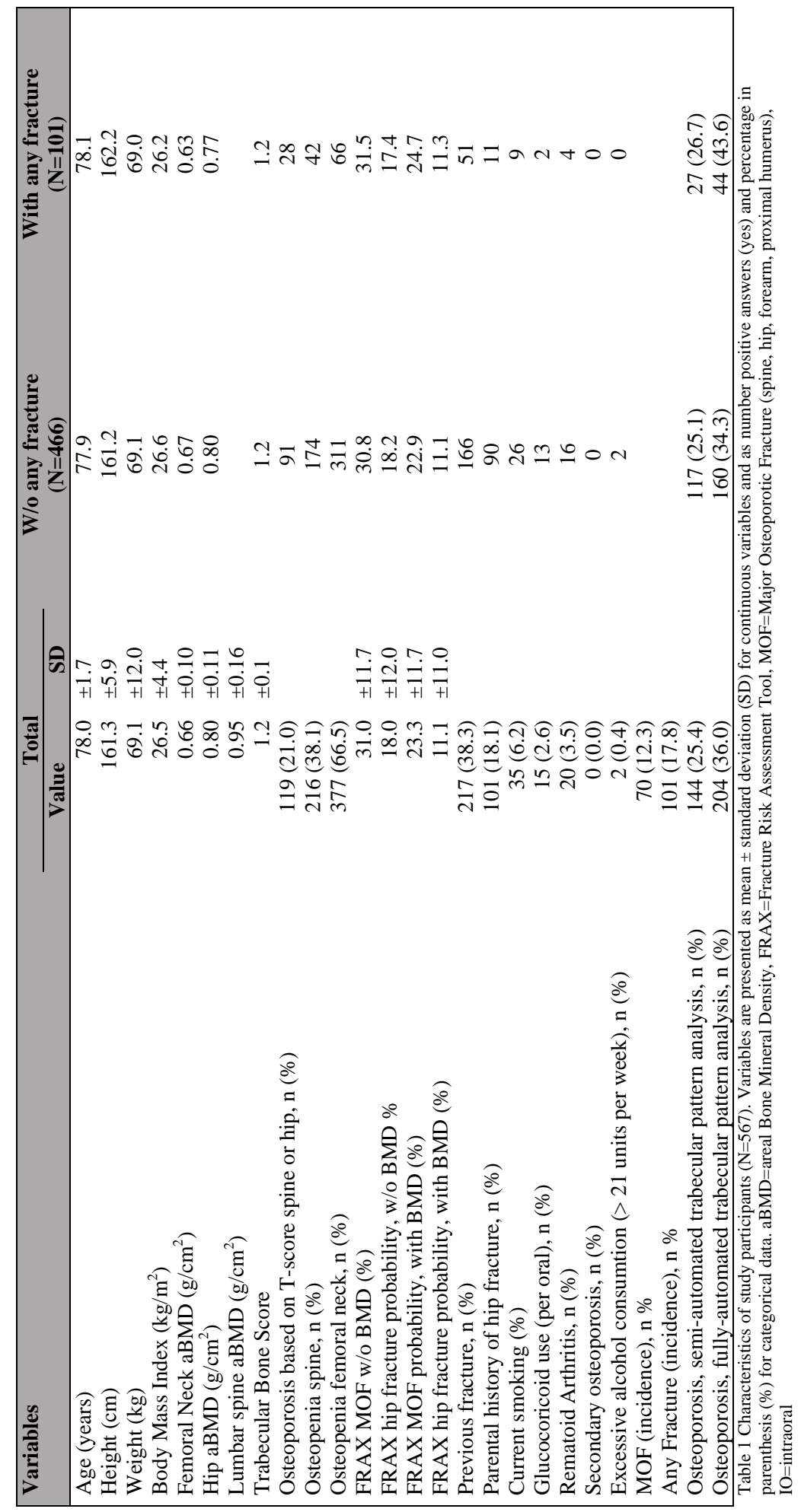




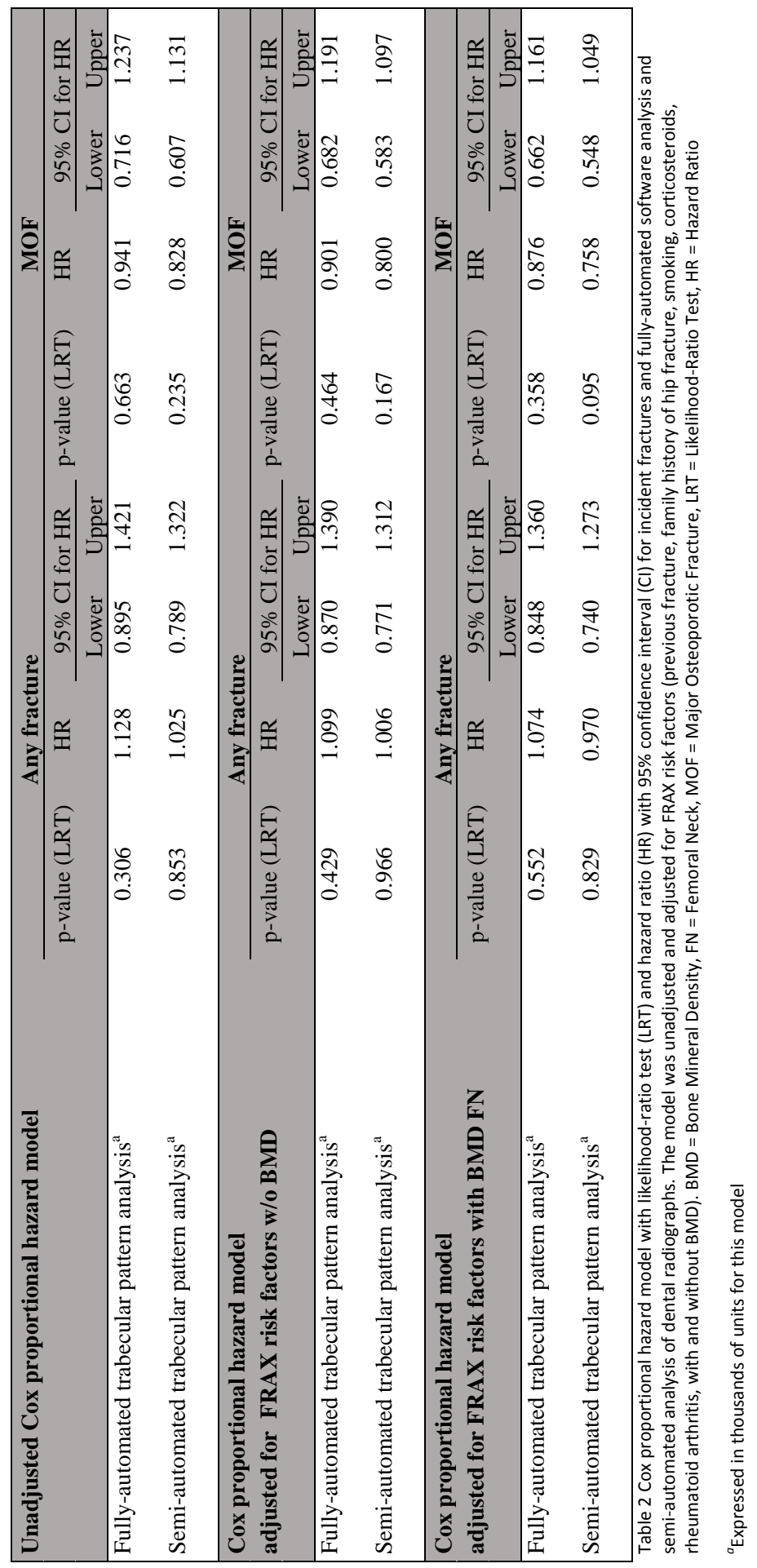




\begin{tabular}{|lccc|}
\hline & N & \multicolumn{2}{c|}{ TBS } \\
\cline { 3 - 4 } & & Pearson Correlation & Sig. (2-tailed) \\
\hline Semi-automated trabecular pattern analysis & 565 & -0.093 & 0.027 \\
& 493 & -0.068 & 0.130 \\
Fully-automated trabecular pattern analysis & 493 & -0.059 & 0.187 \\
\hline
\end{tabular}

Table 3 Pearson correlation analysis between Trabecular Bone Score (TBS) and semi-automated and fully automated analysis of trabecular bone pattern in intraoral radiographs. The correlation for semi-automated analysis was calculated for both the total number of analysed cases $(\mathrm{N}=565)$ and for the selection of cases corresponding to the fully-automated analysis $(\mathrm{N}=493)$. 


\section{Figures}

Fig. 1 Frequency histogram of incidence of any fracture during the study follow-up period of 3.6 years plotted against scores of semi-automated and fully-automated analysis of dental radiographs (3000-9 500 units)

Fig. 2 Intraoral radiograph in the trabecular pattern analysis software with region of interest (ROI) between the roots/apices of premolar area in the lower jaw marked within the trapezoid marker 
Fig. 1 Gronbeck Linden
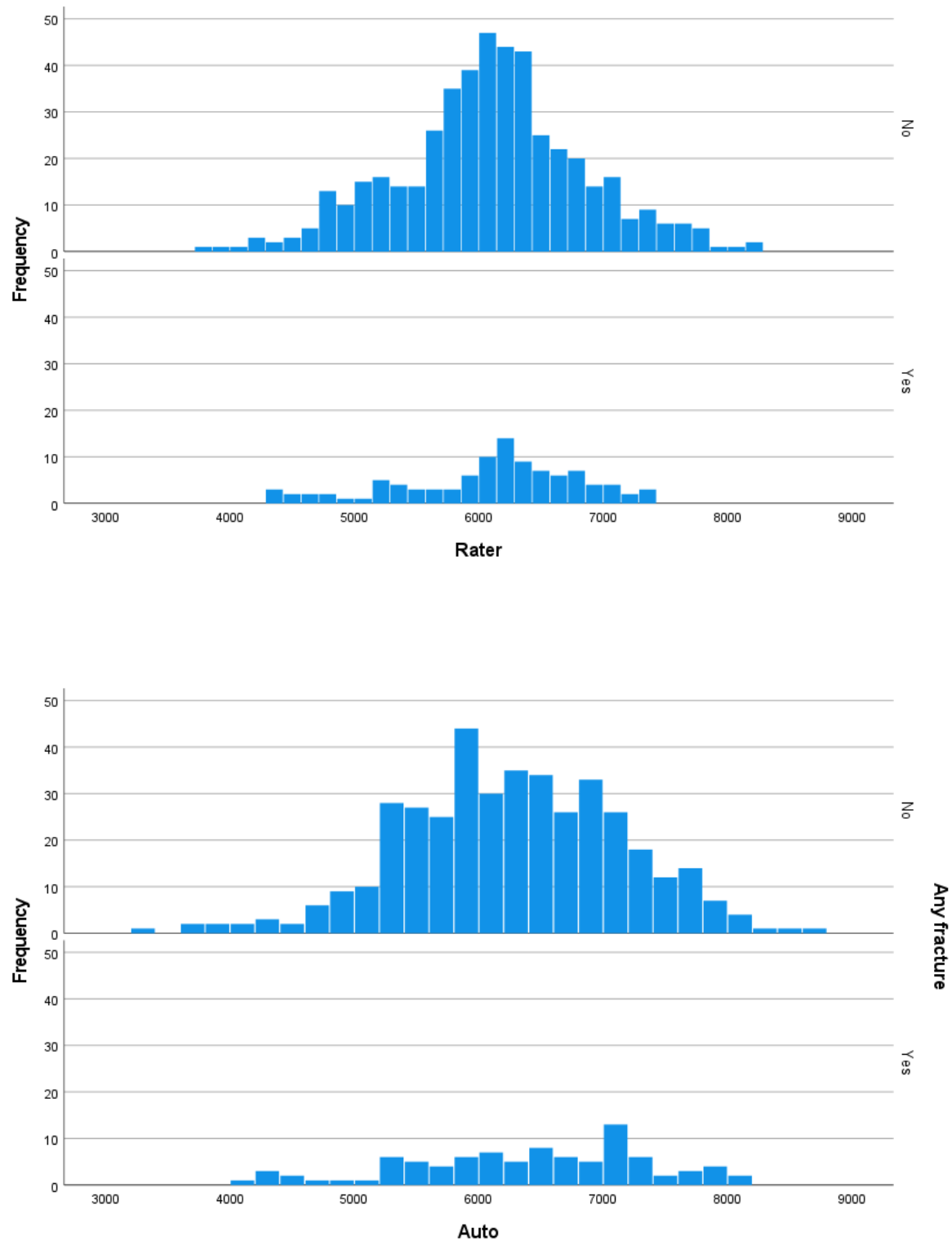
Fig. 2

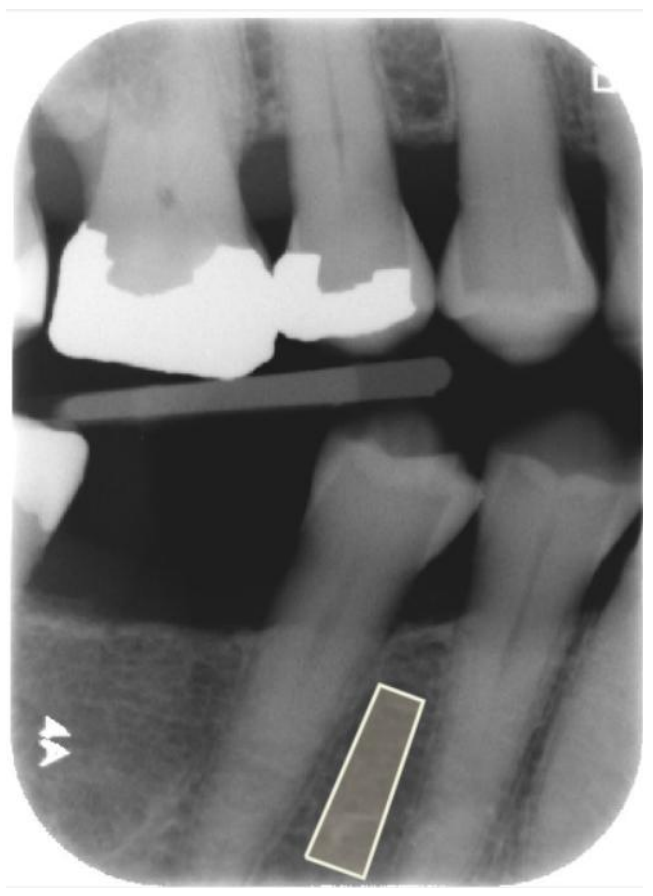




ISBN 978-91-7877-200-1 (print)

ISBN 978-91-7877-201-8 (pdf)

MALMÖ UNIVERSITY 20506 MALMÖ, SWEDEN WWW.MAU.SE 